Ana Carolina Guimarães Oliveira

Eventos arrítmicos em pacientes com canalopatias cardíacas submetidos à anestesia local odontológica: estudo piloto randomizado

Tese apresentada à Faculdade de Medicina da Universidade de São Paulo para obtenção do título de Doutor em Ciências

Programa: Cardiologia

Orientador: Dr. Francisco Carlos da Costa Darrieux

São Paulo 
Ana Carolina Guimarães Oliveira

\title{
Eventos arrítmicos em pacientes com canalopatias cardíacas submetidos à anestesia local odontológica: estudo piloto randomizado
}

\author{
Versão corrigida \\ (Versão original encontra-se na unidade \\ que aloja o Programa de Pós-Graduação)
}

Tese apresentada à Faculdade de Medicina da Universidade de São Paulo para obtenção do título de Doutor em Ciências

Programa: Cardiologia

Orientador: Dr. Francisco Carlos da Costa Darrieux

São Paulo 


\section{Dados Internacionais de Catalogação na Publicação (CIP)}

Preparada pela Biblioteca da

Faculdade de Medicina da Universidade de São Paulo

Creproduçăo autorizada pelo autor

\section{Oliveira, Ana Carolina Guimarães}

Eventos arritmicos em pacientes com canalopatias cardiacas submetidos à anestesia local odontológica : estudo piloto randomizado / Ana Carolina Guimarães Oliveira. -- São Paulo, 2019.

Tese (doutorado)--Faculdade de Medicina da Universidade de São Paulo.

Programa de Cardiologia.

Orientador: Francisco Carlos da Costa Darrieux.

Descritores: 1.Arritmias cardiacas 2. Canalopatias 3.Morte súbita cardiaca 4.Eletrocardiografia ambulatorial 5.Anestesia local 6.Lidocaina 7.Epinefrina 8.Odontologia

USP/FM/DBD-090/19

Responsável: Erinalva da Conceiçăo Batista, CRB-8 6755 


\section{DEDICATÓRIA}

À minha amada família: Maria Aparecida França Guimarães Oliveira e Valter Joaquim de Oliveira, meus pais, e Marília Aparecida Guimarães Oliveira, minha irmã, pelo amor e apoio incondicional em todos os momentos da minha vida.

Ao meu namorado Gabriel Abdalla Guimarães, pela compreensão da minha ausência durante a dedicação a este trabalho e por compartilhar momentos especiais ao meu lado.

Aos amigos e demais familiares que torceram por mim.

Aos profissionais de saúde que buscam excelência no atendimento de seus pacientes.

E aos pacientes deste estudo, pela gentil colaboração, todo meu respeito e dedicação! 


\section{AGRADECIMENTOS}

Ao meu orientador, Dr. Francisco Carlos da Costa Darrieux, pela competência e entusiasmo durante a realização deste estudo. Considero-o um exemplo de professor altamente qualificado e muito dedicado a todas as atividades que desenvolve.

À Dra. Itamara Lucia Itagiba Neves e ao Dr. Ricardo Simões Neves, pelo incentivo e confiança em mim depositados desde minha primeira pósgraduação, o Aprimoramento em Odontologia Hospitalar. Sou-Ihes muito grata e admiro-os pelo profissionalismo, caráter, amizade e ternura.

Às Dras. Luciana Sacilotto e Natália Olivetti pela ajuda, dedicação e paciência.

Ao Dr. Maurício Ibrahim Scanavacca pela sabedoria e bons conselhos.

Às assistentes da Unidade de Odontologia do InCor, Dra. Tânia Cristina Pedroso Montano, Dra. Marcela Alves dos Santos Paul, Dra. Cíntia Maria Alencar de Carvalho e Dra. Maria Cristina Marino de Oliveira pela disposição, amparo e carinho durante todos esse anos. E às funcionárias do InCor: Any Karoline da Rocha Lacerda, Alessandra do Carmo Rodrigues, Márcia Carvalho da Silva Dias, Maria do Perpétuo Socorro Nascimento Soares, Talita Santana, Aline Alves Silva e Maria Eliana da Silveira Brito, pela colaboração, disponibilidade e gentileza.

Ao médicos, Dr. Cesar José Grupi e Dr. Sílvio Alves Barbosa, e funcionárias, Adenilza Gruber (Dedé), Ellen Nary Martins, Neiba Pedroso da 
Silva, do Setor de Monitorização Ambulatorial Eletrocardiográfica do Serviço de Eletrocardiografia, pela valiosa contribuição.

Ao Setor de Eletrocardiograma, Dr. Carlos Alberto Pastore, Adriana Olívia Libert e Gisele Ferreira da Silva, pelo apoio imprescindível.

Ao Rogério Ruscitto do Prado, pela análise estatística.

À Comissão de Pós-graduação, em especial à Juliana Lattari Sobrinho, Mônica Souto e Neuza Rodrigues Dini.

Aos Residentes e Aprimorandos em Odontologia Hospitalar, companheiros dessa longa jornada. 


\section{EPÍGRAFE}

"Nas grandes batalhas da vida, o primeiro passo para a vitória é o desejo de vencer."

Mahatma Gandhi 


\section{NORMALIZAÇÃO ADOTADA}

Esta tese está de acordo com as seguintes normas, em vigor no momento desta publicação:

Referências: adaptado de International Committee of Medical Journals Editors (Vancouver).

Universidade de São Paulo. Faculdade de Medicina. Divisão de Biblioteca e Documentação. Guia de apresentação de dissertações, teses e monografias. Elaborado por Anneliese Carneiro da Cunha, Maria Julia de A. L. Freddi, Maria F. Crestana, Marinalva de Souza Aragão, Suely Campos Cardoso, Valéria Vilhena. 3a ed. São Paulo: Divisão de Biblioteca e Documentação; 2011.

Abreviaturas dos títulos dos periódicos de acordo com List of Journals Indexed in Index Medicus. 


\section{SUMÁRIO}

Lista de siglas e símbolos

Lista de figuras

Lista de tabelas

Lista de gráficos

Resumo

Summary

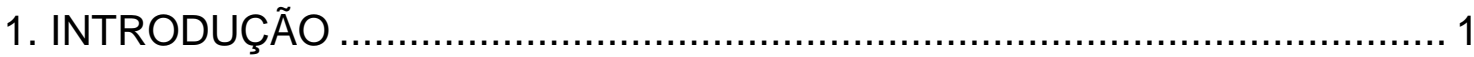

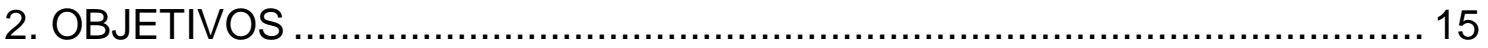

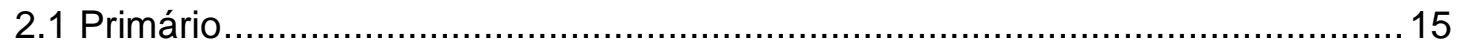

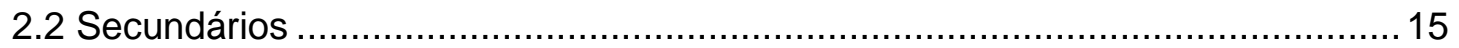

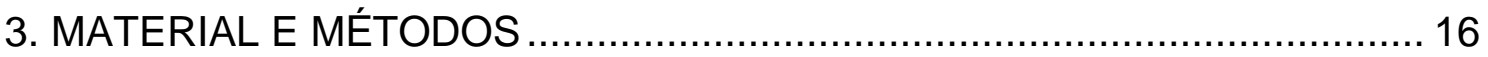

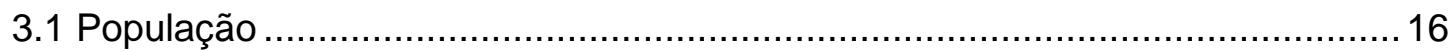

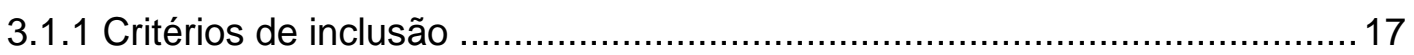

3.1.2 Critérios de exclusão ...................................................................... 17

3.2 Preparo do paciente e procedimentos odontológicos ....................................... 18

3.2.1 Perfil de saúde bucal ............................................................................ 19

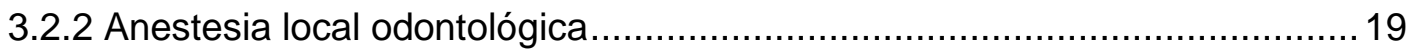

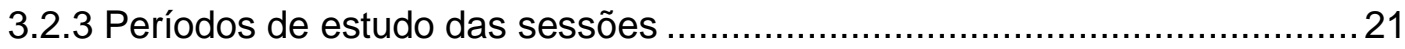

3.2.4 Monitoração eletrocardiográfica ambulatorial contínua ............................... 22

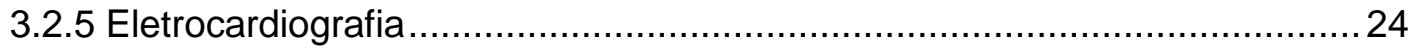

3.2.6 Registro pontual da pressão arterial sistêmica ......................................... 25

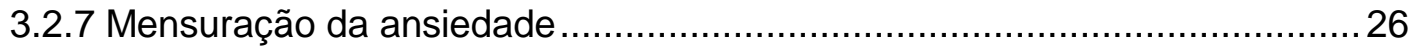

3.2.8 Critérios de segurança do procedimento................................................. 26

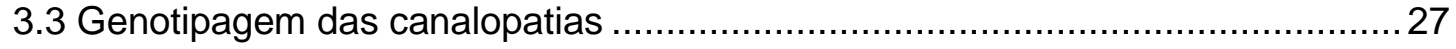

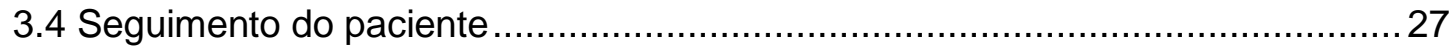

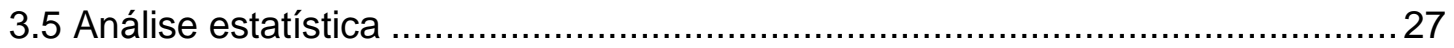

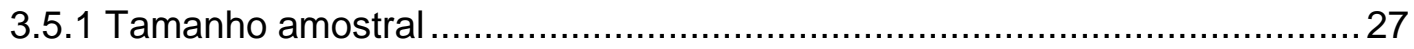

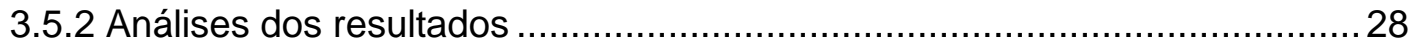

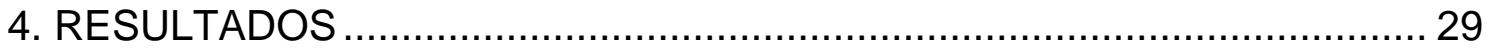




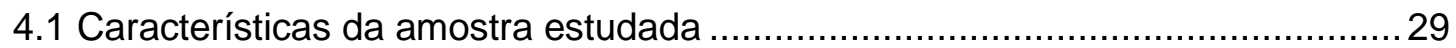

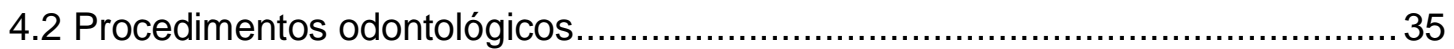

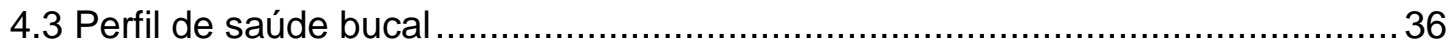

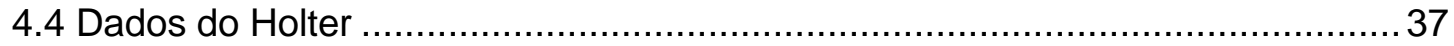

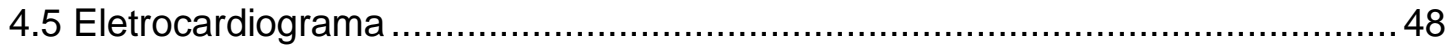

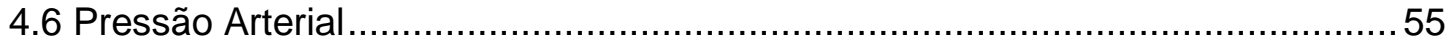

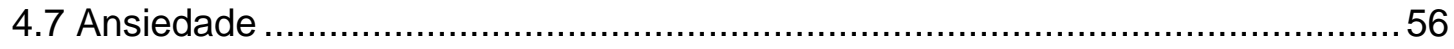

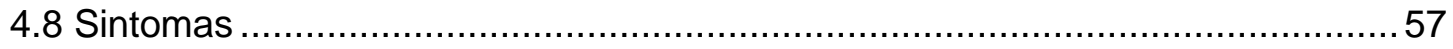

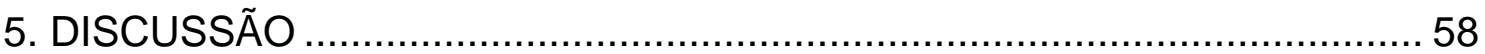

6. LIMITAÇÕES DO ESTUDO ............................................................ 68

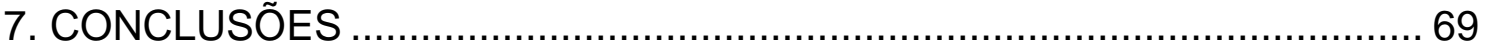

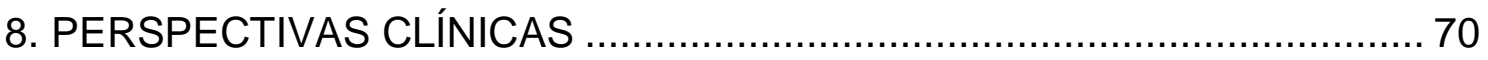

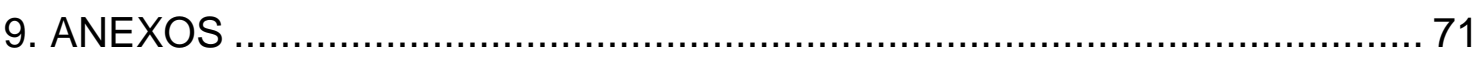

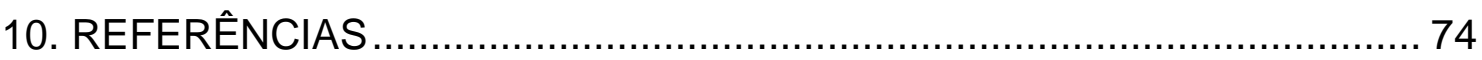

Apêndice 


\section{LISTA DE SIGLAS}

\begin{tabular}{ll} 
bpm & batimentos por minuto \\
CDI & cardiodesfibrilador implantável \\
CPOD & número de dentes permanentes cariados, perdidos e obturados \\
DP & desvio padrão \\
ECG & eletrocardiograma \\
EV & extrassístole ventricular \\
ESSV & extrassístole supraventricular \\
FC & frequência cardíaca \\
FC mín. & frequência cardíaca mínima \\
FC méd. & frequência cardíaca média \\
FC máx. & frequência cardíaca máxima \\
FMUSP & Faculdade de Medicina da Universidade de São Paulo \\
FV & fibrilação ventricular \\
HAS & hipertensão arterial sistêmica \\
HC & Hospital das Clínicas \\
IMC & Índice de massa corporal \\
InCor & Instituto do Coração \\
PA & pressão arterial \\
PAS & pressão arterial sistólica \\
PAD & pressão arterial diastólica \\
QT & intervalo QT do eletrocardiograma \\
QTC & intervalo QT corrigido \\
\hline
\end{tabular}


RCP ressuscitação cardiopulmonar

$\mathrm{SBr} \quad$ Síndrome de Brugada

SCV Sistema Cardiovascular

SNC Sistema Nervoso Central

SQTL Síndrome do QT longo congênito

ST segmento ST do eletrocardiograma

TANS taquicardia atrial não sustentada

TV taquicardia ventricular

TVS taquicardia ventricular sustentada

TVNS taquicardia ventricular não sustentada

TVPC taquicardia ventricular polimórfica catecolaminérgica

TdP torsades de pointes 


\section{LISTA DE SÍMBOLOS}

$\begin{array}{ll}\alpha & \text { alfa } \\ \beta & \text { beta } \\ \text { FP } & \text { fim do procedimento } \\ \text { IA } & \text { início da anestesia } \\ \text { LSA } & \text { lidocaína } 2 \% \text { sem adrenalina } \\ \text { LCA } & \text { lidocaína } 2 \% \text { com adrenalina 1:100.000 } \\ \text { mL } & \text { mililitro } \\ \text { ms } & \text { milissegundo } \\ \text { Mg } & \text { micrograma } \\ \text { mg } & \text { miligrama } \\ \text { mmHg } & \text { milímetro de Mercúrio } \\ \text { p } & \text { nível descritivo } \\ \text { PAn } & \text { período da anestesia } \\ \text { PB } & \text { período basal } \\ \text { PP } & \text { período do procedimento } \\ \text { PPP } & \text { período pós-procedimento } \\ \text { TA } & \text { término da anestesia }\end{array}$




\section{LISTA DE FIGURAS}

página

Figura 1 - Mascaramento da seringa Carpule com papel alumínio........... 20

Figura 2 - Linha do tempo indicando os períodos de estudo................... 21

Figura 3 - Representação do posicionamento dos eletrodos do Holter Seer Light.

Figura 4 - Posição dos eletrodos nas derivações especiais para SBr........ 24

Figura 5 - Escala de mensuração da ansiedade: Facial Image Scale........ 26

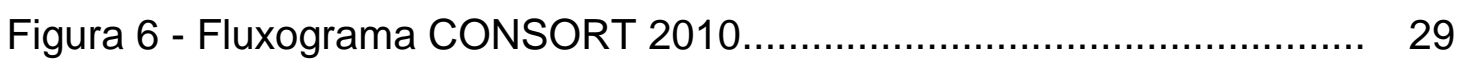

Figura 7 - Traçado Holter de paciente com SBr apresentando alteração dinâmica do padrão eletrocardiográfico durante o Período da Anestesia...

Figura 8 - Exemplo de ECG de paciente com SQTL no Término da

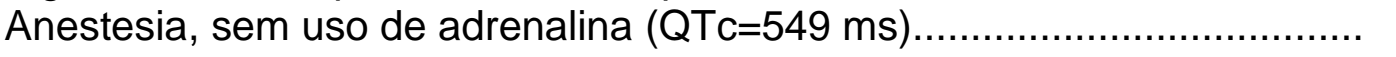

Figura 9 - Exemplo de ECG de paciente com SQTL no Término da Anestesia, com uso de adrenalina (QTc=566 ms).................................

Figura 10 - Exemplo de traçado eletrocardiográfico (com derivações superiores) de paciente com SBr apresentando padrão tipo 1 no Término da Anestesia, sem uso de adrenalina.

Figura 11 - Exemplo de traçado eletrocardiográfico (com derivações superiores) do mesmo paciente com SBr apresentando padrão tipo 1 no Término da Anestesia, com uso de adrenalina 


\section{LISTA DE TABELAS}

página

Tabela 1 - Descrição das características gerais dos pacientes da amostra

Tabela 2 - Descrição dos medicamentos em uso pelos pacientes da amostra.

Tabela 3 - Descrição das comorbidades associadas aos portadores de canalopatias da amostra.

Tabela 4 - Perfil dos pacientes da amostra portadores de SQTL

Tabela 5 - Perfil dos pacientes da amostra portadores de SBr.

Tabela 6 - Perfil dos pacientes da amostra portadores de TVPC.

Tabela 7 - Média, desvio-padrão, mediana, mínimo e máximo do Índice CPOD da amostra.

Tabela 8 - Perfil periodontal da amostra

Tabela 9 - Média, desvio-padrão, mediana, mínimo e máximo da FC, maior pausa e densidade de arritmias da amostra durante o P28h nas condições sem e com adrenalina.

Tabela 10 - Média, desvio-padrão, mediana, mínimo e máximo da FC, maior pausa e densidade de arritmias da amostra durante o PB nas condições sem e com adrenalina

Tabela 11 - Média, desvio-padrão, mediana, mínimo e máximo da FC, maior pausa e densidade de arritmias da amostra durante o PAn nas condições sem e com adrenalina.

Tabela 12 - Média, desvio-padrão, mediana, mínimo e máximo da FC, maior pausa e densidade de arritmias da amostra durante o PP nas condições sem e com adrenalina.

Tabela 13 - Média, desvio-padrão, mediana, mínimo e máximo da FC, maior pausa e densidade de arritmias da amostra durante o PPP nas condições sem e com adrenalina. 
Tabela 14 - Média, desvio-padrão, mediana, mínimo e máximo da FC, maior pausa e densidade de arritmias apenas em pacientes com SQTL durante o PAn, nas condições sem e com adrenalina

Tabela 15 - Média, desvio-padrão, mediana, mínimo e máximo da FC, maior pausa e densidade de arritmias apenas em pacientes com $\mathrm{SBr}$ durante o PAn, nas condições sem e com adrenalina.

Tabela 16 - Média, desvio-padrão, mediana, mínimo e máximo da FC, maior pausa e densidade de arritmias apenas em pacientes com $\mathrm{SBr}$ durante o PP, nas condições sem e com adrenalina.

Tabela 17 - Média, desvio-padrão, mediana, mínimo e máximo do QTc e QTc médio em três momentos (PB, TA e FP), nas condições sem e com adrenalina.

Tabela 18 - Valores absolutos e médias do QTc (em ms) nos três momentos de estudo (PB, TA e FP), nas condições sem e com adrenalina.

Tabela 19 - Alterações do intervalo QTc (categorizados em mais de 10\% no encurtamento ou prolongamento do QTc) após a administração da anestesia local em comparação ao Período Basal, nos pacientes portadores de SQTL

Tabela 20 - Padrão eletrocardiográfico da SBr na amostra em três momentos (PB, TA e FP) em uso de lidocaína, separados por condição com e sem adrenalina.

Tabela 21 - Descrição dos padrões eletrocardiográficos dos pacientes com SBr em três momentos (PB, TA e FP), nas condições sem e com adrenalina.

Tabela 22 - Média, desvio-padrão, mediana, mínimo e máximo dos valores da pressão arterial sistólica (PAS) e diastólica (PAD) em três momentos (PB, TA e FP), nas condições sem e com adrenalina.

Tabela 23 - Correlação entre o grau de ansiedade e valores de pressão arterial sistólica e diastólica nos momentos de estudo (PB, IA/TA e FP), nas condições sem e com adrenalina.

Tabela 24 - Média, desvio-padrão, mediana, mínimo e máximo do Grau de Ansiedade em três momentos (PB, IA e FP), nas condições sem e com adrenalina.

Tabela 25 - Descrição dos escores de ansiedade segundo ordem de realização do procedimento e resultados dos testes comparativos.... 


\section{LISTA DE GRÁFICOS}

página

Gráfico 1 - Valores médios e respectivos erros padrões da FC mínima em cada período de estudo avaliado e resultado das comparações...........

Gráfico 2 - Valores médios e respectivos erros padrões da FC média em cada período de estudo avaliado e resultado das comparações

Gráfico 3 - Valores médios e respectivos erros padrões da FC máxima em cada período de estudo avaliado e resultado das comparações........... 


\section{RESUMO}

Oliveira ACG. Eventos arrítmicos em pacientes com canalopatias cardíacas submetidos à anestesia local odontológica: estudo piloto randomizado [tese]. São Paulo: Faculdade de Medicina, Universidade de São Paulo; 2019.

Introdução: Distúrbios dos canais iônicos cardíacos potencialmente letais, como a síndrome de Brugada (SBr), a síndrome do QT longo congênito (SQTL) e a taquicardia ventricular polimórfica catecolaminérgica (TVPC) podem ser responsáveis por pelo menos um terço do total de casos de morte súbita que permanecem inexplicados. Estes pacientes, por vezes, não obtêm tratamento odontológico e analgesia adequados devido à falta de informações na literatura em relação à dose e tipo de anestésico local recomendado, e ao risco potencial de eventos cardíacos ameaçadores à vida e instabilidade hemodinâmica. Métodos: Trata-se de um estudo piloto, randomizado, duplo-cego e cruzado com portadores de canalopatias cardíacas submetidos a tratamento odontológico restaurador em duas sessões, realizadas com intervalo mínimo de sete dias (wash-out) entre ambas, sendo o paciente seu próprio controle. $\mathrm{Na}$ primeira sessão, por randomização, o paciente recebeu uma das soluções anestésicas: lidocaína $2 \%$ sem vasoconstritor (LSA) ou lidocaína $2 \%$ com adrenalina 1:100.000 (LCA), originando duas condições: sem adrenalina e com adrenalina; na segunda sessão recebeu o outro anestésico. Todos foram monitorados com Holter por 28 horas, contadas a partir de uma hora antes do procedimento, nas duas sessões do estudo. Durante 0 atendimento odontológico, foram feitos registros pontuais em três momentos por meio de eletrocardiograma de 12 derivações, esfigmomanômetro digital para pressão arterial e escala de mensuração da ansiedade. Resultados: Sessenta e dois procedimentos restauradores foram realizados em 31 pacientes: $16(51,6 \%)$ tinham SQTL, $12(38,7 \%)$ SBr e três (9,7\%) TVPC, dentre os quais $12(38,7 \%)$ eram portadores de cardiodesfibrilador implantável. A idade média dos pacientes foi $45,2 \pm 15,8$ anos, sendo $21(67,7 \%)$ do sexo feminino. Os valores médios da frequência cardíaca máxima se mostraram aumentados com o uso de LCA no período da anestesia $(84,4 \times 80,4 \mathrm{bpm} ; \mathrm{p}=0,005)$ com diferença estatisticamente significante entre as duas condições, assim como o QTc em pacientes com SQTL $(465,4 \times 450,1 ; p=0,009)$. Valores de pressão arterial e mensuração da ansiedade não mostraram diferença estatisticamente significante. Não foram observadas arritmias ventriculares ameaçadoras à vida durante os procedimentos. Conclusões: $O$ uso da anestesia local com lidocaína, independente do uso de vasoconstritor, não resultou em arritmias ameaçadoras à vida e foi considerado seguro nos pacientes selecionados. Estes resultados preliminares devem ser confirmados em uma população maior, em um estudo multicêntrico. 
Descritores: Arritmias cardíacas; Canalopatias; Morte súbita cardíaca; Eletrocardiografia ambulatorial; Anestesia local; Lidocaína; Epinefrina, Odontologia 


\section{SUMMARY}

Oliveira ACG. Arrhythmic events in patients with cardiac channelopathies subjected to local dental anesthesia: a randomized pilot study [thesis]. São Paulo: Faculdade de Medicina, Universidade de São Paulo; 2019.

Background: lon channel disorders, such as Brugada syndrome (BS), long QT syndrome (LQTS), and catecholaminergic polymorphic ventricular tachycardia (CPVT), may account for at least one-third of unexplained sudden cardiac deaths. These patients often do not receive adequate dental treatment and analgesia owing to the lack of information in the literature regarding the dose and type of local anesthetic recommended, and due to the potential risk of lifethreatening cardiac events. Methods: This is a randomized, double-blind pilot trial in patients with cardiac CCh underwent to restorative dental treatment in two sessions, with a wash-out period of 7 days (crossover trial). In the first session, by randomization, the patient received one of the anesthetic solutions: $2 \%$ lidocaine without vasoconstrictor (LSA) or $2 \%$ lidocaine with epinephrine 1 : 100,000 (LCA), making two conditions: without epinephrine and with epinephrine; and in the second session received the other anesthetic. Twentyeight-hour Holter monitoring was performed in all patients, initiated one hour before the procedure, in the two study sessions. During the dental treatment, additional specific monitoring including 12-lead electrocardiography (ECG), digital sphygmomanometry and anxiety scale assessments was also applied at three time points. Results: Sixty-two dental procedures were performed in 31 patients with CCh: 16 (51.6\%) had LQTS, 12 (38.7\%) had BS and three $(9.7 \%)$ had CPVT; 12 (38.7\%) patients had an implantable defibrillator. The mean age was $45.2 \pm 15.8$ years, and $21(67.7 \%)$ patients were female. The maximum heart rate was increased after the use of epinephrine during the anesthesia period $(84,4 \times 80,4 \mathrm{bpm}, \mathrm{p}=0.005)$, as well the corrected QT in LQTS patients $(465,4 \times 450,1 ; p=0,009)$. Blood pressure and anxiety measurements showed no statistically significant differences. No life-threatening arrhythmias occurred during the dental treatment. Conclusions: The use of local dental anesthesia with lidocaine, regardless of the use of a vasoconstrictor, did not result in lifethreatening arrhythmias and was considered safe in these selected patients with channelopathies. These preliminary findings need to be confirmed in a larger population study, in a multicenter study.

Descriptors: Arrhythmias, cardiac; Channelopathies; Death, sudden cardiac; Electrocardiography, ambulatory; Anesthesia, local; Lidocaine; Epinephrine, Dentistry 


\section{INTRODUÇÃO}

O uso de anestésicos locais é imprescindível para o controle da dor durante certos procedimentos odontológicos. Estes compostos químicos bloqueiam os canais de sódio da célula nervosa alterando, de modo reversível, o potencial de ação e a propagação do impulso nervoso. A lidocaína é o anestésico local mais utilizado desde 1948, e também um agente antiarrítmico da classe 1B para tratamento de arritmias ventriculares ${ }^{1}$. É considerada o "padrão ouro" em comparação aos demais tipos, com início de ação rápido e duração moderada, tempo de meia-vida de 1,6 horas e baixo risco de alergias ${ }^{2}$.

As propriedades vasodilatadoras dos anestésicos locais aumentam o fluxo sanguíneo local e sua própria absorção para a circulação sistêmica, diminuindo a duração e qualidade da anestesia. Quando injetados em tecidos altamente vascularizados, como os tecidos bucais, esses efeitos são potencializados $^{3}$.

A ocorrência da maioria das reações adversas deve-se a acidente de punção ou superdosagem. Injeções lentas e aspiração prévia cuidadosa evitam a deposição intravascular acidental e sua rápida absorção sistêmica ${ }^{4}$. Em níveis mais altos, pode provocar reações tóxicas causando depressão do sistema nervoso central (SNC) ou do sistema cardiovascular (SCV). A bradicardia sinusal e redução da contratilidade do miocárdio contribuem para diminuição do débito cardíaco e hipotensão, podendo ocorrer colapso cardiovascular após doses excessivas ${ }^{5,6}$. Em grandes doses, a lidocaína pode 
alterar a condução cardíaca, prolongando o intervalo QRS e predispondo à arritmias fatais ${ }^{7}$.

Os resultados da associação dos anestésicos com vasoconstritores superam seus potenciais efeitos deletérios, devido às propriedades de retardar a absorção da solução anestésica, diminuindo a toxicidade sistêmica e prolongando sua atividade local. Além disso, o controle do sangramento local pode ser vantajoso ${ }^{8}$.

Os agentes vasoconstritores mais comumente utilizados são as catecolaminas, como a adrenalina, que agem em receptores pós-sinápticos do sistema nervoso simpático objetivando a vasoconstrição local. A adrenalina provoca contração da musculatura lisa vascular através da estimulação $\alpha$ adrenérgica. Ao ativar receptores $\beta 1$, produz no coração efeito inotrópico e cronotrópico positivos, podendo resultar em taquicardia e aumento da pressão arterial, assim como vasodilatação das arteríolas dos músculos esqueléticos e broncodilatação através da estimulação $\beta 2$-adrenérgica ${ }^{9}$.

nome genérico epinefrina é sinônimo de adrenalina. $O$ primeiro está de acordo com a Denominação Comum Brasileira (DCB) - denominação do fármaco ou princípio ativo aprovado pelo órgão federal responsável pela vigilância sanitária ${ }^{10}$.

A combinação da lidocaína $2 \%$ com adrenalina na proporção de 1:100.000 por cartucho $(1,8 \mathrm{~mL})$ contém $36 \mathrm{mg}$ de lidocaína e 0,018 mg de adrenalina. Essa associação prolonga o efeito da anestesia de 10 para 60 minutos em tecidos duros e polpa e até 3 horas em tecidos moles ${ }^{10}$. Vale ressaltar que esse tipo de anestésico local acidifica-se com adição de bissulfito de sódio para inibir a oxidação do vasopressor ${ }^{11}$. Este pode agir como um 
alérgeno em pessoas hipersensíveis, assim como os preservativos de metilparabeno ${ }^{12}$.

Quando a história médica do paciente sugere doença cardiovascular, deve-se limitar a dose de adrenalina 1:100.000 contida em até três cartuchos de lidocaína 2\%, de acordo com estudo conduzido em diabéticos coronariopatas $^{13}$, demonstrando ser bem tolerada pelos pacientes e seus benefícios superam os riscos.

Pesquisas em portadores de coronariopatias $^{14}$, gestantes com valvopatia

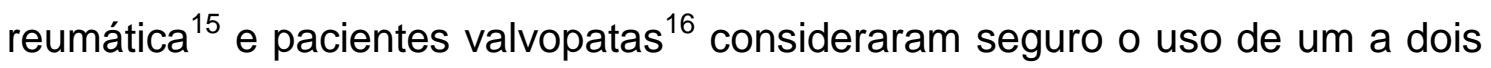
cartuchos $(1,8$ a 3,6 mL) de lidocaína 2\% com adrenalina 1:100.000, sem alterações hemodinâmicas, de frequência cardíaca (FC) ou pressão arterial (PA) em comparação ao uso de lidocaína sem vasoconstritor.

A analgesia inadequada resulta em dor e ansiedade, potentes desencadeadores da ativação do sistema simpático com liberação de maior quantidade de catecolaminas endógenas, influenciando parâmetros como FC, PA e excitabilidade cardíaca. A adrenalina endógena e exógena exerce potentes efeitos no coração, aumentando a contratilidade miocárdica, a condução atrioventricular e a resposta do músculo miocárdico a vários estímulos ${ }^{17,18}$.

A adrenalina exógena adicionada ao anestésico local pode estimular os receptores pré-sinápticos $\beta 2$ nas terminações nervosas simpáticas e na medula adrenal, acelerando a liberação de adrenalina endógena, conforme demonstrado por Takahashi e col. ${ }^{19}$. Foram avaliados neste estudo 43 adultos saudáveis, tendo como metodologia o uso de concentrações variadas do vasoconstritor adrenalina (em 5 titulações de zero a $50 \mu \mathrm{g}$ ) adicionado à 
anestesia local em maxila com $4 \mathrm{~mL}$ de lidocaína a $2 \%$, seguido da coleta de amostras de sangue para checar os níveis plasmáticos de adrenalina e noradrenalina. As concentrações plasmáticas de adrenalina tiveram máxima elevação aos cinco minutos após a injeção nos grupos II, III, IV e V, com posterior declínio, e de noradrenalina em 15 a 20 minutos no grupo $\mathrm{V}(50 \mu \mathrm{g})$. Também se observou diminuição da PA em determinados momentos e a FC não revelou diferenças significativas em relação ao nível basal e entre os grupos.

Lipp e col. coletaram amostras de sangue de 20 homens saudáveis para determinar os níveis séricos de catecolaminas após anestesia local odontológica com adrenalina marcada com trítio. Os pacientes receberam $2 \mathrm{~mL}$ de articaína 4\% com $20 \mu \mathrm{g}$ de adrenalina 1:100.000 para raspagem periodontal com ultrassom. Estes foram divididos em dois grupos: 10 receberam anestesia infiltrativa na maxila e 10 receberam bloqueio nervoso em mandíbula, em apenas um quadrante, mesmo o tratamento sendo realizado em todos os dentes. A adrenalina marcada com trítio correspondeu a $1,2 \%$ do total de adrenalina administrada e foram realizadas monitorização eletrocardiográfica e da pressão arterial. Quatro pacientes demonstraram aumento imediato da adrenalina exógena durante a injeção, sendo que dois destes exibiram extrassístoles supraventriculares e três apresentaram taquicardia. Nestes, as alterações de FC e o aumento da PA foram presumivelmente causados pela estimulação adrenérgica. Observou-se um aumento contínuo da adrenalina aplicada nos outros 16 pacientes, provavelmente explicado por sua absorção e metabolização. Um segundo aumento ocorreu após o início do procedimento dentário e foi associado à administração de catecolaminas exógenas, enquanto 
o tratamento odontológico em regiões sem anestesia não influenciou significativamente os níveis plasmáticos. Os níveis de adrenalina total (endógena e exógena) após a anestesia foram 5 a 10 vezes mais altos que os valores em repouso antes do tratamento. Os autores alertam para o risco de injeção intravascular involuntária em $20 \%$ dos pacientes, apesar da aplicação lenta e aspiração prévia ${ }^{20}$.

Campbell e Langston argumentam a necessidade de monitorização da pressão arterial e frequência cardíaca em resposta ao estresse durante o uso da anestesia local em pacientes ASA II (American Society of Anesthesiologists) apenas para quantidades superiores a $40 \mu \mathrm{g}$ de adrenalina ${ }^{21}$.

Um estudo com 45 pacientes hipertensos submetidos à extração dentária investigou alterações hemodinâmicas da PA e FC em diferentes momentos (três minutos antes, três minutos após a anestesia e três minutos após a extração), com uso de certos anestésicos locais. Os pacientes foram divididos em grupos e receberam dois cartuchos de um dos anestésicos: lidocaína $2 \%$ com adrenalina 1:80.000, prilocaína 3\% com felipressina 0,03 Ul/ml e mepivacaína 3\%. A média da PA sistólica aumentou após a injeção dos anestésicos e diminuiu após a extração nos três grupos. O aumento da PA sistólica após a extração com mepivacaína 3\% foi maior que com lidocaína e adrenalina, com diferença estatisticamente significante. As diferenças nas médias da FC e PA diastólica nos três grupos não foram significativas ${ }^{22}$.

Alterações de FC, PA e depressão do segmento ST foram estudadas em 37 pacientes do sexo masculino (19 cardiopatas) durante extrações dentárias sob anestesia local de lidocaína 2\% com adrenalina 1:100.000, em volumes de acordo com a tolerância da dor. Estes parâmetros foram registrados 
continuamente durante o pré-operatório, administração de anestesia, cirurgia e período pós-operatório. Nos pacientes coronariopatas, valvopatas e hipertensos, a incidência de depressão do segmento ST foi significativamente maior, indicando isquemia miocárdica durante o tratamento odontológico. Nas fases de anestesia e cirurgia, a incidência quase equivalente de depressão do segmento ST sugeriu que a administração de anestesia local é tão estressante quanto a extração de dentes neste grupo de pacientes. No entanto, não foram observadas arritmias ventriculares significantes (batimentos ectópicos ou taquicardia ventricular). Valores de PA foram maiores no grupo de cardiopatas, mas não foram afetados pelo tratamento odontológico em ambos os grupos. Já a FC aumentou significativamente do pré-operatório para a anestesia e cirurgia nos dois grupos. Os autores sugerem o uso de técnicas para diminuir o estresse e indicam que cardiopatas, especialmente com angina ou hipertensão, e pacientes com suspeita de doença cardíaca, podem se beneficiar da consulta médica antes do tratamento odontológico ${ }^{23}$.

Outro estudo, com 80 pacientes saudáveis, correlacionou alterações hemodinâmicas e ansiedade durante extração dentária de terceiro molar inferior com até três cartuchos articaína 4\% com adrenalina 1:100.000. Por meio de duas escalas para avaliação do medo e ansiedade frente ao tratamento dentário, as mulheres apresentaram maiores níveis destes parâmetros, e os pacientes mais ansiosos apresentaram valores mais altos de FC e mais baixos de PA, sem diferença estatisticamente significante. Variações na FC e PA mantiveram-se dentro dos limites normais, mas um aumento da PA sistólica e diastólica foi observado no momento da osteotomia e/ou secção dentária, sem diferença estatisticamente significante. Os valores de saturação 
de oxigênio não apresentaram alterações significativas. Para garantir a segurança da prática clínica, os autores salientam minimizar a ansiedade do paciente e evitar a dor ${ }^{24}$.

A influência da ansiedade no sistema cardiovascular foi observada antes, durante e após a anestesia de bloqueio mandibular com dois cartuchos de lidocaína 2\% com adrenalina 1:100.000 para extração dentária em um estudo com 180 pacientes. Os resultados mostraram maior nível de ansiedade em jovens e mulheres. Pacientes com ansiedade grave apresentaram FC maior em comparação àqueles com ansiedade leve e moderada. A PA sistólica e diastólica aumentaram durante a administração de anestesia local em todos pacientes, mas sem diferença estatisticamente significante. As anormalidades eletrocardiográficas mais comuns foram bradicardia e taquicardia aos cinco e 10 minutos após injeção anestésico local. Os autores salientaram que a analgesia inadequada está associada ao aumento da dor durante os procedimentos dentários, o que pode resultar na produção de mais adrenalina endógena. A dor na injeção foi correlacionada com alterações cardiovasculares, como o aumento da FC durante a administração de anestesia $^{25}$.

No tratamento odontológico deve-se levar em consideração a redução da ansiedade do paciente através de analgesia efetiva e, por vezes, medicação prévia $^{26}$, pois em alguns casos o estresse e estímulos auditivos, comuns no ambiente do consultório, podem funcionar como gatilhos para alterações eletrocardiográficas e até serem fatores de risco para desencadeamento de arritmias malignas em alguns cardiopatas, como portadores de canalopatias ${ }^{27}$. 
A avaliação da história médica é o passo inicial de qualquer plano de tratamento, assim como a boa comunicação com o cardiologista ${ }^{28}$.

As canalopatias são arritmias cardíacas hereditárias resultantes de alterações genéticas em canais iônicos envolvidos no potencial de ação cardíaco, podendo levar à fibrilação ventricular e morte súbita, na ausência de defeitos estruturais ${ }^{29,30}$. As mais prevalentes são a síndrome do QT longo congênito (SQTL), a síndrome de Brugada (SBr) e taquicardia ventricular polimórfica catecolaminérgica (TVPC) ${ }^{31}$, que podem ser responsáveis por pelo menos um terço do total de casos de morte súbita que permanecem inexplicados, afetando principalmente indivíduos jovens e com implicações para familiares em risco 32,33 .

A SQTL é uma desordem da condução elétrica do miocárdio que altera a repolarização ventricular e predispõe ao desenvolvimento de arritmias ventriculares, desencadeadas principalmente pela ativação adrenérgica ${ }^{34}$.

A prevalência desta doença é estimada em um a cada 2.500 nascidos vivos $^{35}$, podendo ser de origem congênita ou induzida. Cerca de $80 \%$ da síndrome é hereditária, causada por mutações em genes que codificam canais iônicos ou proteínas envolvidas na condução cardíaca ${ }^{36}$. Essa síndrome se caracteriza pela diversidade fenotípica e genotípica, mas têm em comum o prolongamento do intervalo QT no eletrocardiograma (ECG), bem como uma atípica taquicardia ventricular polimórfica conhecida como torsades de pointes (TdP), e em muitos casos, uma alta exposição ao risco de morte súbita ${ }^{37}$.

As três primeiras variantes da SQTL, representando aproximadamente 90\% dos indivíduos genotipados, correspondem a: SQTL1 (com mutações no gene KCNQ1), SQTL2 (mutações em KCNH2), ambos comprometendo a 
dinâmica de canais de potássio, e SQTL3 (gene SCN5A) relacionado à recuperação de canais de sódio ${ }^{38}$. A SQTL1 é a forma genética mais frequente, abrangendo 30 a $35 \%$ de todos os casos da síndrome ${ }^{39}$.

Mesmo que indivíduos partilhem a mesma mutação causadora da doença, há significativas diferenças fenotípicas, incluindo uma ampla distribuição do intervalo QT e a presença ou ausência de eventos cardíacos ${ }^{40}$. A maioria desses eventos está associada a exercícios físicos na SQTL1, ao estresse e estímulos auditivos na SQTL2, enquanto na SQTL3 ocorrem principalmente durante o sono ou repouso ${ }^{41}$.

Segundo as mais recentes diretrizes publicadas por experts na área ${ }^{34}$, o diagnóstico da SQTL inclui o intervalo QTc $\geq 480 \mathrm{~ms}$ em eletrocardiogramas seriados de 12 derivações ou pela aplicação do escore de probabilidade de Schwartz $^{42}$. Este último é baseado na pontuação de critérios eletrocardiográficos, clínicos e história familiar, sendo um escore $\geq 3,5$ considerado diagnóstico da doença. Na presença de síncope inexplicada, o intervalo QTc $\geq 460$ ms pode ser suficiente para fazer o diagnóstico.

O teste de provocação por adrenalina pode ajudar a desmascarar alguns pacientes com SQTL e pode ser conduzido com segurança nestes pacientes, já que o prolongamento do intervalo QT induzido por adrenalina se mostra patognomônico para SQTL1, de acordo com estudo de Ackerman e colaboradores $^{43}$.

A SBr foi publicada pela primeira vez em 1992 e consiste na elevação característica do segmento ST em pelo menos uma das derivações precordiais direitas (V1 a V3), com risco de morte súbita como resultado de fibrilação ventricular $^{44}$. Originalmente descrita com maior frequência em asiáticos ${ }^{45}$, tem 
prevalência estimada em 5:10.000 habitantes ${ }^{46}$, acometendo em sua maioria homens adultos ${ }^{47}$ com média de 40 anos de idade ${ }^{48}$.

O principal gene associado à SBr é o SCN5A, que codifica a subunidade alfa dos canais de sódio cardíacos ${ }^{49}$. Os canais alterados modificam o influxo dos íons e a duração normal do potencial de ação. A mutação do gene SCN5A está presente em até $30 \%$ dos casos e em 5 a 10\% dos casos de mortes súbita em adultos e crianças ${ }^{50,51}$.

Como a arritmia ventricular nesses pacientes geralmente ocorre em repouso, especialmente durante o sono, supõe-se que a atividade vagal represente importante papel na fisiopatologia da doença ${ }^{52}$. Outros fatores se apresentam como gatilho de eventos cardíacos induzindo a taquicardia ventricular, tais como: febre ${ }^{53-56}$, refeições copiosas, desequilíbrio hidroeletrolítico, drogas e fármacos ${ }^{57,58}$. Estes últimos se encontram listados, incluindo certos anestésicos locais como a bupivacaína, que devem ser evitados em pacientes com $\mathrm{SBr}^{59}$.

Esta alteração pode ser diagnosticada espontaneamente pelo achado eletrocardiográfico padrão tipo 1 ou induzida por fármacos específicos, sendo auxiliada pela colocação dos eletrodos em posições superiores ${ }^{34,60}$.

A TVPC, descrita em $1975^{61}$, é caracterizada por síncopes e taquicardia ventricular induzidas pela liberação de catecolaminas endógenas provocadas por estresse físico ou emocional, podendo causar morte súbita na ausência de causas secundárias ${ }^{62}$.

As manifestações clínicas geralmente ocorrem na infância ou juventude ${ }^{63}$, com prevalência estimada em 1:10.000 ${ }^{64}$. Em 30\% dos pacientes, há história familiar de síncope ou morte súbita ${ }^{65}$. 
O principal mecanismo deriva de disfunções nos canais de cálcio dos miócitos, provocadas por mutações no receptor de rianodina cardíaco (RyR2 autossômico dominante) ou calsequestrina (CaSQ2 - autossômico recessivo), responsáveis pela regulação do cálcio intracelular ${ }^{66,67}$.

O diagnóstico da TVPC muitas vezes é desafiador, visto que esses pacientes apresentam ECG de repouso normal. A confirmação diagnóstica é estabelecida pelo teste de esforço, que desencadeia e documenta TV polimórfica ou bidirecional, sustentada ou não sustentada, na ausência de cardiopatia estrutural demonstrável ${ }^{68}$.

A história médica e o exame físico geralmente são inconclusivos diante de alguns sintomas sugestivos de arritmias cardíacas, dificultando 0 diagnóstico. O eletrocardiograma é considerado referência para registrar a variação do potencial elétrico cardíaco, mas a obtenção de um padrão sintomático geralmente não é possível ${ }^{69}$. Assim, são indicados métodos de monitorização para facilitar o diagnóstico ambulatorial, como o sistema Holter, que registra continuamente a atividade elétrica para detectar e quantificar arritmias cardíacas. Os pacientes devem manter um diário durante o período para associar as alterações eletrocardiográficas à ocorrência de sintomas ${ }^{70}$.

O teste genético é recomendado para dar suporte ao diagnóstico clínico, pesquisar a relação genótipo-fenótipo e detectar precocemente os potenciais fatores de risco do paciente e familiares, através de medidas preventivas e orientação adequada, além da elucidação de casos inconclusivos após autópsia ${ }^{71-74}$. No entanto, o diagnóstico molecular desses distúrbios ainda é complexo e caro, limitando seu uso rotineiro, porém torna-se importante em estudos científicos para que a seleção da amostra seja otimizada. Apesar da 
investigação de vários genes envolvidos, a taxa de diagnóstico genético é variável entre as canalopatias, com muitos casos inconclusivos ${ }^{75,76}$.

O principal objetivo do tratamento das canalopatias é evitar arritmias e morte súbita. Geralmente os beta-bloqueadores, nos casos de SQTL e TVPC, têm sido usados para otimização terapêutica, minimizando as diversas alterações da repolarização e reduzindo também arritmias ventriculares. Em casos de episódios de síncope, TdP ou parada cardíaca exigindo ressuscitação cardiopulmonar (RCP), o implante do cardiodesfibrilador implantável (CDI) e/ou denervação simpática cardíaca são alternativas na abordagens desses pacientes $^{77}$. Já nos pacientes com $\mathrm{SBr}$ a estratificação de risco é mais desafiadora, sendo indicado CDI, quinidina ou até ablação por cateter em casos selecionados ${ }^{34,76}$.

O atendimento odontológico de rotina é dificultado pela escassez de estudos sobre a segurança de anestésicos locais em pacientes portadores de canalopatias, quase sempre descritos como relatos de caso. De acordo com $W_{y n n}{ }^{78}$, o efeito dos anestésicos locais usados em Odontologia e sua associação com adrenalina em pacientes com história de prolongamento do intervalo QT congênito ou adquirido ainda é desconhecido. A formulação de articaína 4\% com 1:200.000 de adrenalina poderia beneficiar pacientes com história de doenças cardiovasculares (incluindo SQTL) e para aqueles que necessitam de cuidados quanto ao vasoconstritor devido à menor estimulação cardiovascular produzida nessa concentração do que em 1:100.000 do mesmo anestésico. A menor concentração de adrenalina não compromete a efetividade anestésica da articaína 4\%, apresentando efeitos similares de início e duração do efeito para ambas as doses. 
Segundo relato de caso de Theodotou e Cillo ${ }^{79}$, a lidocaína com adrenalina 1:100.000 foi usada na anestesia local para tratamento odontológico em um paciente com 55 anos, portador de $\mathrm{SBr}, \mathrm{CDI}$, valvopatia e coronariopatia, submetido à drenagem de abscesso e exodontia sob anestesia geral induzida com 50 mg lidocaína, 160 mg de propofol e 100 mg de succinilcolina. Para a manutenção da anestesia foi usado sevoflurano e mistura gasosa de oxigênio e óxido nitroso (1:1 L/min). Foram aplicados $15 \mathrm{mg}$ de lidocaína com 1:100.000 de adrenalina na região intraoral para anestesia local da área operada. Vale ressaltar que a concentração de lidocaína $2 \%$ em um cartucho é de $36 \mathrm{mg}$. Não ocorreram complicações intraoperatórias ou cardíacas neste paciente.

O atendimento odontológico ambulatorial em portadora de TVPC com 13 anos de idade foi descrito em um relato de caso, cuja paciente já havia sido submetida a tratamento dentário anterior sob anestesia geral. Em razão da recorrência de lesões cariosas e necessidade de nova intervenção, o cardiologista não contraindicou o uso de anestésico local com adrenalina. Porém, o dentista considerou prudente utilizar mepivacaína 3\% para anestesia local na quantidade de três cartuchos, além da administração de óxido nitroso para realizar as restaurações dentárias ${ }^{80}$.

As condutas relacionadas à segurança da adrenalina associada aos anestésicos locais de uso odontológico em pacientes com canalopatias são limitadas pela ausência de estudos sobre administração dessas formulações nessas populações e pela raridade dessas doenças. Fica evidente que nestes pacientes com condições cardíacas de maior risco, ao necessitarem de tratamento odontológico, o cirurgião-dentista precisará de conhecimento 
técnico-científico em relação aos anestésicos locais, bem como às canalopatias e suas repercussões. Estes pacientes muitas vezes não obtêm atendimento e analgesia adequados devido ao risco potencial de eventos ameaçadores à vida, como: taquicardias ventriculares sustentadas (TVS), terapias pelo CDI durante a intervenção e síncopes arrítmicas ${ }^{81}$. Assim, tornam-se necessários estudos para orientar futuros protocolos de tratamento odontológico em pacientes com canalopatias.

O interesse pela segurança da anestesia local em portadores de canalopatias, não resultando na ocorrência de arritmias cardíacas ameaçadoras à vida, norteou os princípios desta investigação científica. 


\section{OBJETIVOS}

\subsection{Primário}

Comparar os aspectos de segurança quanto aos desfechos arrítmicos com o uso da anestesia local odontológica com lidocaína sem vasoconstritor e lidocaína associada à adrenalina em portadores de canalopatias cardíacas.

\subsection{Secundários}

- Analisar a ocorrência e densidade de arritmias ventriculares e supraventriculares utilizando o sistema de monitorização eletrocardiográfica contínua (Holter).

- Analisar os aspectos eletrocardiográficos antes, durante e após os procedimentos, incluindo as mensurações do intervalo QTc nos portadores de SQTL e o comportamento do padrão morfológico nos portadores de SBr.

- Descrever os dados da pressão arterial sistêmica e da avaliação da ansiedade antes, durante e após os procedimentos. 


\section{MATERIAL E MÉTODOS}

Trata-se de um estudo piloto randomizado, duplo-cego com cross-over. A pesquisa teve aprovação da Comissão de Ética do Hospital das Clínicas da Faculdade de Medicina da Universidade de São Paulo (SDC: 3922/13/047 Apêndice), recebeu apoio financeiro da Fundação de Amparo à Pesquisa do Estado de São Paulo (FAPESP) - Processo: 2013/24283-1 (Apêndice) e foi registrada no sítio eletrônico internacional ClinicalTrials.gov (ID: NCT03182777).

\subsection{População}

Portadores de canalopatias cardíacas foram encaminhados pelo Núcleo Clínico-Cirúrgico de Arritmias Cardíacas (NCCAC) do Instituto do Coração do Hospital das Clinicas da Faculdade de Medicina da Universidade de São Paulo à Unidade de Odontologia da mesma instituição. Estes pacientes foram selecionados e convidados a participar do estudo, sendo esclarecidos verbalmente sobre os objetivos da pesquisa, anestesia e restauração dentária, exames e monitorização eletrocardiográfica. Todos os pacientes procederam à leitura e assinatura do Termo de Consentimento Livre e Esclarecido (Apêndice). 
3.1.1 Critérios de inclusão

- Pacientes portadores das canalopatias abaixo, mantidos sob terapia medicamentosa otimizada, com ou sem CDI:

- Síndrome do QT longo congênito

- Síndrome de Brugada

- Taquicardia Ventricular Polimórfica Catecolaminérgica

- Presença de cárie dentária ou restaurações insatisfatórias em mandíbula, indicando a necessidade de tratamento odontológico restaurador

\subsubsection{Critérios de exclusão}

- Pacientes submetidos à terapia por CDI há menos de três meses

- Pacientes com síncopes recorrentes nos últimos três meses

- Pacientes com arritmias sustentadas documentadas há menos de três meses

- Pacientes que tivessem sido medicados com adrenalina nas 24 horas anteriores

- Pacientes alérgicos à bissulfito de sódio e metilparabeno

- Pacientes com peso corporal menor que 20 kg (dose máxima segura de lidocaína - 4,4 mg/kg ${ }^{82}$ ) 
Os pacientes foram incluídos consecutivamente, participando randomicamente do estudo em duas sessões matinais, realizadas com intervalo mínimo de sete dias (wash-out) entre ambas, sendo o paciente seu próprio controle. Em cada uma das sessões foi realizado um procedimento odontológico restaurador sob anestesia local.

3.2 Preparo do paciente e procedimentos odontológicos

Em sessão prévia, foi realizado exame clínico odontológico, preenchimento da ficha clínica (Apêndice) e efetuada radiografia ortopantomográfica (radiografia panorâmica de maxila e mandíbula) para investigação de focos infecciosos presentes. Na presença de doença periodontal, múltiplas lesões cariosas ou dentes com indicação de extração, era realizada a adequação do meio bucal, através de intervenções para a remoção de focos infecciosos e reestabelecimento da saúde bucal do paciente.

Foram selecionados pacientes cujos dentes da arcada inferior apresentassem cárie ou restaurações insatisfatórias e que necessitassem de tratamento restaurador, implicando na remoção do tecido cariado, preenchimento e reconstrução com material apropriado. As restaurações foram realizadas conforme as cavidades especificadas em classe I, II ou V de Black ${ }^{83}$, com resina composta, ionômero de vidro/ material provisório, conforme indicação do caso. 


\subsubsection{Perfil de saúde bucal}

Em associação ao tratamento odontológico, foi realizada orientação de higiene oral e registro do índice de CPOD (número de dentes permanentes cariados, perdidos e obturados) ${ }^{84}$, assim como análise simplificada das condições periodontais (presença de gengivite, cálculo e doença periodontal).

\subsubsection{Anestesia local odontológica}

Na primeira sessão, por randomização, o paciente recebeu 3,6 $\mathrm{mL}$ (dois cartuchos) de uma das soluções anestésicas: lidocaína $2 \%$ sem vasoconstritor (72.000 $\mu \mathrm{g}$ de lidocaína - LSA) ou lidocaína 2\% com adrenalina 1:100.000 (36 $\mu \mathrm{g}$ de adrenalina - LCA), originando duas condições: sem adrenalina e com adrenalina (cross-over). Na segunda sessão, recebeu a outra solução anestésica.

A randomização da solução anestésica foi realizada por meio de uma tabela em aplicativo Excel (Microsoft Office), elaborada pelo pesquisador responsável, que distribuiu aleatoriamente as duas condições na planilha por meio de algoritmos, sendo cega para o pesquisador executante e para 0 paciente (Anexo A).

O mascaramento da seringa Carpule com o cartucho anestésico foi feito pelo pesquisador responsável, que recobriu a seringa com papel alumínio estéril, impedindo a identificação da solução pelo pesquisador executante e 
pelo paciente (Figura 1). Somente após a segunda sessão do experimento, 0 pesquisador responsável comunicou ao executante os dados da randomização.

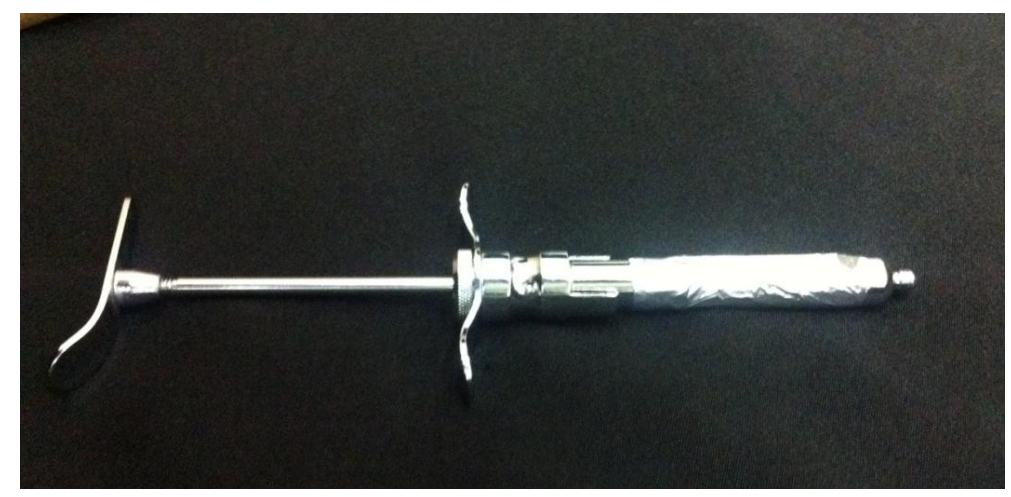

Figura 1 - Mascaramento da seringa Carpule com papel alumínio

Para minimizar o desconforto causado durante a punção da agulha utilizada na injeção da solução anestésica, foi aplicado anestésico tópico (gel de benzocaína $20 \%$ ) no local, mantido em contato com a mucosa bucal seca com gaze, por um minuto.

A introdução da agulha longa de calibre 25 (25G) e a injeção do anestésico obedeceram à técnica padronizada de bloqueio do nervo alveolar inferior $^{85}$, indicada para dentes inferiores, que possibilita maior concentração do anestésico na corrente sanguínea, permitindo a avaliação de possíveis efeitos sobre o sistema cardiovascular ${ }^{86}$.

A solução anestésica foi depositada lentamente, na velocidade de $1 \mathrm{~mL}$ por minuto e a confirmação do sucesso da técnica foi garantido pela anestesia da língua e lábio inferior do lado designado. 


\subsubsection{Períodos de estudo das sessões}

Conforme randomização realizada na primeira sessão, o paciente foi alocado para uma das duas condições: com adrenalina e sem adrenalina. Cada uma das sessões compreendeu os seguintes períodos de análise (Figura 2):

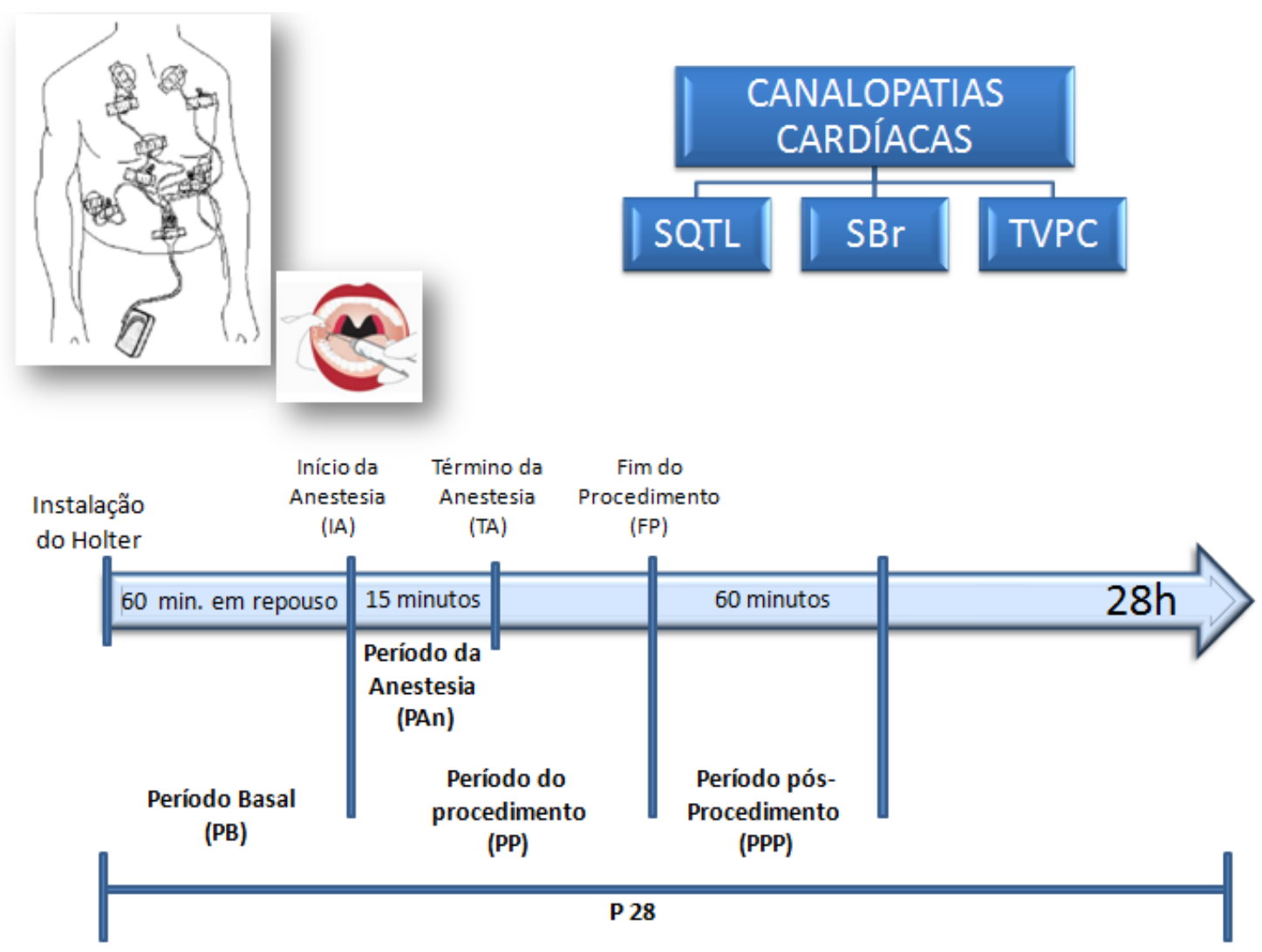

Figura 2 - Linha do tempo indicando os períodos de estudo

- período das 28 horas (P28): do início da gravação até desinstalação do Holter

- período basal (PB): 60 minutos em repouso após instalação do Holter 
- período da aplicação da anestesia (PAn): momento de início da aplicação da solução anestésica (IA) até 15 minutos após término da aplicação anestésica $(\mathrm{TA})$

- período do procedimento (PP): de IA até o fim do procedimento (FP) com a saída do paciente da cadeira odontológica

- período pós-procedimento (PPP): 60 minutos a partir do FP

3.2.4 Monitoração eletrocardiográfica ambulatorial contínua

A monitorização eletrocardiográfica ambulatorial foi obtida por meio do gravador Holter Seer Light Extend (GE Healthcare do Brasil - Registro ANVISA no 80071260180) instalado no início da manhã pelo técnico da Seção de Monitorização Eletrocardiográfica Ambulatorial do Serviço de Eletrocardiografia do InCor (MEA).

De acordo com as informações do fabricante, o gravador foi projetado para adquirir três canais de sinal eletrocardiográfico da superfície torácica dos pacientes através de sete eletrodos. Os canais 1,2 e 3 correspondem respectivamente às derivações V5, V1 e V3 (Figura 3). 


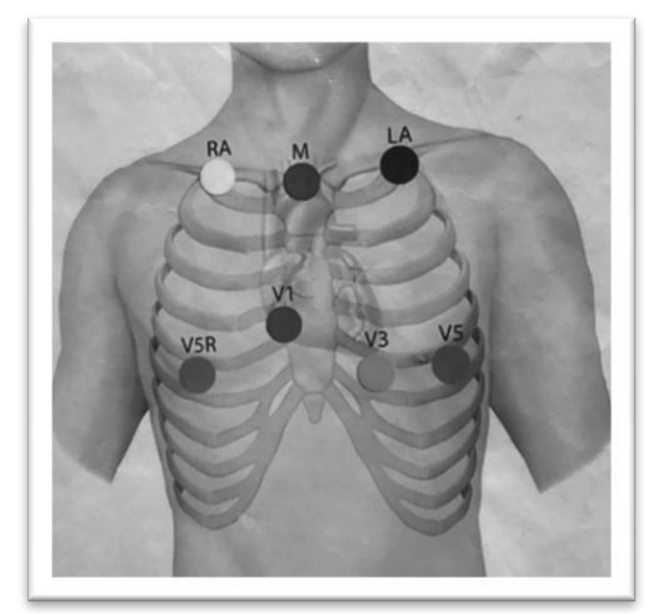

Figura 3 - Representação do posicionamento dos eletrodos do Holter Seer Light

O equipamento permaneceu instalado por 28 horas, contadas a partir de uma hora antes do procedimento, em ambas as sessões.

O exame foi analisado inicialmente de forma automática por sistema computadorizado, seguido de revisão visual e manual por técnico especializado, na qual os batimentos cardíacos prematuros supraventriculares e ventriculares foram filtrados com rigor e posteriormente revisados por dois médicos da MEA. O equipamento adquirido para realização do projeto foi o mesmo padronizado pelo setor, dispensando aquisição de novo software de análise.

O paciente foi orientado a preencher o relatório convencional de eventos do Holter durante as 28 horas, exceto durante o procedimento odontológico, no qual o pesquisador fez as anotações relativas ao procedimento odontológico e as relatadas pelo paciente, acionando a tecla de eventos, quando necessário, e registrando estas informações no diário de eventos para orientar a futura análise do exame. 
As variáveis eletrocardiográficas estudadas foram ocorrência e densidade de arritmias supraventriculares e ventriculares: extrassístole supraventricular/hora (ESSV/h), extrassístole ventricular/hora $(E V / h)$, taquicardia atrial não sustentada (TANS), taquicardia ventricular não sustentada (TVNS), monomórficas e/ou polimórficas, e arritmias sustentadas identificadas no traçado obtido minuto a minuto e comparadas durante os períodos de estudos. Também foram observadas as FC mínima, média e máxima e pausas de cada análise do Holter.

\subsubsection{Eletrocardiografia}

Foram realizados pontualmente registros eletrocardiográficos de 12 derivações em todos os pacientes nos três momentos: PB, TA e FP. Nos pacientes portadores de $\mathrm{SBr}$, o posicionamento dos eletrodos era modificado com a realização de derivações superiores, também nos três momentos (Figura 4).

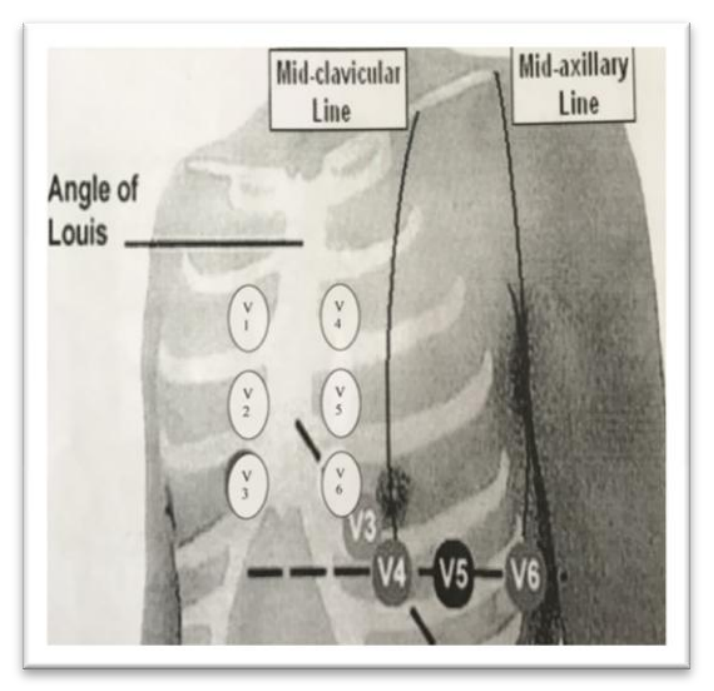

Figura 4 - Posição dos eletrodos nas derivações especiais para SBr 
Os padrões eletrocardiográficos nos portadores de $\mathrm{SBr}$ foram classificados em normal, padrão tipo 1 ou não tipo 1.

Para os portadores de SQTL, os intervalos QT foram medidos manualmente e o QTc foi calculado pela fórmula de Bazett ${ }^{87}$, considerando o método da tangente preferencial na derivação DII; quando aplicável (dificuldade de interpretação do final da repolarização) poderia ser escolhida a derivação V2 ou V5. O QTc foi considerado normal com valor $<450 \mathrm{~ms}$ em homens e $<460 \mathrm{~ms}$ em mulheres ${ }^{88}$. Todas as medidas foram feitas de forma cega pelo mesmo cardiologista e confirmadas, posteriormente, por um segundo cardiologista. Discordâncias ocasionais foram resolvidas por consenso. Pela possibilidade de variação do QTc entre os pacientes com SQTL, optou-se também pela inclusão da variável categórica de comparação entre os momentos de estudo, classificadas como variação maior ou menor que $10 \%$ do QTc em relação ao QTc basal.

Nos pacientes com TVPC, eram analisadas as ocorrências de arritmias ventriculares no eletrocardiograma.

\subsubsection{Registro pontual da pressão arterial sistêmica}

As pressões arteriais sistólica (PAS) e diastólica (PAD) foram monitoradas por meio da média de três aferições consecutivas, nos momentos: PB, TA e FP, utilizando esfigmomanômetro digital de pulso Microlife BP W100 (Registro ANVISA no 10222460055), validado pela Sociedade Europeia de Hipertensão ${ }^{89}$. 


\subsubsection{Mensuração da ansiedade}

A Escala de Imagem Facial ou Facial Image Scale, desenvolvida por Buchanan e Niven ${ }^{90}$, foi utilizada para mensurar a ansiedade frente ao tratamento odontológico. O paciente era questionado sobre como se sentia naquele momento, apontando para a figura que mais expressasse o seu perfil de ansiedade.

A escala de mensuração da ansiedade (Figura 5) foi aplicada nos momentos: PB, IA e FP, com a pergunta "Qual destas faces expressa melhor como você se sente agora?"

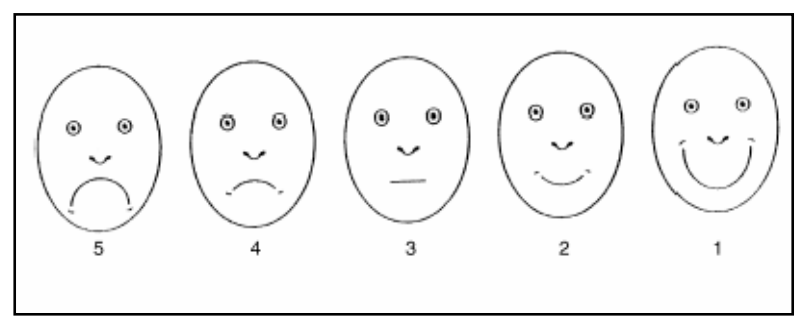

Figura 5 - Escala de mensuração da ansiedade: Facial Image Scale

\subsubsection{Critérios de segurança do procedimento}

Foram considerados critérios de segurança a não ocorrência de arritmias ameaçadoras à vida (TV sustentada monomórfica ou polimórfica, choque por CDI) ou de síncope de causa presumidamente arrítmica. Dentro do planejamento do protocolo, caso ocorresse eventos arrítmicos ameaçadores à vida, o procedimento odontológico seria interrompido, incluindo prontoatendimento médico. 
3.3 Genotipagem das canalopatias

Foi obtida análise genética da amostra por meio dos resultados de outro projeto do mesmo grupo de pesquisa, que compreendeu tal investigação e permanece em andamento.

3.4 Seguimento do paciente

Após a coleta de dados, os pacientes deram seguimento ao tratamento odontológico na Unidade de Odontologia do InCor para realização dos demais procedimentos, quando necessário.

\subsection{Análise estatística}

\subsubsection{Tamanho amostral}

Não houve cálculo do tamanho da amostra por se tratar de estudo exploratório (piloto). Desta forma, não há possibilidade de estimar a incidência de arritmias pelo uso de anestésicos locais odontológicos em portadores de canalopatias, devido à ausência de dados na literatura. 


\subsubsection{Análises dos resultados}

Inicialmente todas as variáveis foram analisadas descritivamente. A normalidade das variáveis quantitativas foi avaliada com o teste de Kolmogorov-Smirnov. As características quantitativas foram descritas em todos os pacientes com uso de medidas resumo (média, desvio padrão, mediana, mínimo e máximo), enquanto as características qualitativas foram descritas com uso de frequências absolutas e relativas.

Os parâmetros avaliados foram descritos segundo uso de adrenalina e comparados entre as sessões com testes t-Student pareados ou testes Wilcoxon pareados. As análises foram realizadas para canalopatias específicas, além da amostra total, e para o padrão eletrocardiográfico da $\mathrm{SBr}$ verificou-se a associação entre as sessões com testes McNemar ${ }^{91}$.

Os escores de ansiedade foram descritos e comparados entre as ordens de realização dos procedimentos com uso de testes Wilcoxon pareados. Foram calculadas as correlações de Spearman ${ }^{91}$ entre as pressões arteriais e os escores de ansiedade nos momentos específicos de avaliação para verificar a existência de correlação entre elas.

Para realização das análises foi utilizado o software IBM-SPSS ("Statistical Package for the Social Sciences"), versão 20.0 (SPSS, Inc., Chicago, IL, USA) e para tabulação dos dados foi utilizado o software Microsoft Excel 2003. Todos os testes foram bicaudais e realizados com nível de significância de $5 \%$. 


\section{RESULTADOS}

Foram realizados sessenta e dois procedimentos odontológicos restauradores sob anestesia local com lidocaína, sem e com adrenalina.

\subsection{Características da amostra estudada}

No período de maio de 2016 a agosto de 2018, 76 pacientes foram contatados e 49 foram avaliados. Destes, 32 foram submetidos ao tratamento odontológico em duas sessões. Um paciente foi excluído devido à perda das gravações do Holter e por não querer mais repetir o exame (Figura 6).

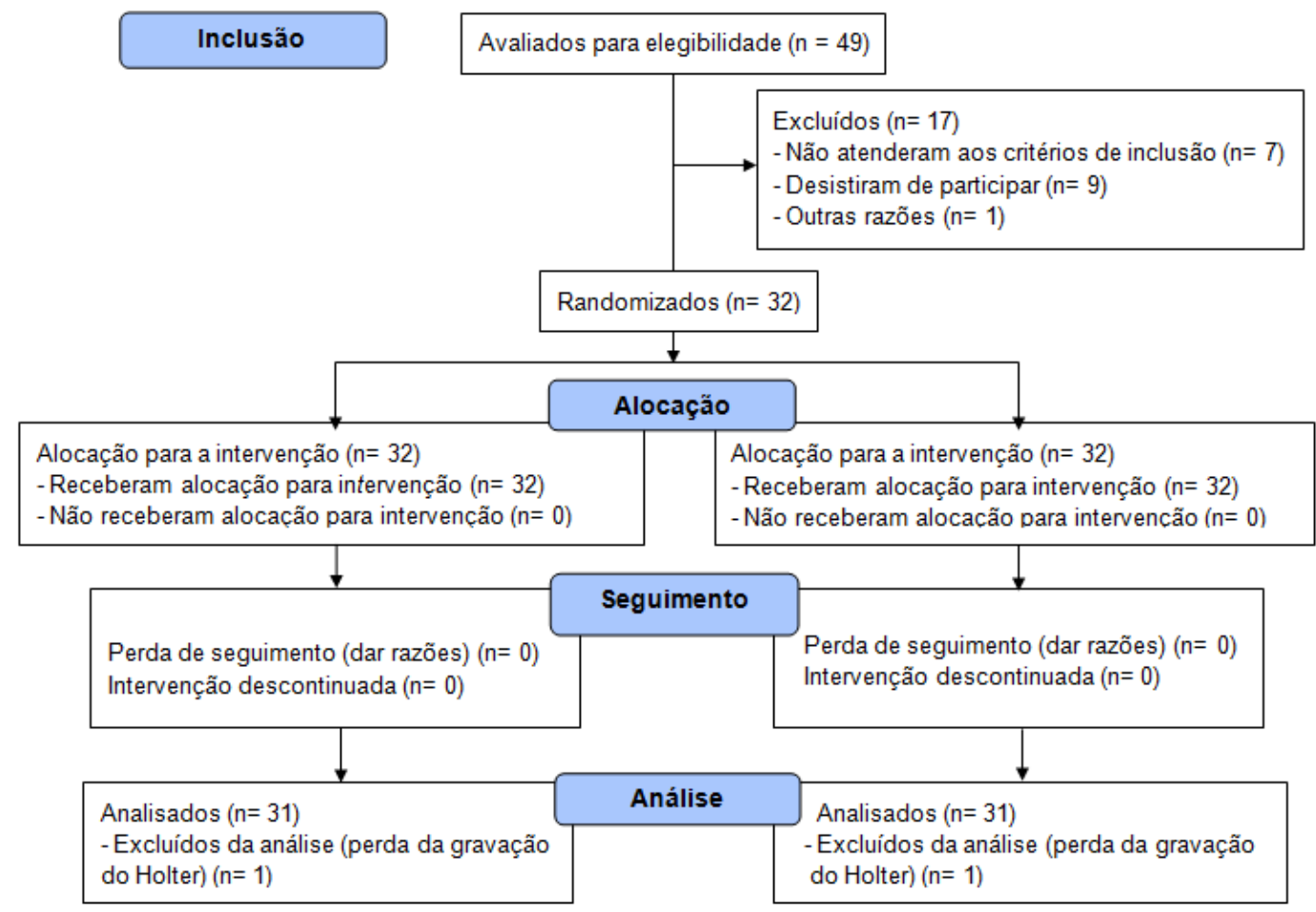

Figura 6 - Fluxograma CONSORT 2010 
A amostra de 31 pacientes foi composta por $16(51,6 \%)$ portadores de SQTL, $12(38,7 \%)$ com SBr e três $(9,7 \%)$ pacientes com TVPC, dentre os quais $12(38,7 \%)$ possuíam CDI. A média de idade foi de 45,2 $\pm 15,8$ anos, sendo 10 $(32,3 \%)$ homens e $21(67,7 \%)$ mulheres, com $23(74,2 \%)$ pacientes da raça branca (Tabela 1).

Tabela 1 - Descrição das características gerais dos pacientes da amostra

\begin{tabular}{|c|c|c|c|}
\hline \multicolumn{2}{|l|}{ Características } & \multicolumn{2}{|c|}{ Descrição (N = 31) } \\
\hline \multicolumn{4}{|l|}{ Idade (anos) } \\
\hline média \pm DP & & & $45,2 \pm 15,8$ \\
\hline mediana (mín.; máx.) & & & $46(16 ; 74)$ \\
\hline \multicolumn{4}{|l|}{ Sexo, n (\%) } \\
\hline Feminino & & & $21(67,7)$ \\
\hline Masculino & & & $10(32,3)$ \\
\hline \multicolumn{4}{|l|}{ Raça, n (\%) } \\
\hline Branca & & & $23(74,2)$ \\
\hline Parda & & & $5(16,1)$ \\
\hline Negra & & & $3(9,7)$ \\
\hline \multicolumn{4}{|l|}{ Peso $(\mathrm{Kg})$} \\
\hline média $\pm \mathrm{DP}$ & & & $74,8 \pm 17,2$ \\
\hline mediana (mín.; máx.) & & & $73(55 ; 145)$ \\
\hline \multicolumn{4}{|l|}{ Altura (m) } \\
\hline média \pm DP & & & $1,63 \pm 0,07$ \\
\hline mediana (mín.; máx.) & & & $1,63(1,5 ; 1,77)$ \\
\hline \multicolumn{4}{|l|}{ IMC $\left(\mathrm{Kg} / \mathrm{m}^{2}\right)$} \\
\hline média \pm DP & & & $28,1 \pm 6,6$ \\
\hline mediana (mín.; máx.) & & & $27,2(19,1 ; 56,6)$ \\
\hline \multicolumn{4}{|l|}{ Canalopatias, n (\%) } \\
\hline SQTL & & & $16(51,6)$ \\
\hline $\mathrm{SBr}$ & & & $12(38,7)$ \\
\hline TVPC & & & $3(9,7)$ \\
\hline CDI, n (\%) & & & $12(38,7)$ \\
\hline \multicolumn{4}{|c|}{ Análise genética, n (\%) } \\
\hline & positiva & negativa & em andamento \\
\hline SQTL & $12(75)$ & $3(18,7)$ & $1(6,2)$ \\
\hline $\mathrm{SBr}$ & 0 & $12(100)$ & 0 \\
\hline TVPC & $2(66,6)$ & $1(33,3)$ & 0 \\
\hline
\end{tabular}


Outras características clínicas da amostra como medicamentos em uso, comorbidades associadas e perfil de gravidade estão descritas nas Tabelas 2 a 6 de acordo com as canalopatias específicas dos pacientes. As dosagens dos medicamentos estão apresentadas no Anexo B.

Tabela 2 - Descrição dos medicamentos em uso pelos pacientes da amostra

\begin{tabular}{lc}
\hline \multirow{2}{*}{ Medicamentos } & Descrição (N=31) \\
\cline { 2 - 2 } & $\mathrm{n}(\%)$ \\
\hline Beta-bloqueadores & $21(67,7)$ \\
Bloqueadores dos canais de cálcio & $6(19,4)$ \\
Propafenona & $2(6,5)$ \\
Quinidina & $2(6,5)$ \\
Cilostazol & $2(6,5)$ \\
Inibidores da enzima conversora de Angiotensina & $8(25,8)$ \\
Bloqueadores de receptores AT1 & $5(16,1)$ \\
Diuréticos & $4(12,9)$ \\
Bloqueador do SNC & $2(6,5)$ \\
Vasodilatadores de ação direta & $1(3,2)$ \\
Estatinas & $12(38,7)$ \\
Fibratos & $1(3,2)$ \\
Hipoglicemiantes orais & $1(3,2)$ \\
Insulina & $1(3,2)$ \\
Levotiroxina sódica & $1(3,2)$ \\
Antiácidos orais & $7(22,6)$ \\
Antidepressivos & $5(16,1)$ \\
Ansiolítico & $4(12,9)$ \\
Anticonvulsivante & $1(3,2)$ \\
Anticoagulantes orais & $1(3,2)$ \\
\hline
\end{tabular}


Tabela 3 - Descrição das comorbidades associadas aos portadores de canalopatias da amostra

\begin{tabular}{lc}
\hline \multirow{2}{*}{ Comorbidades associadas } & Descrição $(\mathrm{N}=31)$ \\
\cline { 2 - 2 } & $\mathrm{n}(\%)$ \\
\hline \hline Hipertensão Arterial Sistêmica & $12(38,7)$ \\
Dislipidemia & $14(45,2)$ \\
Diabetes Mellitus & $1(3,2)$ \\
Hipotireoidismo & $2(6,5)$ \\
Prótese Valvar & $0(0)$ \\
Acidente Vascular Cerebral & $0(0)$ \\
Insuficiência Renal Crônica & $0(0)$ \\
Doença Pulmonar Obstrutiva Crônica & $0(0)$ \\
Tromboembolismo Pulmonar & $1(3,2)$ \\
Artrose & $2(6,5)$ \\
Dispneia & $1(3,2)$ \\
Asma & $2(6,5)$ \\
Obesidade & $5(16,1)$ \\
\hline
\end{tabular}


Tabela 4 - Perfil dos pacientes da amostra portadores de SQTL

\begin{tabular}{|c|c|c|c|c|c|c|c|c|c|c|c|}
\hline \multicolumn{12}{|c|}{ SQTL } \\
\hline Rand. & Sexo & Idade & CDI & Prevenção & Tipo & Sintomas & AF & QTc & ESch & Ritmo & Gene \\
\hline 2 & M & 48 & Não & & 2 & Assintomático & Sim & 449 & 5 & & $\mathrm{KCNH} 2$ \\
\hline 7 & $\mathrm{~F}$ & 74 & Não & & 1 & Síncope & Sim & 510 & 4 & Não registrado & KCNQ1 \\
\hline 12 & $\mathrm{~F}$ & 67 & Sim & secundária & 2 & PCRr & Sim & 500 & 4 & $\mathrm{TdP}$ & $\mathrm{KCNH} 2$ \\
\hline 17 & $M$ & 16 & Não & & 2 & Assintomático & Sim & 471 & 3,5 & & $\mathrm{KCNH} 2$ \\
\hline 19 & $\mathrm{~F}$ & 35 & Não & & 2 & Síncope & Sim & 496 & 6 & TV polimórfica & $\mathrm{KCNH} 2$ \\
\hline 20 & $\mathrm{~F}$ & 62 & Não & & 1 & Assintomática & Não & 490 & 4 & & KCNQ1 \\
\hline 21 & $\mathrm{~F}$ & 41 & Sim & secundária & 1 & PCRr & Não & 566 & 4 & FV & ausente \\
\hline 22 & $\mathrm{~F}$ & 36 & Sim & primária & 1 & Assintomática & Sim & 554 & 5 & & KCNQ1 \\
\hline 23 & $M$ & 28 & Sim & primária & 2 & Síncope & Não & 540 & 5,5 & Não registrado & $\mathrm{KCNH} 2$ \\
\hline 24 & $\mathrm{~F}$ & 26 & Não & & induzido & Assintomática & Sim & 460 & 5 & & ausente \\
\hline 25 & $\mathrm{~F}$ & 49 & Não & & 2 & Assintomática & Não & 460 & 4,5 & & $\mathrm{KCNH} 2$ \\
\hline 26 & $M$ & 17 & Sim & secundária & 2 & PCRr & Não & 580 & 6 & $\mathrm{TdP}$ & $\mathrm{KCNH} 2$ \\
\hline 27 & $\mathrm{~F}$ & 53 & Sim & secundária & 1 & PCRr & Sim & 478 & 4 & $\mathrm{FV}$ & ausente \\
\hline 29 & $\mathrm{~F}$ & 41 & Sim & secundária & 2 & PCRr & Sim & 540 & 5 & Não registrado & $\mathrm{KCNH} 2$ \\
\hline 30 & $M$ & 65 & Não & & 3 & Assintomático & Sim & 530 & 4 & & SCN5A \\
\hline 32 & $\mathrm{~F}$ & 66 & Não & & induzido & Síncope & Não & 480 & 4 & Não registrado & em andamento \\
\hline
\end{tabular}

Legenda: Rand. - Randomização

AF - Antecedente familiar de morte súbita precoce ou de SQTL confirmada

ESch- - score de Schwartz

Sexo - M: masculino / F: feminino

ESch - escore de Schwartz

$N E$ - Não encontradas variantes nos genes relacionados com SQTL

STC - Intervalo QT corrigido

PCRr - Parada cardiorrespiratória recuperada

FV - fibrilação ventricular

$C D I$ - cardiodesfibrilador implantável 
Tabela 5 - Perfil dos pacientes da amostra portadores de SBr

\begin{tabular}{|c|c|c|c|c|c|c|c|c|}
\hline & & & & & $\mathrm{SBr}$ & & & \\
\hline Rand. & Sexo & Idade & CDI & Prevenção & Tipo & Sintomas & $\mathrm{AF}$ & Gene \\
\hline 3 & $\mathrm{~F}$ & 44 & Não & & Br1l & Palpitações & Não & Ausente \\
\hline 4 & $M$ & 42 & Não & & Br1E & Palpitações & Sim & Ausente \\
\hline 5 & $M$ & 51 & Sim & secundária & Br1E & PCRr & Não & Ausente \\
\hline 6 & $M$ & 67 & Não & & Br1E & Assintomática & Não & Ausente \\
\hline 8 & $M$ & 46 & Não & & Br1E & Assintomático & Não & Ausente \\
\hline 9 & $M$ & 52 & Não & & $\mathrm{Br} 2$ & Assintomático & Sim & Ausente \\
\hline 10 & $\mathrm{~F}$ & 16 & Não & & Br1l & Síncope & Sim & Ausente \\
\hline 11 & $M$ & 39 & Sim & primária & $\mathrm{Br} 1 \mathrm{E}$ & Síncope & Sim & Ausente \\
\hline 13 & $\mathrm{~F}$ & 62 & Sim & primária & $\mathrm{Br} 1 \mathrm{E}$ & Palpitações & Sim & Ausente \\
\hline 14 & $M$ & 51 & Não & & Br1E & Assintomático & Não & Ausente \\
\hline 15 & $M$ & 41 & Sim & primária & Br1l & Palpitações & Sim & Ausente \\
\hline 31 & $M$ & 51 & Não & & Br1l & Assintomática & Sim & Ausente \\
\hline
\end{tabular}

Legenda: Rand. - Randomização

AF - Antecedente familiar de morte súbita precoce ou de SBr confirmada

$C D I$ - cardiodesfibrilador implantável

Sexo - M: masculino / F: feminino

PCRr - Parada cardiorrespiratória recuperada

Br1l - Brugada tipo 1 induzido

Br1E - Brugada tipo 1 espontâneo

Br 2 - Brugada tipo 2 
Tabela 6 - Perfil dos pacientes da amostra portadores de TVPC

\begin{tabular}{|c|c|c|c|c|c|c|c|c|c|}
\hline \multicolumn{10}{|c|}{ TVPC } \\
\hline Rand. & Sexo & Idade & CDI & Prevenção & $\begin{array}{c}\text { ECG } \\
\text { repouso }\end{array}$ & Sintomas & AF & $\begin{array}{c}\text { Teste } \\
\text { ergométrico }\end{array}$ & Gene \\
\hline 16 & $\mathrm{~F}$ & 34 & Sim & secundária & Normal & PCRr & Não & TVS & Ausente \\
\hline 18 & $\mathrm{~F}$ & 25 & Não & & Normal & Síncope & Sim & TVNS & RYR2 \\
\hline 33 & $\mathrm{~F}$ & 55 & Não & & Normal & Assintomática & Sim & TVNS & RYR2 \\
\hline & end & $\begin{array}{l}C D I-c a l \\
A F-A n t \\
T V S-t a\end{array}$ & zuicard & $\begin{array}{l}\text { nização } \\
\text { fibrilador implar } \\
\text { te familiar de m } \\
\text { lia ventricular nâ }\end{array}$ & $\begin{array}{l}\text { thável } \\
\text { orte súbita } \\
\text { go sustenta }\end{array}$ & $\begin{array}{r}\text { Sexo - M: } \\
P C R r-P a \\
\text { precoce ou de SC } \\
\text { da TVNS - ta }\end{array}$ & yuicard & $\begin{array}{l}\text { no / F: feminino } \\
\text { rdiorrespiratória } \\
\text { irmada } \\
\text { a ventricular nã }\end{array}$ & $\begin{array}{l}\text { recuperada } \\
\text { sustentada }\end{array}$ \\
\hline
\end{tabular}

\subsection{Procedimentos odontológicos}

A duração dos procedimentos odontológicos foi de 32 a 93 minutos, com média de $54 \pm 16$ minutos. Todos os pacientes receberam dois cartuchos de anestésicos LSA e LCA nas duas sessões, sem queixa de dor durante a realização do tratamento.

Foram realizados 62 procedimentos restauradores: 26 (42\%) restaurações Classe I, 18 (29\%) Classe II e 18 (29\%) Classe V, sendo 61 $(98,4 \%)$ em resina composta. 


\subsection{Perfil de saúde bucal}

As condições de saúde bucal da amostra em relação ao CPOD e análise simplificada do perfil periodontal estão descritas nas Tabelas 7 e 8 .

Tabela 7 - Média, desvio-padrão, mediana, mínimo e máximo do Índice CPOD da amostra

\begin{tabular}{ccccc}
\hline & \multicolumn{4}{c}{ CPOD } \\
\cline { 2 - 5 } & $\mathrm{C}$ & $\mathrm{P}$ & $\mathrm{O}$ & $\mathrm{D}$ \\
\hline \hline média \pm DP & $3,13 \pm 1,36$ & $8,19 \pm 6,16$ & $7,36 \pm 4,25$ & $18,7 \pm 7,2$ \\
mediana (mín.; máx.) & $3(2 ; 7)$ & $7(0 ; 22)$ & $8(0 ; 15)$ & $21(4 ; 30)$ \\
\hline
\end{tabular}

$$
\begin{aligned}
& \text { Legenda: C: dentes cariados } \\
& \text { P: dentes perdidos } \\
& \text { O: dentes obturados } \\
& \text { D: total de dentes }
\end{aligned}
$$

Tabela 8 - Perfil periodontal da amostra

\begin{tabular}{ccccccc}
\hline \multirow{2}{*}{ Presença } & \multicolumn{2}{c}{ Gengivite } & \multicolumn{2}{c}{ Cálculo periodontal } & \multicolumn{2}{c}{ Doença periodontal } \\
\cline { 2 - 6 } & $\mathrm{n}$ & $\%$ & $\mathrm{n}$ & $\%$ & $\mathrm{n}$ & $\%$ \\
\hline \hline Sim & 7 & 22,6 & 15 & 48,4 & 3 & 9,7 \\
Não & 24 & 72,2 & 16 & 66,7 & 28 & 83,3 \\
\hline Total & 31 & 100 & 31 & 100 & 31 & 100 \\
\hline
\end{tabular}




\subsection{Dados do Holter}

A distribuição das FC mínima, média e máxima, pausas e densidade de arritmias supraventriculares e ventriculares da amostra estão relacionadas conforme os períodos de estudo (P28, PB, PAn, PP e PPP) e condição sem e com adrenalina (Tabelas 9 a 13).

Tabela 9 - Média, desvio-padrão, mediana, mínimo e máximo da FC, maior pausa e densidade de arritmias da amostra durante o P28 nas condições sem e com adrenalina

\begin{tabular}{|c|c|c|c|}
\hline Período das 28h & Sem adrenalina & Com adrenalina & $\mathbf{p}$ \\
\hline $\begin{array}{l}\text { FC mín. (em bpm) } \\
\text { média } \pm \text { DP } \\
\text { mediana (mín.; máx.) }\end{array}$ & $\begin{array}{l}54,5 \pm 10,8 \\
55(39 ; 86)\end{array}$ & $\begin{array}{l}53,3 \pm 11,5 \\
52(36 ; 88)\end{array}$ & 0,135 \\
\hline $\begin{array}{l}\text { FC méd. (em bpm) } \\
\text { média } \pm \text { DP } \\
\text { mediana (mín.; máx.) }\end{array}$ & $\begin{array}{c}75,7 \pm 11 \\
77(55 ; 98)\end{array}$ & $\begin{array}{c}74,6 \pm 10 \\
74(56 ; 92)\end{array}$ & 0,276 \\
\hline $\begin{array}{l}\text { FC máx. (em bpm) } \\
\text { média } \pm \text { DP } \\
\text { mediana (mín.; máx.) }\end{array}$ & $\begin{array}{r}124,2 \pm 20,9 \\
123(80 ; 182)\end{array}$ & $\begin{array}{r}122,5 \pm 14,3 \\
126(87 ; 144) \\
\end{array}$ & 0,528 \\
\hline $\begin{array}{l}\text { Pausa (em segundos) } \\
\text { média } \pm \text { DP } \\
\text { mediana (mín.; máx.) }\end{array}$ & $\begin{array}{c}1,25 \pm 0,24 \\
1,2(0,8 ; 1,7)\end{array}$ & $\begin{array}{c}1,26 \pm 0,28 \\
1,3(0,6 ; 1,7) \\
\end{array}$ & 0,696 \\
\hline $\begin{array}{l}\text { ESSV (no/ hora) } \\
\text { média } \pm \text { DP } \\
\text { mediana (mín.; máx.) }\end{array}$ & $\begin{array}{l}1,04 \pm 2,23 \\
0,1(0 ; 10)\end{array}$ & $\begin{array}{c}1,51 \pm 4,62 \\
0,1(0 ; 24,5) \\
\end{array}$ & $0,891^{*}$ \\
\hline $\begin{array}{l}\text { EV (no/ hora) } \\
\text { média } \pm \text { DP } \\
\text { mediana (mín.; máx.) }\end{array}$ & $\begin{array}{l}7,45 \pm 18,77 \\
0,3(0 ; 96,7)\end{array}$ & $\begin{array}{c}16,79 \pm 71,21 \\
0(0 ; 397,8) \\
\end{array}$ & $0,080^{*}$ \\
\hline $\begin{array}{l}\text { TVNS (no em 28h) } \\
\text { média } \pm \text { DP } \\
\text { mediana (mín.; máx.) }\end{array}$ & $\begin{array}{c}0,13 \pm 0,56 \\
0(0 ; 3)\end{array}$ & $\begin{array}{c}3,07 \pm 16,88 \\
0(0 ; 94)\end{array}$ & $0,854^{*}$ \\
\hline $\begin{array}{l}\text { TANS (no em 28h) } \\
\text { média } \pm \text { DP } \\
\text { mediana (mín.; máx.) }\end{array}$ & $\begin{array}{c}1,58 \pm 6,66 \\
0(0 ; 37)\end{array}$ & $\begin{array}{c}1,1 \pm 5,03 \\
0(0 ; 28)\end{array}$ & $0,085^{*}$ \\
\hline \multicolumn{4}{|l|}{ Teste t-Student pareado; * Teste Wilcoxon pareado } \\
\hline $\begin{array}{c}\text { Legenda: FC mín. - frequência cardíaca mínima } \\
\text { FC méd. - frequência cardíaca média } \\
\text { FC máx. - frequência cardíaca máxima } \\
\text { P28 - período das } 28 \mathrm{~h}\end{array}$ & $\begin{array}{l}\text { ESSV - extrassístole } \\
\text { EV-extrassístole ven } \\
\text { TVNS - taquicardia ve } \\
\text { TANS - taquicardia at }\end{array}$ & $\begin{array}{l}\text { praventricular } \\
\text { icular } \\
\text { tricular não sustentada } \\
\text { al não sustentada }\end{array}$ & \\
\hline
\end{tabular}


Tabela 10 - Média, desvio-padrão, mediana, mínimo e máximo da FC, maior pausa e densidade de arritmias da amostra durante o PB nas condições sem e com adrenalina

\begin{tabular}{|c|c|c|c|}
\hline Período Basal & Sem adrenalina & Com adrenalina & $\mathbf{p}$ \\
\hline $\begin{array}{l}\text { FC mín. (em bpm) } \\
\text { média } \pm \text { DP } \\
\text { mediana (mín.; máx.) }\end{array}$ & $\begin{array}{c}60,1 \pm 11 \\
61(39 ; 90)\end{array}$ & $\begin{array}{l}58,8 \pm 11,6 \\
59(37 ; 89)\end{array}$ & 0,241 \\
\hline $\begin{array}{l}\text { FC méd. (em bpm) } \\
\text { média } \pm \text { DP } \\
\text { mediana (mín.; máx.) }\end{array}$ & $\begin{array}{l}70,4 \pm 11,5 \\
72(46 ; 93)\end{array}$ & $\begin{array}{l}69,3 \pm 12,2 \\
72(47 ; 91) \\
\end{array}$ & 0,404 \\
\hline $\begin{array}{l}\text { FC máx. (em bpm) } \\
\text { média } \pm \text { DP } \\
\text { mediana (mín.; máx.) } \\
\end{array}$ & $\begin{array}{l}92,9 \pm 14,6 \\
91(55 ; 121)\end{array}$ & $\begin{array}{c}93 \pm 16,8 \\
92(61 ; 135) \\
\end{array}$ & 0,958 \\
\hline $\begin{array}{l}\text { Pausa (segundos) } \\
\text { média } \pm \text { DP } \\
\text { mediana (mín.; máx.) }\end{array}$ & $\begin{array}{c}1,12 \pm 0,24 \\
1,1(0,7 ; 1,9)\end{array}$ & $\begin{array}{c}1,14 \pm 0,24 \\
1,1(0,7 ; 1,6) \\
\end{array}$ & 0,520 \\
\hline $\begin{array}{l}\text { ESSV (no/ hora) } \\
\text { média } \pm \text { DP } \\
\text { mediana (mín.; máx.) } \\
\end{array}$ & $\begin{array}{c}0,84 \pm 2,31 \\
0(0 ; 12)\end{array}$ & $\begin{array}{c}0,58 \pm 1,31 \\
0(0 ; 6) \\
\end{array}$ & $0,392^{*}$ \\
\hline $\begin{array}{l}\text { EV (no/ hora) } \\
\text { média } \pm \text { DP } \\
\text { mediana (mín.; máx.) }\end{array}$ & $\begin{array}{c}4,9 \pm 18,0 \\
0(0 ; 98)\end{array}$ & $\begin{array}{c}26,7 \pm 124,7 \\
0(0 ; 694) \\
\end{array}$ & $0,859^{*}$ \\
\hline $\begin{array}{l}\text { TVNS (no em } 60 \text { min.) } \\
\text { média } \pm \text { DP } \\
\text { mediana (mín.; máx.) }\end{array}$ & $\begin{array}{c}0 \pm 0 \\
0(0 ; 0)\end{array}$ & $\begin{array}{c}0,52 \pm 2,87 \\
0(0 ; 16) \\
\end{array}$ & $0,317^{*}$ \\
\hline $\begin{array}{l}\text { TANS (no em } 60 \text { min.) } \\
\text { média } \pm \text { DP } \\
\text { mediana (mín.; máx.) }\end{array}$ & $\begin{array}{c}0,03 \pm 0,18 \\
0(0 ; 1)\end{array}$ & $\begin{array}{c}0 \pm 0 \\
0(0 ; 0)\end{array}$ & $0,317^{*}$ \\
\hline \multicolumn{4}{|l|}{ Teste t-Student pareado; * Teste Wilcoxon pareado } \\
\hline $\begin{array}{l}\text { Legenda: } F C \text { mín. - frequência cardíaca mínima } \\
\text { FC méd. - frequência cardíaca média } \\
\text { FC máx. - frequência cardíaca máxima } \\
\text { PB - período basal (60 minutos) }\end{array}$ & $\begin{array}{l}\text { ESSV - extrassístole } \\
\text { EV - extrassístole ven } \\
\text { TVNS - taquicardia ve } \\
\text { TANS - taquicardia at }\end{array}$ & $\begin{array}{l}\text { upraventricular } \\
\text { ricular } \\
\text { tricular não sustentada } \\
\text { al não sustentada }\end{array}$ & \\
\hline
\end{tabular}


Tabela 11 - Média, desvio-padrão, mediana, mínimo e máximo da FC, maior pausa e densidade de arritmias da amostra durante o PAn nas condições sem e com adrenalina

\begin{tabular}{|c|c|c|c|}
\hline Período da Anestesia & Sem adrenalina & Com adrenalina & $\mathbf{p}$ \\
\hline $\begin{array}{l}\text { FC mín. (em bpm) } \\
\text { média } \pm \text { DP } \\
\text { mediana (mín.; máx.) }\end{array}$ & $\begin{array}{l}59,3 \pm 10,5 \\
59(39 ; 89)\end{array}$ & $\begin{array}{l}59,4 \pm 10,5 \\
59(41 ; 89)\end{array}$ & 0,877 \\
\hline $\begin{array}{l}\text { FC méd. (em bpm) } \\
\text { média } \pm \text { DP } \\
\text { mediana (mín.; máx.) }\end{array}$ & $\begin{array}{l}66,5 \pm 9,8 \\
67(45 ; 91)\end{array}$ & $\begin{array}{l}67,9 \pm 10,8 \\
70(49 ; 91)\end{array}$ & 0,181 \\
\hline $\begin{array}{l}\text { FC máx. (em bpm) } \\
\text { média } \pm \text { DP } \\
\text { mediana (mín.; máx.) }\end{array}$ & $\begin{array}{c}80,4 \pm 12,2 \\
81(58 ; 105)\end{array}$ & $\begin{array}{c}84,4 \pm 15 \\
82(58 ; 113)\end{array}$ & 0,005 \\
\hline $\begin{array}{l}\text { Pausa (segundos) } \\
\text { média } \pm \text { DP } \\
\text { mediana (mín.; máx.) }\end{array}$ & $\begin{array}{c}1,09 \pm 0,21 \\
1,1(0,7 ; 1,6)\end{array}$ & $\begin{array}{c}1,09 \pm 0,23 \\
1,1(0,4 ; 1,5)\end{array}$ & 0,974 \\
\hline $\begin{array}{l}\text { ESSV (no/ hora) } \\
\text { média } \pm \text { DP } \\
\text { mediana (mín.; máx.) }\end{array}$ & $\begin{array}{c}0,13 \pm 0,72 \\
0(0 ; 4)\end{array}$ & $\begin{array}{c}1,29 \pm 3,33 \\
0(0 ; 16)\end{array}$ & $0,054^{*}$ \\
\hline $\begin{array}{l}\text { EV (no/ hora) } \\
\text { média } \pm \text { DP } \\
\text { mediana (mín.; máx.) }\end{array}$ & $\begin{array}{c}9,5 \pm 37 \\
0(0 ; 184)\end{array}$ & $\begin{array}{c}28,3 \pm 125,4 \\
0(0 ; 692) \\
\end{array}$ & $0,345^{*}$ \\
\hline $\begin{array}{l}\text { TVNS (no em } 15 \text { min.) } \\
\text { média } \pm \text { DP } \\
\text { mediana (mín.; máx.) }\end{array}$ & $\begin{array}{c}0 \pm 0 \\
0(0 ; 0)\end{array}$ & $\begin{array}{c}0,03 \pm 0,18 \\
0(0 ; 1)\end{array}$ & $0,317^{*}$ \\
\hline $\begin{array}{l}\text { TANS (no em } 15 \text { min.) } \\
\text { média } \pm \text { DP } \\
\text { mediana (mín.; máx.) }\end{array}$ & $\begin{array}{c}0 \pm 0 \\
0(0 ; 0)\end{array}$ & $\begin{array}{c}0 \pm 0 \\
0(0 ; 0)\end{array}$ & $>0,999^{*}$ \\
\hline Teste t-Student pareado; ${ }^{*}$ Teste Wilcoxon pareado & & & \\
\hline $\begin{array}{l}\text { Legenda: FC mín. - frequência cardíaca mínima } \\
\text { FC méd. - frequênncia cardíaca média } \\
\text { FC máx. - frequência cardíaca máxima } \\
\text { PAn - período da anestesia (15 minutos) }\end{array}$ & \multicolumn{3}{|c|}{$\begin{array}{l}\text { ESSV - extrassístole supraventricular } \\
\text { EV - extrassístole ventricular } \\
\text { TVNS - taquicardia ventricular não sustentada } \\
\text { TANS - taquicardia atrial não sustentada }\end{array}$} \\
\hline
\end{tabular}

A FC máxima no Período da Anestesia (PAn) foi em média estatisticamente maior com o uso de LCA $(84,4 \times 80,4$ bpm; $p=0,005)$. Os gráficos 1, 2 e 3 ilustram os valores médios da FC mínima, média e máxima durante os períodos estudados. 


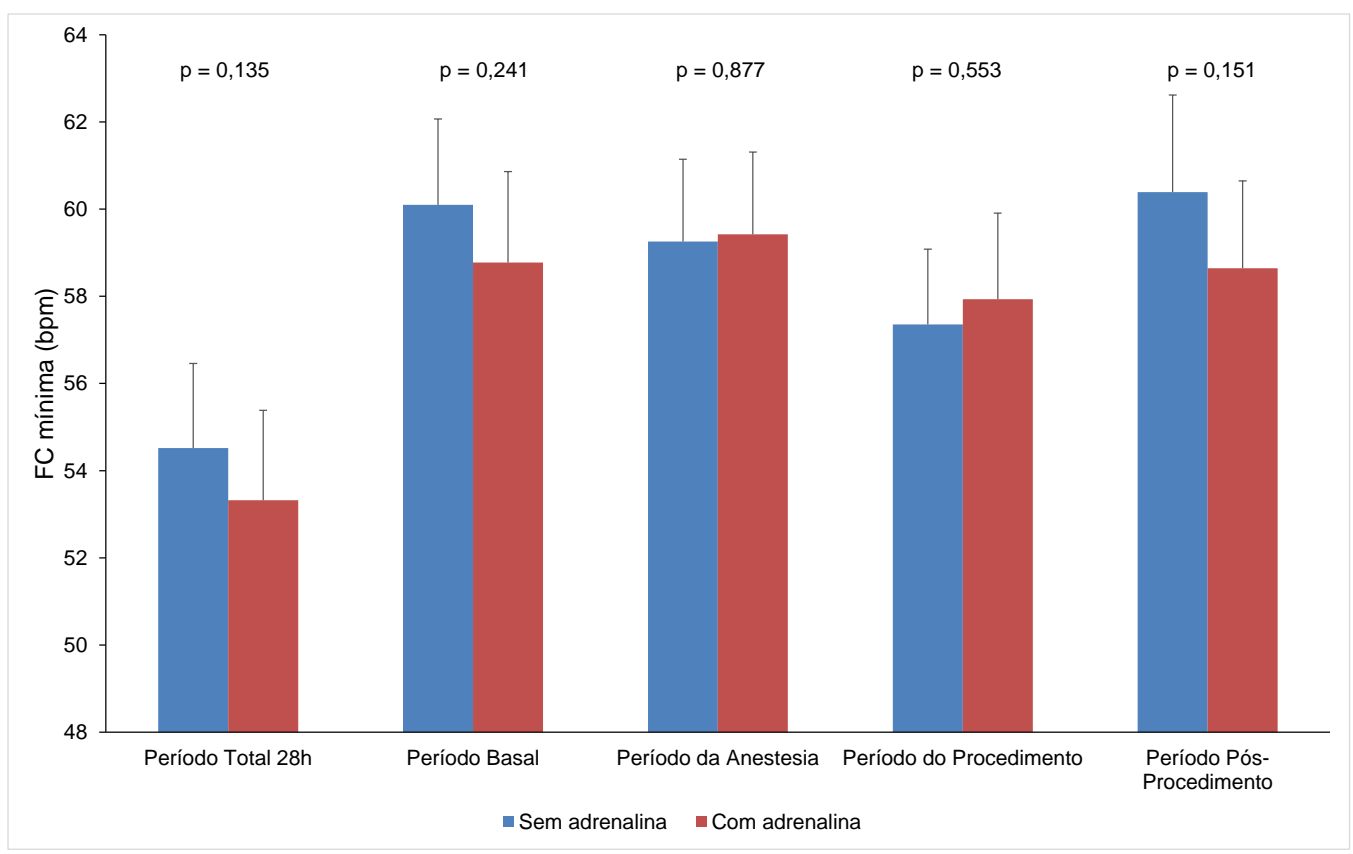

Gráfico 1 - Valores médios e respectivos erros padrões da FC mínima em cada período de estudo avaliado e resultado das comparações

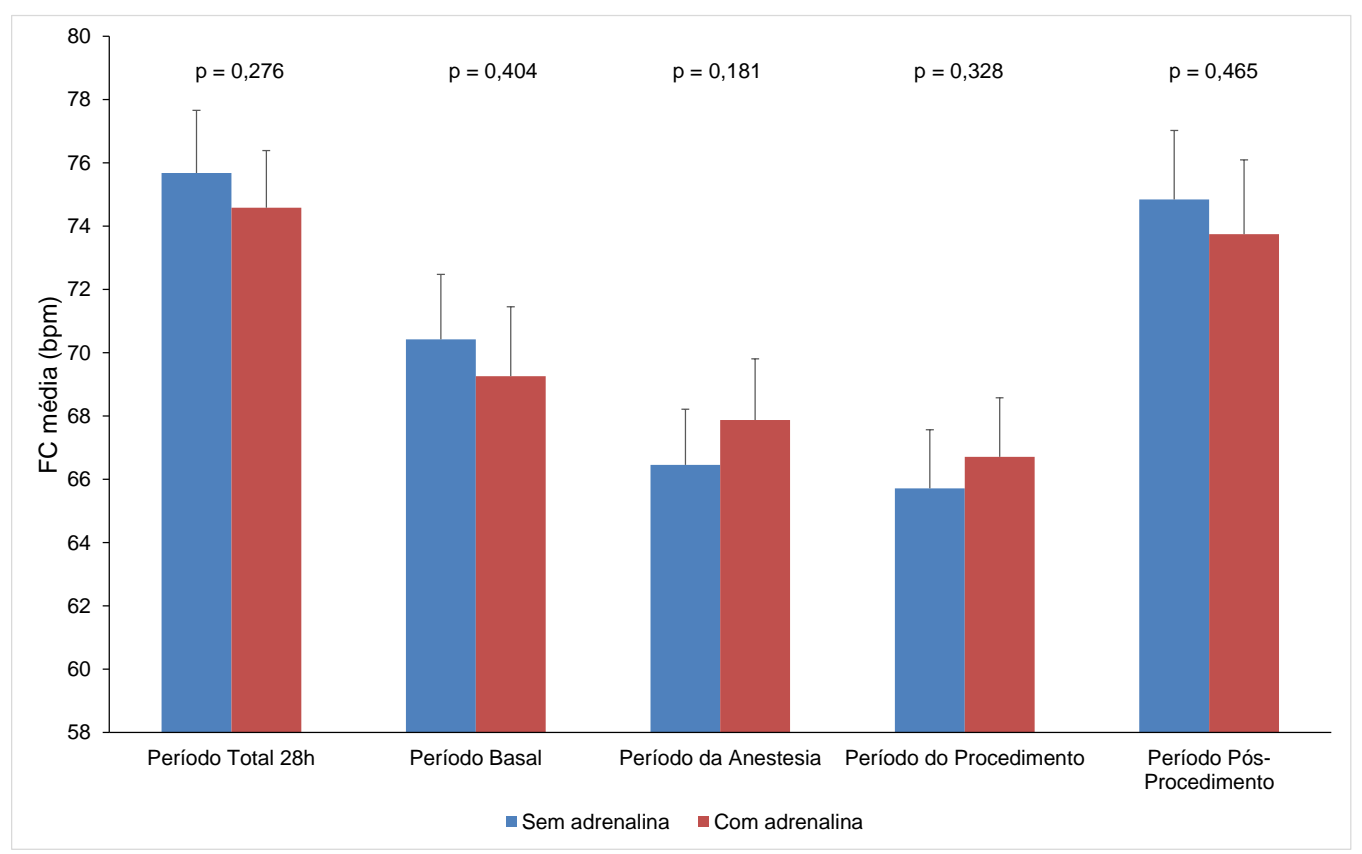

Gráfico 2 - Valores médios e respectivos erros padrões da FC média em cada período de estudo avaliado e resultado das comparações 


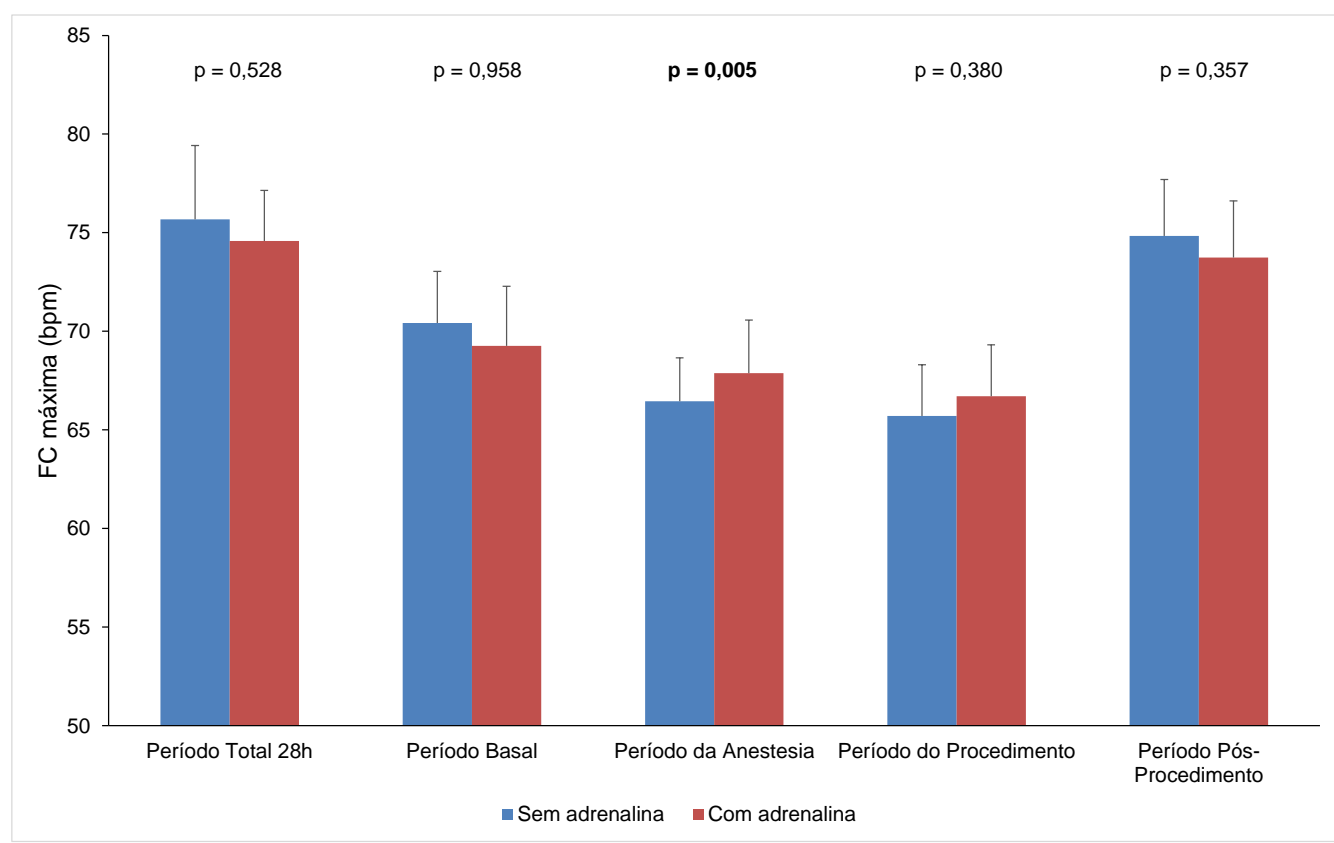

Gráfico 3 - Valores médios e respectivos erros padrões da FC máxima em cada período de estudo avaliado e resultado das comparações

Os demais parâmetros avaliados (ESSV/h, EV/h, TVNS, TANS e pausas) não apresentaram diferença estatisticamente significante para os pacientes da amostra $(p>0,05)$. 
Tabela 12 - Média, desvio-padrão, mediana, mínimo e máximo da FC, maior pausa e densidade de arritmias da amostra durante o PP nas condições sem e com adrenalina

\begin{tabular}{|c|c|c|c|}
\hline Período do Procedimento & Sem adrenalina & Com adrenalina & $\mathbf{p}$ \\
\hline $\begin{array}{l}\text { FC mín. (em bpm) } \\
\text { média } \pm \text { DP } \\
\text { mediana (mín.; máx.) }\end{array}$ & $\begin{array}{l}57,4 \pm 9,6 \\
58(39 ; 77)\end{array}$ & $\begin{array}{c}57,9 \pm 11 \\
58(38 ; 89) \\
\end{array}$ & 0,553 \\
\hline $\begin{array}{l}\text { FC méd. (em bpm) } \\
\text { média } \pm \text { DP } \\
\text { mediana (mín.; máx.) } \\
\end{array}$ & $\begin{array}{l}65,7 \pm 10,3 \\
68(44 ; 91)\end{array}$ & $\begin{array}{l}66,7 \pm 10,4 \\
69(46 ; 91) \\
\end{array}$ & 0,328 \\
\hline $\begin{array}{l}\text { FC máx. (em bpm) } \\
\text { média } \pm \text { DP } \\
\text { mediana (mín.; máx.) }\end{array}$ & $\begin{array}{l}87,2 \pm 14,4 \\
90(59 ; 113)\end{array}$ & $\begin{array}{l}88,6 \pm 14,5 \\
88(58 ; 120)\end{array}$ & 0,380 \\
\hline $\begin{array}{l}\text { Pausa (segundos) } \\
\text { média } \pm \text { DP } \\
\text { mediana (mín.; máx.) }\end{array}$ & $\begin{array}{c}1,2 \pm 0,23 \\
1,2(0,9 ; 1,7)\end{array}$ & $\begin{array}{c}1,17 \pm 0,22 \\
1,1(0,7 ; 1,6)\end{array}$ & 0,370 \\
\hline $\begin{array}{l}\text { ESSV (no/ hora) } \\
\text { média } \pm \text { DP } \\
\text { mediana (mín.; máx.) }\end{array}$ & $\begin{array}{c}0,56 \pm 1,19 \\
0(0 ; 4,8)\end{array}$ & $\begin{array}{c}1,29 \pm 3,68 \\
0(0 ; 16,8)\end{array}$ & $0,510^{*}$ \\
\hline $\begin{array}{l}\text { EV (no/ hora) } \\
\text { média } \pm \text { DP } \\
\text { mediana (mín.; máx.) }\end{array}$ & $\begin{array}{c}10,3 \pm 40,6 \\
0(0 ; 207)\end{array}$ & $\begin{array}{c}22,8 \pm 103,6 \\
0(0 ; 575,3)\end{array}$ & $0,646^{*}$ \\
\hline $\begin{array}{l}\text { TVNS (no em } 54 \text { min.) } \\
\text { média } \pm \text { DP } \\
\text { mediana (mín.; máx.) }\end{array}$ & $\begin{array}{c}0 \pm 0 \\
0(0 ; 0)\end{array}$ & $\begin{array}{c}0,23 \pm 1,26 \\
0(0 ; 7)\end{array}$ & $0,317^{*}$ \\
\hline $\begin{array}{l}\text { TANS (no em } 54 \text { min.) } \\
\text { média } \pm \text { DP } \\
\text { mediana (mín.; máx.) }\end{array}$ & $\begin{array}{c}0 \pm 0 \\
0(0 ; 0)\end{array}$ & $\begin{array}{c}0,03 \pm 0,18 \\
0(0 ; 1)\end{array}$ & $0,317^{*}$ \\
\hline \multicolumn{4}{|l|}{ Teste t-Student pareado; * Teste Wilcoxon pareado } \\
\hline $\begin{array}{l}\text { Legenda: FC mín. - frequência cardíaca mínima } \\
\text { FC méd. - frequência cardíaca média } \\
\text { FC máx. - frequência cardíaca máxima } \\
\text { PP - período do procedimento (média de } 54 \text { minutos }\end{array}$ & \multicolumn{3}{|c|}{$\begin{array}{l}\text { ESSV - extrassístole supraventricular } \\
\text { EV - extrassístole ventricular } \\
\text { TVNS - taquicardia ventricular não sustentada } \\
\text { TANS - taquicardia atrial não sustentada }\end{array}$} \\
\hline
\end{tabular}


Tabela 13 - Média, desvio-padrão, mediana, mínimo e máximo da FC, maior pausa e densidade de arritmias da amostra durante o PPP nas condições sem e com adrenalina

\begin{tabular}{|c|c|c|c|}
\hline Período Pós-Procedimento & Sem adrenalina & Com adrenalina & $\mathbf{p}$ \\
\hline $\begin{array}{l}\text { FC mín. (em bpm) } \\
\text { média } \pm \text { DP } \\
\text { mediana (mín.; máx.) }\end{array}$ & $\begin{array}{l}60,4 \pm 12,4 \\
60(39 ; 97)\end{array}$ & $\begin{array}{l}58,6 \pm 11,1 \\
58(39 ; 89)\end{array}$ & 0,151 \\
\hline $\begin{array}{l}\text { FC méd. (em bpm) } \\
\text { média } \pm \text { DP } \\
\text { mediana (mín.; máx.) }\end{array}$ & $\begin{array}{l}74,8 \pm 12,1 \\
73(53 ; 106)\end{array}$ & $\begin{array}{l}73,7 \pm 13,1 \\
72(48 ; 99) \\
\end{array}$ & 0,465 \\
\hline $\begin{array}{l}\text { FC máx. (em bpm) } \\
\text { média } \pm \text { DP } \\
\text { mediana (mín.; máx.) }\end{array}$ & $\begin{array}{r}101,6 \pm 15,9 \\
100(74 ; 142)\end{array}$ & $\begin{array}{c}99,7 \pm 16 \\
99(65 ; 127)\end{array}$ & 0,357 \\
\hline $\begin{array}{l}\text { Pausa (segundos) } \\
\text { média } \pm \text { DP } \\
\text { mediana (mín.; máx.) }\end{array}$ & $\begin{array}{c}1,11 \pm 0,22 \\
1,1(0,7 ; 1,5)\end{array}$ & $\begin{array}{c}1,14 \pm 0,22 \\
1,1(0,7 ; 1,6)\end{array}$ & 0,283 \\
\hline $\begin{array}{l}\text { ESSV (no/ hora) } \\
\text { média } \pm \text { DP } \\
\text { mediana (mín.; máx.) }\end{array}$ & $\begin{array}{c}0,74 \pm 1,39 \\
0(0 ; 5)\end{array}$ & $\begin{array}{c}1,52 \pm 4,55 \\
0(0 ; 24)\end{array}$ & $0,307^{*}$ \\
\hline $\begin{array}{l}\text { EV (no/ hora) } \\
\text { média } \pm \text { DP } \\
\text { mediana (mín.; máx.) }\end{array}$ & $\begin{array}{c}10,1 \pm 37,2 \\
0(0 ; 190)\end{array}$ & $\begin{array}{c}21,6 \pm 83,6 \\
0(0 ; 462) \\
\end{array}$ & $0,975^{*}$ \\
\hline $\begin{array}{l}\text { TVNS (no em } 60 \text { min.) } \\
\text { média } \pm \text { DP } \\
\text { mediana (mín.; máx.) }\end{array}$ & $\begin{array}{c}0 \pm 0 \\
0(0 ; 0)\end{array}$ & $\begin{array}{c}0,65 \pm 3,59 \\
0(0 ; 20)\end{array}$ & $0,317^{*}$ \\
\hline $\begin{array}{l}\text { TANS (no em } 60 \text { min.) } \\
\text { média } \pm \text { DP } \\
\text { mediana (mín.; máx.) } \\
\end{array}$ & $\begin{array}{c}0 \pm 0 \\
0(0 ; 0)\end{array}$ & $\begin{array}{c}0 \pm 0 \\
0(0 ; 0)\end{array}$ & $>0,999^{*}$ \\
\hline Teste t-Student pareado; * Teste Wilcoxon pareado & & & \\
\hline $\begin{array}{l}\text { Legenda: FC mín. - frequência cardíaca mínima } \\
\text { FC méd. - frequência cardíaca média } \\
\text { FC máx. - frequência cardíaca máxima } \\
\text { PPP - período pós-procedimento (60 minutos) }\end{array}$ & \multicolumn{3}{|c|}{$\begin{array}{l}\text { ESSV - extrassístole supraventricular } \\
\text { EV - extrassístole ventricular } \\
\text { TVNS - taquicardia ventricular não sustentada } \\
\text { TANS - taquicardia atrial não sustentada }\end{array}$} \\
\hline
\end{tabular}

Não foi observada maior complexidade das arritmias (TVNS e TANS) em nenhum paciente e não ocorreu terapia/choque pelo CDI durante os procedimentos, independente do uso ou não do vasoconstritor adrenalina.

No total da amostra, nenhum paciente apresentou pausas significativamente importantes ( $\geq 2,5$ segundos).

De acordo com a canalopatia específica, apenas pacientes com SQTL apresentaram pausas estatisticamente maiores com uso de LCA no Período da Anestesia $(1,12 \times 1,05$ segundos; $p=0,045)$, porém sem relevância clínica 
(Tabela 14). Os demais parâmetros cardiológicos foram estatisticamente semelhantes nas duas condições nestes pacientes.

Tabela 14 - Média, desvio-padrão, mediana, mínimo e máximo da FC, maior pausa e densidade de arritmias apenas em pacientes com SQTL durante o PAn, nas condições sem e com adrenalina

\begin{tabular}{|c|c|c|c|}
\hline Período da Anestesia & Sem adrenalina & Com adrenalina & $\mathbf{p}$ \\
\hline $\begin{array}{l}\text { FC mín. (em bpm) } \\
\text { média } \pm \text { DP } \\
\text { mediana (mín.; máx.) }\end{array}$ & $\begin{array}{c}61,1 \pm 11,9 \\
58,5(41 ; 89)\end{array}$ & $\begin{array}{c}58,9 \pm 12,5 \\
58,5(41 ; 89)\end{array}$ & 0,113 \\
\hline $\begin{array}{l}\text { FC méd. (em bpm) } \\
\text { média } \pm \text { DP } \\
\text { mediana (mín.; máx.) }\end{array}$ & $\begin{array}{c}66,6 \pm 10,9 \\
65,5(47 ; 91)\end{array}$ & $\begin{array}{c}64,9 \pm 11 \\
62,5(49 ; 91)\end{array}$ & 0,238 \\
\hline $\begin{array}{l}\text { FC máx. (em bpm) } \\
\text { média } \pm \text { DP } \\
\text { mediana (mín.; máx.) }\end{array}$ & $\begin{array}{c}76,9 \pm 11,2 \\
77,5(58 ; 100)\end{array}$ & $\begin{array}{c}76,8 \pm 11,7 \\
75,5(58 ; 99)\end{array}$ & 0,965 \\
\hline $\begin{array}{l}\text { Pausa (segundos) } \\
\text { média } \pm \text { DP } \\
\text { mediana (mín.; máx.) } \\
\end{array}$ & $\begin{array}{c}1,05 \pm 0,21 \\
1,1(0,7 ; 1,6)\end{array}$ & $\begin{array}{c}1,12 \pm 0,23 \\
1,1(0,7 ; 1,5) \\
\end{array}$ & 0,045 \\
\hline $\begin{array}{l}\text { ESSV (no/ hora) } \\
\text { média } \pm \text { DP } \\
\text { mediana (mín.; máx.) }\end{array}$ & $\begin{array}{c}0,25 \pm 1 \\
0(0 ; 4)\end{array}$ & $\begin{array}{c}2,25 \pm 4,37 \\
0(0 ; 16) \\
\end{array}$ & $0,084^{*}$ \\
\hline $\begin{array}{l}\text { EV (no/ hora) } \\
\text { média } \pm \text { DP } \\
\text { mediana (mín.; máx.) }\end{array}$ & $\begin{array}{l}11,5 \pm 46 \\
0(0 ; 184)\end{array}$ & $\begin{array}{c}44,3 \pm 172,8 \\
0(0 ; 692) \\
\end{array}$ & $0,655^{*}$ \\
\hline $\begin{array}{l}\text { TVNS (no em } 15 \text { min.) } \\
\text { média } \pm \text { DP } \\
\text { mediana (mín.; máx.) }\end{array}$ & $\begin{array}{c}0 \pm 0 \\
0(0 ; 0)\end{array}$ & $\begin{array}{c}0,06 \pm 0,25 \\
0(0 ; 1)\end{array}$ & $0,317^{*}$ \\
\hline $\begin{array}{l}\text { TANS ( } n^{\circ} \text { em } 15 \text { min.) } \\
\text { média } \pm \text { DP } \\
\text { mediana (mín.; máx.) }\end{array}$ & $\begin{array}{c}0 \pm 0 \\
0(0 ; 0)\end{array}$ & $\begin{array}{c}0 \pm 0 \\
0(0 ; 0)\end{array}$ & $>0,999^{*}$ \\
\hline
\end{tabular}

Teste t-Student pareado; * Teste Wilcoxon pareado

Legenda: FC mín. - frequência cardíaca mínima

FC méd. - frequência cardíaca média

FC máx. - frequência cardíaca máxima

ESSV - extrassístole supraventricular

EV - extrassístole ventricular

PAn - período da anestesia (15 minutos)

TVNS - taquicardia ventricular não sustentada

TANS - taquicardia atrial não sustentada

As FC média $(74,7$ x 69,2 bpm; $p=0,001)$ e máxima $(97,8$ x 89 bpm; $\mathrm{p}<0,001)$ no Período da Anestesia e FC média $(72 \times 68 ; \mathrm{p}=0,017)$ no Período do Procedimento foram em média estatisticamente maiores apenas nos 
pacientes com SBr com uso de LCA $(p<0,05)$, (Tabelas 15 e 16). Os demais parâmetros cardiológicos foram estatisticamente semelhantes nas duas condições nestes pacientes.

Tabela 15 - Média, desvio-padrão, mediana, mínimo e máximo da FC, maior pausa e densidade de arritmias apenas em pacientes com SBr durante o PAn, nas condições sem e com adrenalina

\begin{tabular}{|c|c|c|c|}
\hline Período da Anestesia & Sem adrenalina & Com adrenalina & $\mathbf{p}$ \\
\hline $\begin{array}{l}\text { FC mín. (em bpm) } \\
\text { média } \pm \text { DP } \\
\text { mediana (mín.; máx.) }\end{array}$ & $\begin{array}{c}59,3 \pm 5,6 \\
59,5(51 ; 67)\end{array}$ & $\begin{array}{l}62,1 \pm 5,6 \\
62(55 ; 73) \\
\end{array}$ & 0,117 \\
\hline $\begin{array}{l}\text { FC méd. (em bpm) } \\
\text { média } \pm \text { DP } \\
\text { mediana (mín.; máx.) }\end{array}$ & $\begin{array}{l}69,2 \pm 4,4 \\
68(63 ; 76)\end{array}$ & $\begin{array}{c}74,7 \pm 5,1 \\
75(65 ; 83)\end{array}$ & 0,001 \\
\hline $\begin{array}{l}\text { FC máx. (em bpm) } \\
\text { média } \pm \text { DP } \\
\text { mediana (mín.; máx.) }\end{array}$ & $\begin{array}{c}89 \pm 7,4 \\
88,5(80 ; 105)\end{array}$ & $\begin{array}{c}97,8 \pm 9,5 \\
97,5(81 ; 113) \\
\end{array}$ & $<0,001$ \\
\hline $\begin{array}{l}\text { Pausa (segundos) } \\
\text { média } \pm \text { DP } \\
\text { mediana (mín.; máx.) }\end{array}$ & $\begin{array}{c}1,09 \pm 0,14 \\
1,1(0,9 ; 1,3)\end{array}$ & $\begin{array}{c}1 \pm 0,23 \\
1,1(0,4 ; 1,4)\end{array}$ & 0,318 \\
\hline $\begin{array}{l}\text { ESSV (no/ hora) } \\
\text { média } \pm \text { DP } \\
\text { mediana (mín.; máx.) }\end{array}$ & $\begin{array}{c}0 \pm 0 \\
0(0 ; 0)\end{array}$ & $\begin{array}{c}0,33 \pm 1,15 \\
0(0 ; 4) \\
\end{array}$ & $0,317^{*}$ \\
\hline $\begin{array}{l}\text { EV (no/ hora) } \\
\text { média } \pm \text { DP } \\
\text { mediana (mín.; máx.) }\end{array}$ & $\begin{array}{l}1 \pm 2,5 \\
0(0 ; 8)\end{array}$ & $\begin{array}{l}3,3 \pm 7,2 \\
0(0 ; 24) \\
\end{array}$ & $0,180^{*}$ \\
\hline $\begin{array}{l}\text { TVNS (no em } 15 \text { min.) } \\
\text { média } \pm \text { DP } \\
\text { mediana (mín.; máx.) }\end{array}$ & $\begin{array}{c}0 \pm 0 \\
0(0 ; 0)\end{array}$ & $\begin{array}{c}0 \pm 0 \\
0(0 ; 0)\end{array}$ & $>0,999^{*}$ \\
\hline $\begin{array}{l}\text { TANS (no em } 15 \text { min.) } \\
\text { média } \pm \text { DP } \\
\text { mediana (mín.; máx.) }\end{array}$ & $\begin{array}{c}0 \pm 0 \\
0(0 ; 0)\end{array}$ & $\begin{array}{c}0 \pm 0 \\
0(0 ; 0)\end{array}$ & $>0,999^{*}$ \\
\hline Teste t-Student pareado; ${ }^{*}$ Teste Wilcoxon pareado & & & \\
\hline $\begin{array}{c}\text { Legenda: FC mín. - frequência cardíaca mínima } \\
\text { FC méd. - frequência cardíaca média } \\
\text { FC máx. - frequência cardíaca máxima } \\
\text { PAn - período da anestesia (15 minutos) }\end{array}$ & \multicolumn{3}{|c|}{$\begin{array}{l}\text { ESSV - extrassístole supraventricular } \\
\text { EV - extrassístole ventricular } \\
\text { TVNS - taquicardia ventricular não sustentada } \\
\text { TANS - taquicardia atrial não sustentada }\end{array}$} \\
\hline
\end{tabular}


Tabela 16 - Média, desvio-padrão, mediana, mínimo e máximo da FC, maior pausa e densidade de arritmias apenas em pacientes com SBr durante o PP, nas condições sem e com adrenalina

\begin{tabular}{|c|c|c|c|}
\hline Período do Procedimento & Sem adrenalina & Com adrenalina & $\mathbf{p}$ \\
\hline $\begin{array}{l}\text { FC mín. (em bpm) } \\
\text { média } \pm \text { DP } \\
\text { mediana (mín.; máx.) }\end{array}$ & $\begin{array}{c}57,2 \pm 3,5 \\
57,5(51 ; 62)\end{array}$ & $\begin{array}{c}59,4 \pm 5,7 \\
58,5(50 ; 69) \\
\end{array}$ & 0,147 \\
\hline $\begin{array}{l}\text { FC méd. (em bpm) } \\
\text { média } \pm \text { DP } \\
\text { mediana (mín.; máx.) }\end{array}$ & $\begin{array}{c}68 \pm 4,2 \\
68(61 ; 76)\end{array}$ & $\begin{array}{c}72 \pm 5,2 \\
71,5(63 ; 82)\end{array}$ & 0,017 \\
\hline $\begin{array}{l}\text { FC máx. (em bpm) } \\
\text { média } \pm \text { DP } \\
\text { mediana (mín.; máx.) }\end{array}$ & $\begin{array}{c}94 \pm 6,4 \\
93,5(83 ; 105)\end{array}$ & $\begin{array}{c}98,8 \pm 10,6 \\
98,5(81 ; 120) \\
\end{array}$ & 0,059 \\
\hline $\begin{array}{l}\text { Pausa (segundos) } \\
\text { média } \pm \text { DP } \\
\text { mediana (mín.; máx.) }\end{array}$ & $\begin{array}{l}1,19 \pm 0,17 \\
1,2(1 ; 1,5)\end{array}$ & $\begin{array}{c}1,12 \pm 0,15 \\
1,1(0,9 ; 1,4) \\
\end{array}$ & 0,400 \\
\hline $\begin{array}{l}\text { ESSV (no/ hora) } \\
\text { média } \pm \text { DP } \\
\text { mediana (mín.; máx.) }\end{array}$ & $\begin{array}{c}0,13 \pm 0,43 \\
0(0 ; 1,5)\end{array}$ & $\begin{array}{c}0,51 \pm 0,81 \\
0(0 ; 2,2) \\
\end{array}$ & $0,225^{*}$ \\
\hline $\begin{array}{l}\text { EV (no/ hora) } \\
\text { média } \pm \text { DP } \\
\text { mediana (mín.; máx.) }\end{array}$ & $\begin{array}{l}0,6 \pm 1,5 \\
0(0 ; 4,5)\end{array}$ & $\begin{array}{l}3,5 \pm 6,9 \\
0(0 ; 21) \\
\end{array}$ & $0,109^{*}$ \\
\hline $\begin{array}{l}\text { TVNS (no em } 54 \text { min.) } \\
\text { média } \pm \text { DP } \\
\text { mediana (mín.; máx.) }\end{array}$ & $\begin{array}{c}0 \pm 0 \\
0(0 ; 0)\end{array}$ & $\begin{array}{c}0 \pm 0 \\
0(0 ; 0)\end{array}$ & $>0,999^{*}$ \\
\hline $\begin{array}{l}\text { TANS (no em } 54 \text { min.) } \\
\text { média } \pm \text { DP } \\
\text { mediana (mín.; máx.) }\end{array}$ & $\begin{array}{c}0 \pm 0 \\
0(0 ; 0)\end{array}$ & $\begin{array}{c}0 \pm 0 \\
0(0 ; 0)\end{array}$ & $>0,999^{*}$ \\
\hline
\end{tabular}

Teste t-Student pareado; * Teste Wilcoxon pareado

Legenda: FC mín. - frequência cardíaca mínima

FC méd. - frequência cardíaca média

ESSV - extrassístole supraventricular

FC máx. - frequência cardíaca máxima

EV - extrassístole ventricular

$P P$ - período do procedimento (média de 54 minutos)

TVNS - taquicardia ventricular não sustentada

TANS - taquicardia atrial não sustentada

Um paciente portador de SBr apresentou alteração dinâmica do Holter no período da monitorização de 28h variando entre não tipo 1 e tipo 1 durante 0 sono, no dia do uso da LCA. 
Outro paciente apresentou padrão dinâmico variando entre tipo 1 e não tipo 1 no período das 28h, quando foi usada LSA. No Período da Anestesia apresentou padrão tipo 1 com LSA e não tipo 1 com LCA (Figura 7).

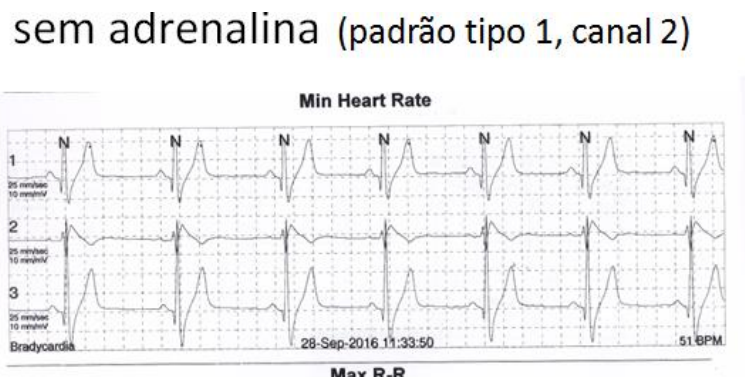

com adrenalina (sem padrão)
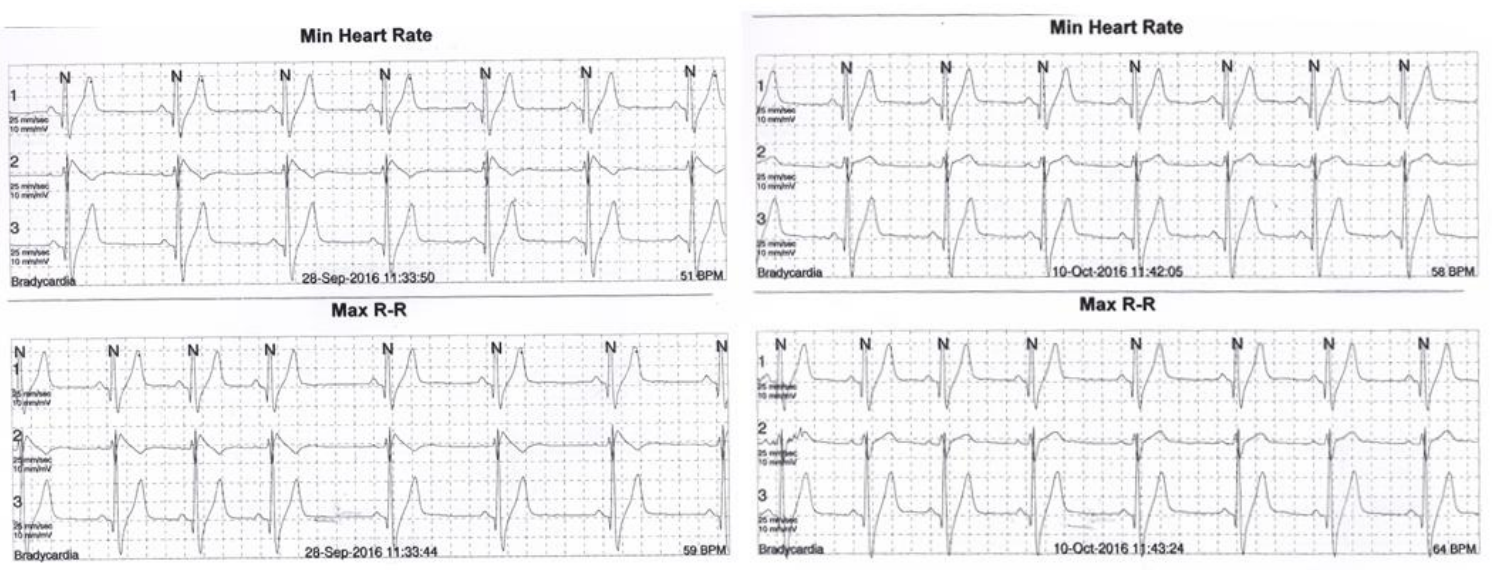

Figura 7 - Traçado Holter de paciente com SBr apresentando alteração dinâmica do padrão eletrocardiográfico durante o Período da Anestesia 


\subsection{Eletrocardiograma}

Em pacientes com SQTL, o QTc foi estatisticamente maior com LCA após

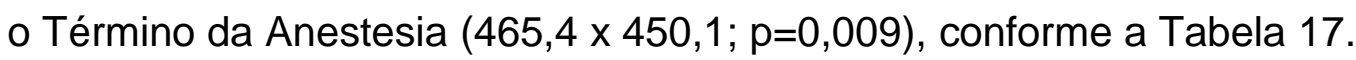

Tabela 17 - Média, desvio-padrão, mediana, mínimo e máximo do QTc e QTc médio em três momentos (PB, TA e FP), nas condições sem e com adrenalina

\begin{tabular}{lccc}
\hline & Sem adrenalina & Com adrenalina & p \\
\hline Período Basal & & & 0,487 \\
QTc & & & \\
média \pm DP & $465,4 \pm 45,4$ & $471,8 \pm 50,3$ & \\
mediana (mín.; máx.) & $448(408 ; 548)$ & $456,5(389 ; 592)$ & \\
\hline Término da Anestesia & & & $\mathbf{0 , 0 0 9}$ \\
QTc & & & \\
média \pm DP & $450,1 \pm 41,8$ & $465,4 \pm 42,9$ & \\
mediana (mín.; máx.) & $445(385 ; 549)$ & $458(390 ; 566)$ & \\
\hline Fim do Procedimento & & & 0,208 \\
QTc & & & \\
média \pm DP & $456,1 \pm 34,6$ & $463,1 \pm 41,6$ & \\
mediana (mín.; máx.) & $451(410 ; 529)$ & $447(390 ; 557)$ & \\
\hline QTc médio & & & \\
média \pm DP & $457,2 \pm 38,7$ & $466,8 \pm 43,9$ & \\
mediana (mín.; máx.) & $447(402,7 ; 542)$ & $457(389,7 ; 571,7)$ & \\
\hline Teste t-Student pareado & & &
\end{tabular}


A Tabela 18 mostra os intervalos QTc individuais nos momentos PB, TA e FP, sem e com o uso de adrenalina.

Tabela 18 - Valores absolutos e médias do QTc (em ms) nos três momentos de estudo (PB, TA e FP), nas condições sem e com adrenalina

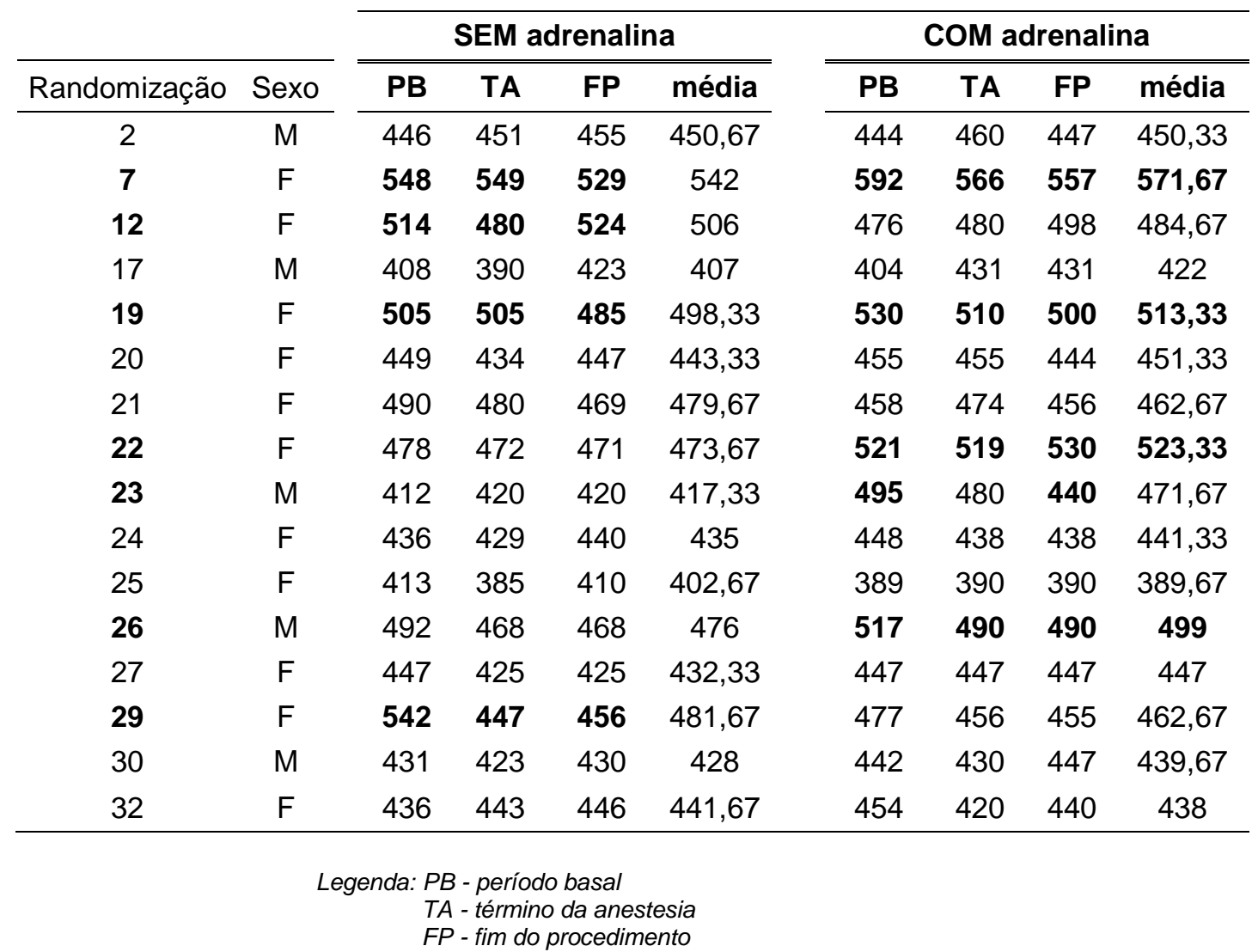

Seis pacientes $(7,12,19,22,26$ e 29) apresentaram QTc> 500 ms no PB e a variação do QTc médio entre os momentos TA e FP não foi significativa quando sob efeito da anestesia, exceto para a paciente de randomização 22 que apresentou aumento do QTc após uso de adrenalina (QTc médio entre TA e $\mathrm{FP}=524,5 \mathrm{~ms}$ ), porém sem preencher o critério categórico de aumento $>10 \%$ do QTc basal e sem ocorrência de eventos adversos. 
Dois pacientes (23 e 29) apresentaram diminuição de mais de $10 \%$ do QTc após administração do anestésico com e sem vasoconstritor, respectivamente, em comparação ao Período Basal (Tabela 19).

Tabela 19 - Alterações do intervalo QTc (categorizados em mais de $10 \%$ no encurtamento ou prolongamento do QTc) após a administração da anestesia local em comparação ao Período Basal, nos pacientes portadores de SQTL

\begin{tabular}{|c|c|c|c|}
\hline Randomização & Condição (aleatória) & Tipo de SQTL & Alterações do intervalo QTc \\
\hline \multirow{2}{*}{2} & sem adrenalina & \multirow{2}{*}{2} & não \\
\hline & com adrenalina & & não \\
\hline \multirow{2}{*}{7} & com adrenalina & \multirow{2}{*}{1} & não \\
\hline & sem adrenalina & & não \\
\hline \multirow{2}{*}{12} & sem adrenalina & \multirow{2}{*}{2} & não \\
\hline & com adrenalina & & não \\
\hline \multirow{2}{*}{17} & sem adrenalina & \multirow{2}{*}{2} & não \\
\hline & com adrenalina & & não \\
\hline \multirow{2}{*}{19} & sem adrenalina & \multirow{2}{*}{2} & não \\
\hline & com adrenalina & & não \\
\hline \multirow{2}{*}{20} & com adrenalina & \multirow{2}{*}{1} & não \\
\hline & sem adrenalina & & não \\
\hline \multirow{2}{*}{21} & com adrenalina & \multirow{2}{*}{1} & não \\
\hline & sem adrenalina & & não \\
\hline \multirow{2}{*}{22} & sem adrenalina & \multirow{2}{*}{1} & não \\
\hline & com adrenalina & & não \\
\hline \multirow{2}{*}{23} & com adrenalina & \multirow{2}{*}{2} & sim (encurtamento) \\
\hline & sem adrenalina & & não \\
\hline \multirow{2}{*}{24} & sem adrenalina & \multirow{2}{*}{ induzido } & não \\
\hline & com adrenalina & & não \\
\hline \multirow{2}{*}{25} & sem adrenalina & \multirow{2}{*}{2} & não \\
\hline & com adrenalina & & não \\
\hline \multirow{2}{*}{26} & com adrenalina & \multirow{2}{*}{2} & não \\
\hline & sem adrenalina & & não \\
\hline \multirow{2}{*}{27} & com adrenalina & \multirow{2}{*}{1} & não \\
\hline & sem adrenalina & & não \\
\hline \multirow{2}{*}{29} & com adrenalina & \multirow{2}{*}{2} & não \\
\hline & sem adrenalina & & sim (encurtamento) \\
\hline \multirow{2}{*}{30} & sem adrenalina & \multirow{2}{*}{3} & não \\
\hline & com adrenalina & & não \\
\hline \multirow{2}{*}{32} & sem adrenalina & & não \\
\hline & com adrenalina & Induzıdo & não \\
\hline
\end{tabular}


As figuras 8 e 9 ilustram o eletrocardiograma de uma paciente (randomização 7) que apresentou prolongamento do intervalo QTc após o uso de anestesia sem e com adrenalina. Nota-se, de acordo com a Tabela 18, que após o uso da adrenalina o QTc diminuiu em relação ao PB (QTc=566 ms).

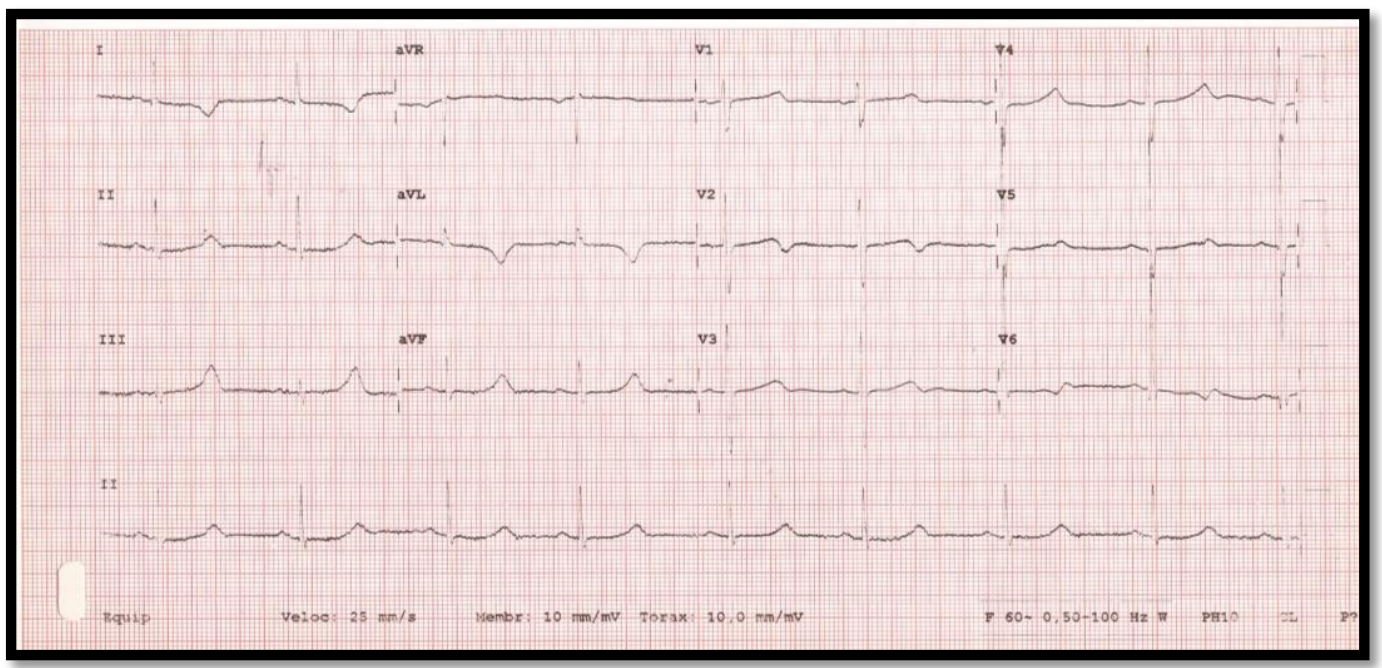

Figura 8 - Exemplo de ECG de paciente com SQTL no Término da Anestesia, sem uso de adrenalina (QTc=549 $\mathrm{ms}$ )

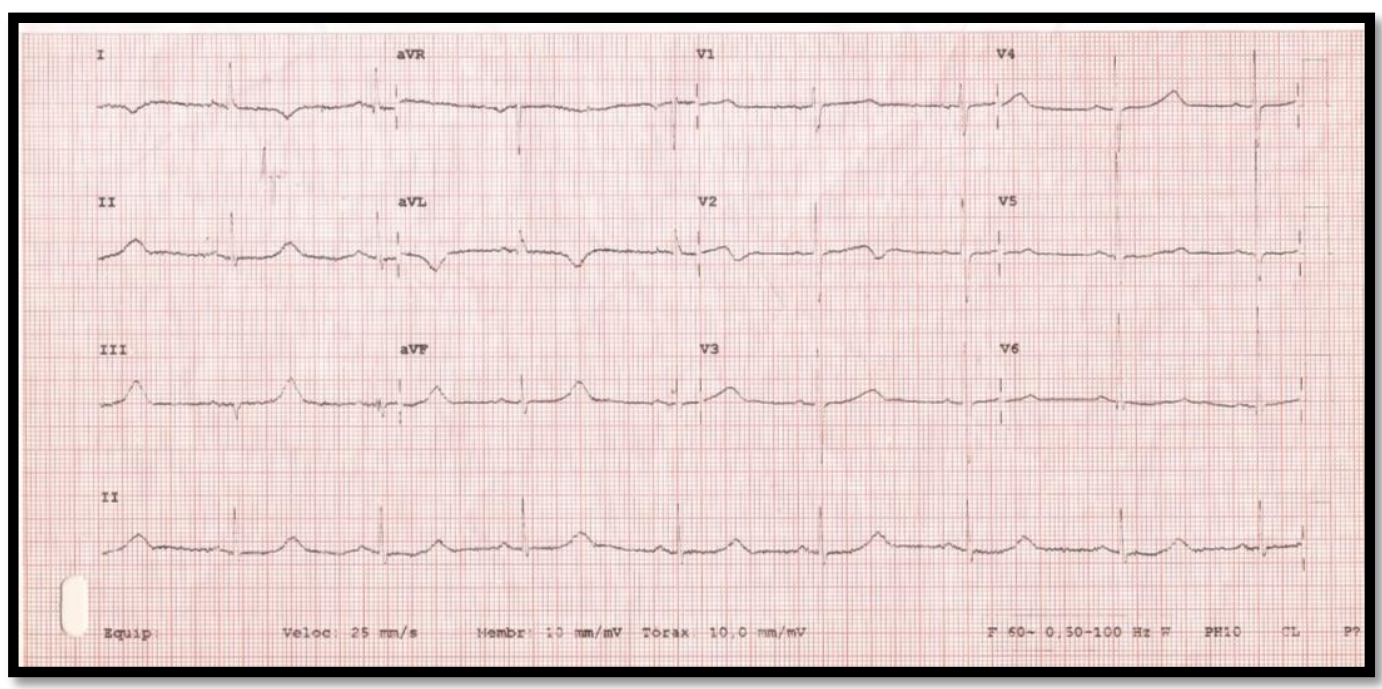

Figura 9 - Exemplo de ECG de paciente com SQTL no Término da Anestesia, com uso de adrenalina (QTc=566 ms) 
Dos 12 pacientes com SBr, 10 mantiveram o mesmo padrão eletrocardiográfico em ambas as condições sem e com adrenalina, durante os momentos estudados: dois apresentaram padrão tipo 1 e oito padrão não tipo 1. Apenas dois pacientes demonstraram alterações eletrocardiográficas, sem eventos ameaçadores à vida. Essas alterações foram relacionadas aos aspectos morfológicos (padrão tipo 1 versus não tipo 1), que ocorreram independentemente do uso de adrenalina (Tabela 20).

Tabela 20 - Padrão eletrocardiográfico da SBr na amostra em três momentos (PB, TA e FP) em uso de lidocaína, separados por condição com e sem adrenalina

\begin{tabular}{|c|c|c|c|}
\hline Randomização & $\begin{array}{l}\text { Condição } \\
\text { (aleatória) }\end{array}$ & $\begin{array}{c}\text { Padrão SBr } \\
\text { tipo1 }\end{array}$ & $\begin{array}{c}\text { Alterações no padrão ECG durante os } \\
\text { momentos de estudo (PB, TA, FP) } \\
\end{array}$ \\
\hline \multirow{2}{*}{4} & com adrenalina & $\operatorname{sim}$ & não \\
\hline & sem adrenalina & $\operatorname{sim}$ & não \\
\hline \multirow{2}{*}{8} & sem adrenalina & $\operatorname{sim}$ & não \\
\hline & com adrenalina & $\operatorname{sim}$ & não \\
\hline \multirow{2}{*}{5} & com adrenalina & não & não \\
\hline & sem adrenalina & não & não \\
\hline \multirow{2}{*}{6} & sem adrenalina & não & não \\
\hline & com adrenalina & não & não \\
\hline \multirow{2}{*}{9} & sem adrenalina & não & não \\
\hline & com adrenalina & não & não \\
\hline \multirow{2}{*}{10} & com adrenalina & não & não \\
\hline & sem adrenalina & não & não \\
\hline \multirow{2}{*}{11} & com adrenalina & não & não \\
\hline & sem adrenalina & não & não \\
\hline \multirow{2}{*}{13} & com adrenalina & não & não \\
\hline & sem adrenalina & não & não \\
\hline \multirow{2}{*}{15} & sem adrenalina & não & não \\
\hline & com adrenalina & não & não \\
\hline \multirow{2}{*}{31} & com adrenalina & não & não \\
\hline & sem adrenalina & não & não \\
\hline \multirow{2}{*}{3} & com adrenalina & não & $\operatorname{sim}(T A)$ \\
\hline & sem adrenalina & não & não \\
\hline \multirow{2}{*}{14} & sem adrenalina & não & $\operatorname{sim}(T A$ e $F P)$ \\
\hline & com adrenalina & não & $\operatorname{sim}(T A$ e $F P)$ \\
\hline
\end{tabular}

Legenda: $P B$ - período basal

TA - término da anestesia

FP - fim do procedimento 
Os padrões eletrocardiográficos da SBr foram avaliados estatisticamente na Tabela 21 e nas figuras 10 e 11 foram apresentados exemplos de traçados eletrocardiográficos destes pacientes.

Tabela 21 - Descrição dos padrões eletrocardiográficos dos pacientes com SBr em três momentos (PB, TA e FP), nas condições sem e com adrenalina

\begin{tabular}{lccc}
\hline Padrão ECG na SBr & Sem adrenalina & Com adrenalina & p \\
\hline Período Basal & & & $>0,999^{\star *}$ \\
Normal & $0(0)$ & $1(8,3)$ & \\
Tipo 1 & $2(16,7)$ & $2(16,7)$ & \\
Não tipo 1 & $10(83,3)$ & $9(75)$ & \\
\hline Término da Anestesia & & & $>0,999^{\star *}$ \\
Tipo 1 & $3(25)$ & $4(33,3)$ & \\
Não tipo 1 & $9(75)$ & $8(66,7)$ & \\
Fim do procedimento & & & $>0,999^{\star *}$ \\
Tipo 1 & $3(25)$ & $3(25)$ & \\
Não tipo 1 & $9(75)$ & $9(75)$ & \\
\hline
\end{tabular}

** Teste McNemar

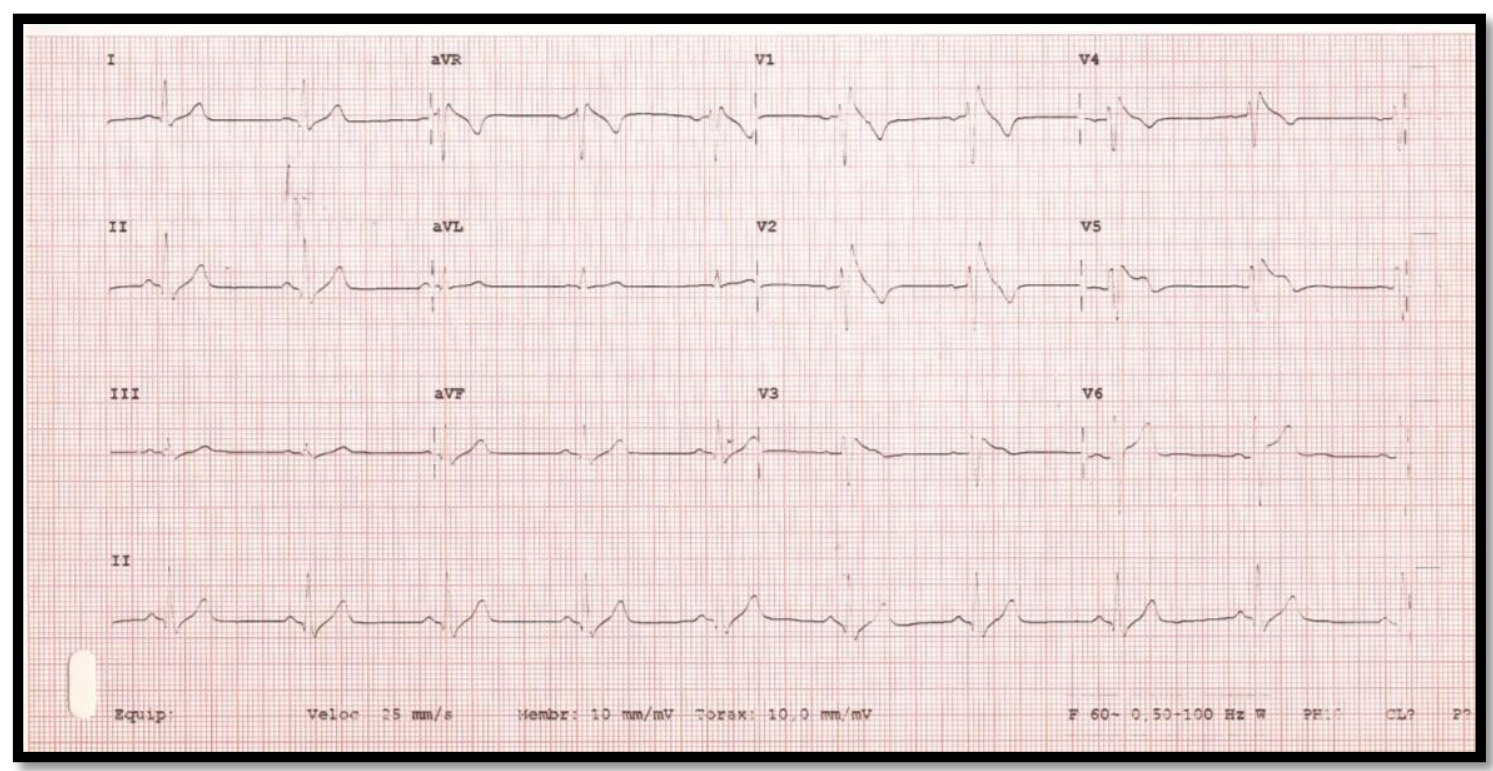

Figura 10 - Exemplo de traçado eletrocardiográfico (com derivações superiores) de paciente com SBr apresentando padrão tipo 1 no Término da Anestesia, sem uso de adrenalina 


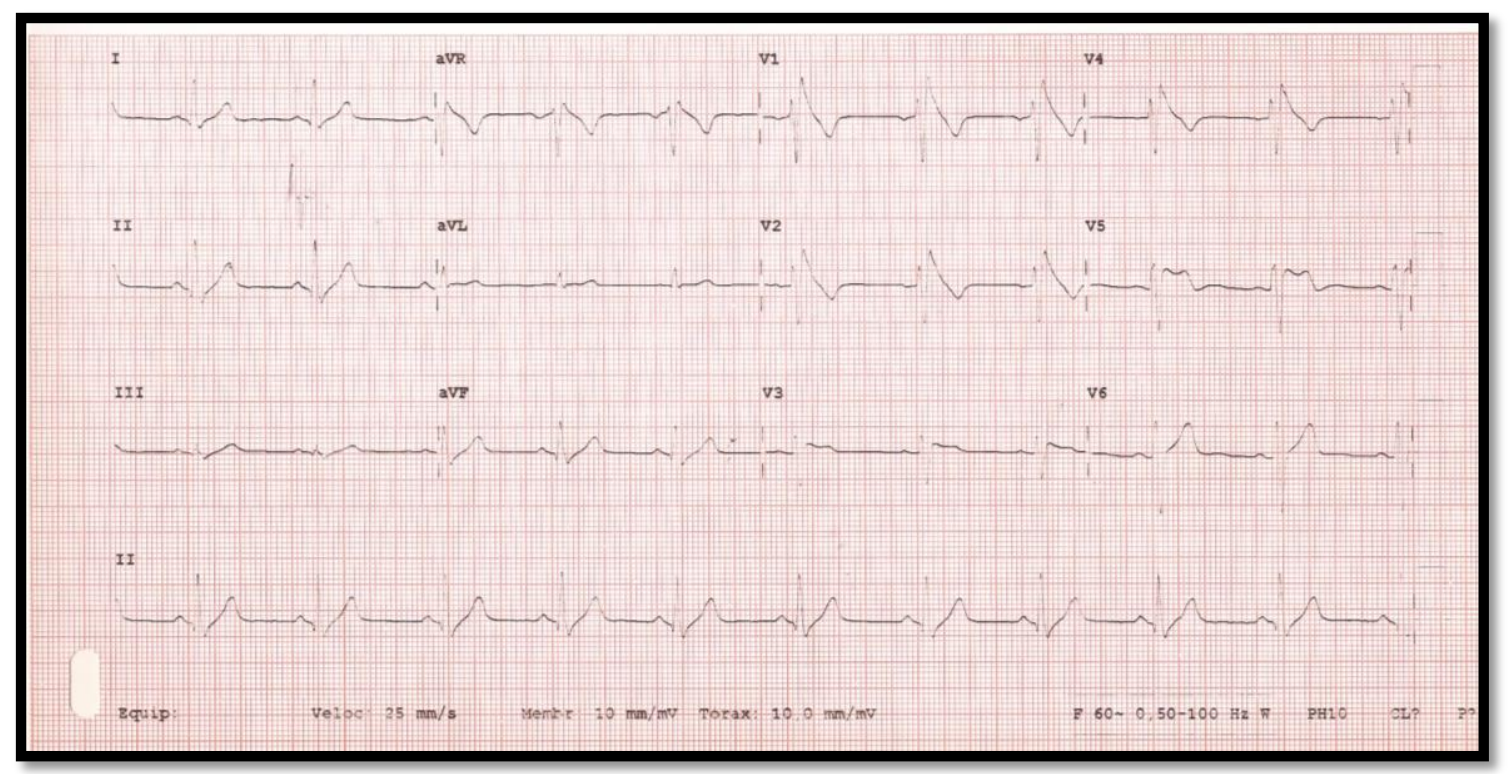

Figura 11 - Exemplo de traçado eletrocardiográfico (com derivações superiores) do mesmo paciente com SBr apresentando padrão tipo 1 no Término da Anestesia, com uso de adrenalina

Nos pacientes com TVPC, não houve ocorrência e documentação de arritmia ventricular nos traçados eletrocardiográficos nos momentos do estudo. 


\subsection{Pressão Arterial}

Os valores da PA sistólica e diastólica foram estatisticamente semelhantes nos momentos de estudo (PB, TA e FP) utilizando-se LSA e LCA (Tabela 22).

Tabela 22 - Média, desvio-padrão, mediana, mínimo e máximo dos valores da pressão arterial sistólica (PAS) e diastólica (PAD) em três momentos (PB, TA e FP), nas condições sem e com adrenalina

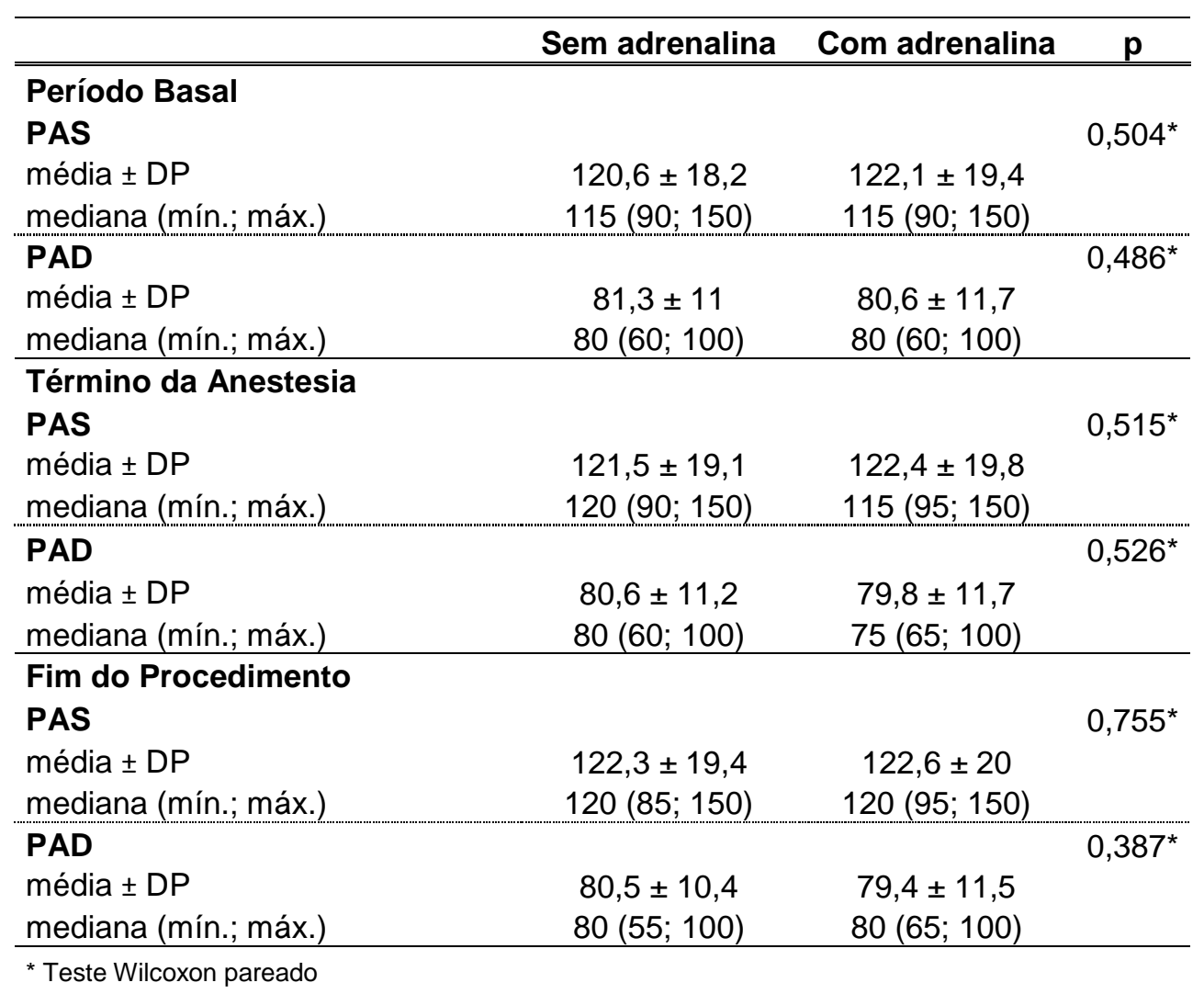

Pela Tabela 23, não houve correlação estatisticamente significativa do Grau de Ansiedade com as pressões arteriais sistólica e diastólica nos momentos de estudo (PB, IA/TA e FP), $(p>0,05)$. 
Tabela 23 - Correlação entre o grau de ansiedade e valores de pressão arterial sistólica e diastólica nos momentos de estudo (PB, IA/TA e FP), nas condições sem e com adrenalina

\begin{tabular}{ccccccc}
\hline Sessão & & & & Correlação & $\mathbf{N}$ & p \\
\hline \hline \multirow{5}{*}{$\begin{array}{c}\text { Sem } \\
\text { adrenalina }\end{array}$} & Período Basal - & Pressão & PAS & 0,298 & 31 & 0,103 \\
& Período da Anestesia & Pressão & PAS & 0,145 & 31 & 0,436 \\
& - Grau de Ansiedade & Arterial & PAD & $-0,100$ & 31 & 0,593 \\
\cline { 2 - 7 } & Fim do Procedimento & Pressão & PAS & $-0,079$ & 31 & 0,673 \\
& - Grau de Ansiedade & Arterial & PAD & $-0,111$ & 31 & 0,552 \\
\hline \multirow{5}{*}{ Com } & Período Basal - & Pressão & PAS & 0,277 & 31 & 0,132 \\
& Grau de Ansiedade & Arterial & PAD & $-0,074$ & 31 & 0,693 \\
\hline \multirow{2}{*}{ adrenalina } & Período da Anestesia & Pressão & PAS & 0,287 & 31 & 0,118 \\
& - Grau de Ansiedade & Arterial & PAD & $-0,115$ & 31 & 0,539 \\
\cline { 2 - 7 } & Fim do Procedimento & Pressão & PAS & $-0,024$ & 31 & 0,898 \\
& - Grau de Ansiedade & Arterial & PAD & $-0,109$ & 31 & 0,559 \\
\hline
\end{tabular}

Correlação de Spearman

\subsection{Ansiedade}

Não houve diferença estatisticamente significante no Grau de Ansiedade nos momentos de estudo (PB, IA e FP) com LSA e LCA (Tabela 24).

Tabela 24 - Média, desvio-padrão, mediana, mínimo e máximo do Grau de Ansiedade em três momentos (PB, IA e FP), nas condições sem e com adrenalina

\begin{tabular}{lccc}
\hline Grau de Ansiedade & Sem adrenalina & Com adrenalina & $\mathbf{p}$ \\
\hline \hline Período Basal & & & $0,331^{*}$ \\
média \pm DP & $1,26 \pm 0,58$ & $1,39 \pm 0,62$ & \\
mediana (mín.; máx.) & $1(1 ; 3)$ & $1(1 ; 3)$ & \\
\hline Início da Anestesia & $1,48 \pm 0,77$ & $1,58 \pm 0,76$ & $0,490^{*}$ \\
média \pm DP & $1(1 ; 3)$ & $1(1 ; 3)$ & \\
mediana (mín.; máx.) & & & $0,527^{*}$ \\
\hline Fim do Procedimento & $1,29 \pm 0,64$ & $1,36 \pm 0,55$ & \\
média \pm DP & $1(1 ; 3)$ & $1(1 ; 3)$ & \\
mediana (mín.; máx.) &
\end{tabular}

* Teste Wilcoxon pareado 
A ordem de execução dos procedimentos influenciou na ansiedade dos pacientes. Pela Tabela 25, tem-se que o Grau de Ansiedade na $1^{\text {a }}$ sessão foi estatisticamente maior que na $2^{2}$ sessão apenas no Início da Anestesia $(1,68 \mathrm{x}$ $1,39 ; p=0,038)$, mas sugeriu maior escore também no fim do procedimento $(1,42 \times 1,23 ; p=0,058)$.

Tabela 25 - Descrição dos escores de ansiedade segundo ordem de realização do procedimento e resultados dos testes comparativos

\begin{tabular}{|c|c|c|c|}
\hline Grau de Ansiedade & 1a sessão & $2^{a}$ sessão & $\mathbf{p}$ \\
\hline $\begin{array}{l}\text { Período Basal } \\
\text { média } \pm \text { DP } \\
\text { mediana (mín.; máx.) }\end{array}$ & $\begin{array}{c}1,39 \pm 0,67 \\
1(1 ; 3)\end{array}$ & $\begin{array}{c}1,26 \pm 0,51 \\
1(1 ; 3) \\
\end{array}$ & 0,331 \\
\hline $\begin{array}{l}\text { Início da Anestesia } \\
\text { média } \pm \text { DP } \\
\text { mediana (mín.; máx.) }\end{array}$ & $\begin{array}{c}1,68 \pm 0,83 \\
1(1 ; 3)\end{array}$ & $\begin{array}{c}1,39 \pm 0,67 \\
1(1 ; 3) \\
\end{array}$ & 0,038 \\
\hline $\begin{array}{l}\text { Fim do Procedimento } \\
\text { média } \pm \text { DP } \\
\text { mediana (mín.; máx.) }\end{array}$ & $\begin{array}{c}1,42 \pm 0,62 \\
1(1 ; 3) \\
\end{array}$ & $\begin{array}{c}1,23 \pm 0,56 \\
1(1 ; 3) \\
\end{array}$ & 0,058 \\
\hline
\end{tabular}

Teste Wilcoxon pareado

\subsection{Sintomas}

O tratamento odontológico foi bem tolerado pelos pacientes, sem a presença de sintomas ou complicações que justificassem a interrupção do procedimento. 


\section{DISCUSSÃO}

Os resultados do nosso estudo demonstraram que não foram observadas arritmias ameaçadoras à vida em pacientes com canalopatias cardíacas durante o tratamento odontológico, sob anestesia local com lidocaína sem vasoconstritor e quando associada à adrenalina, sugerindo que o seu uso é seguro nas doses padronizadas.

Verificamos o aumento da FC máxima no Período da Anestesia com o uso de LCA em todos pacientes da amostra, embora não tenham sido observadas diferenças significativas no aumento da PA, sem implicações clínicas.

Não houve prolongamento significativo do intervalo QTc nos pacientes com SQTL. Observamos encurtamento do intervalo QTC em dois de 16 pacientes com SQTL, o que pode, na verdade, corroborar a segurança dos anestésicos utilizados nessa população em nosso protocolo de estudo.

Os pacientes com SBr não apresentaram alterações dinâmicas no Holter e dez dos 12 pacientes com SB mantiveram o mesmo padrão eletrocardiográfico em ambas as condições, com e sem epinefrina, durante os três momentos estudados: dois apresentaram padrão tipo 1 e oito apresentaram padrão não-tipo 1. Somente em dois pacientes as alterações no ECG foram observadas e relacionadas aos aspectos morfológicos (padrões tipo 1 vs não tipo 1), que ocorreram independentemente do uso de epinefrina, sem nenhum evento com risco de vida. 
Em nosso estudo, o grau de ansiedade não se alterou significativamente nos momentos estudados quando as condições sem e com adrenalina foram comparadas. Ainda foi possível observar que na primeira sessão do tratamento houve aumento deste parâmetro apenas no início da anestesia. Quando a ansiedade foi comparada à PA, não houve correlação significativa.

Nossos resultados estão em concordância com a revisão da literatura que reuniu publicações da última década sobre o uso de anestésicos locais em cardiopatas. Na maioria desses estudos, não foram observadas diferenças significativas entre anestésicos com ou sem vasoconstritores, e quando tais diferenças foram estatisticamente significantes, os autores não as consideraram críticas do ponto de vista clínico. A conclusão foi que quantidades limitadas de adrenalina contidas em um ou dois cartuchos não resultaram no desenvolvimento de complicações para pacientes com doenças cardiovasculares controladas, desde que a escolha e execução da técnica anestésica sejam adequadas ${ }^{92}$

No estudo de Blinder e col. ${ }^{93,94}$, pacientes cardiopatas foram submetidos à exodontia sob anestesia local com até três cartuchos $(5,4 \mathrm{~mL})$ de lidocaína $2 \%$ com adrenalina 1:100.000 e mepivacaína 3\% sem vasoconstritor. As alterações eletrocardiográficas ocorreram durante o período de duas horas após a injeção do anestésico em 37,5\% dos pacientes que utilizaram vasoconstritor e em 35\% daqueles que não fizeram uso. Quando o Holter dos pacientes foi comparado, a complicação mais frequente após a administração do anestésico local com vasoconstritor foi taquicardia ou aumento da $\mathrm{FC}$ de $53,3 \%$ versus $7,1 \%$ em pacientes que receberam o anestésico local sem vasoconstritor. 
Em nossa pesquisa, uma das preocupações residia no fato que os pacientes com SQTL e TVPC pudessem estar mais propensos a algum risco arrítmico nos momentos de incremento da FC, o que felizmente não ocorreu, provavelmente por se tratarem de pacientes selecionados como "estáveis", sem eventos arrítmicos recentes e medicados com beta-bloqueadores. Além disso, a lidocaína também possui propriedades antiarrítmicas e pode encurtar o intervalo QTc ${ }^{95}$, podendo conferir proteção adicional aos pacientes.

Niwa e col. ${ }^{18}$ avaliaram as consequências hemodinâmicas através de impedância cardiográfica em 27 pacientes com doença cardiovascular distribuídos em classe funcional de I a III. Estes receberam um cartucho de lidocaína 2\% com adrenalina 1:80.000 para tratamento odontológico, mostrando aumento de $5,1 \%$ na FC imediatamente após a injeção do anestésico e de 4,1\% na PA sistólica; porém, a PA diastólica e média permaneceram inalteradas. Não foram observadas alterações eletrocardiográficas e, portanto, não houve diferenças significativas entre os três grupos com a dose de adrenalina utilizada $(22,5 \mu \mathrm{g})$.

Matsumura e col. ${ }^{96}$ incluíram 40 pacientes saudáveis com 19 a 74 anos de idade, submetidos à exodontia em ambiente hospitalar. Foi realizado exame de Holter antes e durante o procedimento, com administração de anestésico local lidocaína 2\% contendo adrenalina 1:80.000, e os pacientes não apresentaram mudanças significativas no segmento ST. A cirurgia dentária com anestesia local causou aumento significativo da FC e da PA em pacientes mais velhos. No entanto, nosso estudo apresentou valores semelhantes de PA com LSA e LCA. 
Bouloux e col. ${ }^{97}$ realizaram um estudo cross-over randomizado duplocego em 23 pacientes saudáveis submetidos à exodontia de terceiros molares em dois momentos diferentes, com uso de bupivacaína 0,5\% com adrenalina 1:200.000 de um lado e lidocaína $2 \%$ com adrenalina 1:100.000 no outro. Foram avaliados: experiência de dor, consumo de analgésico, resposta cardiovascular, concentração sanguínea e toxicidade sistêmica do anestésico. A cardiotoxicidade da bupivacaína tem sido atribuída tanto ao bloqueio dos canais de sódio miocárdicos quanto à depressão direta do bulbo do SNC. O estudo mostrou que não houve diferença na resposta cardiovascular entre a bupivacaína e a lidocaína, mas uma diminuição estatisticamente significativa na FC média ocorreu entre 15 e 30 minutos após a administração de ambos anestésicos, resultante da diminuição das catecolaminas endógenas associadas ao término do procedimento cirúrgico. A análise de amostras de sangue colhidas mostrou não haver anestésico presente. Não houve diferença na experiência de dor transoperatória. A média da PA permaneceu constante e não houve diferença estatisticamente significante entre os dois agentes anestésicos, assim como da FC.

Dez pacientes hipertensos foram submetidos randomicamente a estudo cross-over para tratamento periodontal, realizado semanalmente com 1,8 $\mathrm{mL}$ de diferentes anestésicos em cada quadrante: articaína com 0,018 mg de adrenalina, articaína com 0,036 mg de adrenalina, mepivacaína 3\% sem vasoconstritor e mepivacaína $2 \%$ com $0,018 \mathrm{mg}$ de adrenalina. Os pacientes apresentaram aumento estatisticamente significante da FC e PA, porém sem complicações cardiovasculares ou alterações isquêmicas ${ }^{98}$. 
Segundo Cáceres e col. ${ }^{99}$, não foram observadas alterações no número e complexidade de extrassístoles ventriculares, PA e FC durante o tratamento odontológico de 65 pacientes com arritmia ventricular complexa (33 pacientes chagásicos e 32 com doença arterial coronária). Para o procedimento, utilizouse de dois a quatro cartuchos de prilocaína $3 \%$ associada à felipressina 0,03 Ul/mL e lidocaína $2 \%$ sem vasoconstritor.

De acordo com Conrado e col., $2007^{100}, 54$ pacientes coronariopatas submetidos à exodontia sob anestesia local foram divididos em dois grupos, para uso de mepivacaína 2\% associada à adrenalina 1:100.000 e mepivacaína $3 \%$ sem vasoconstritor. Três pacientes apresentaram depressão do segmento ST com a utilização do anestésico com vasoconstritor, na fase de injeção.

É recomendado pela literatura evitar o uso de vasoconstritor adrenérgico em pacientes com angina instável, infarto do miocárdio ou cirurgia de revascularização recentes, nas arritmias refratárias, hipertensão arterial nãocontrolada e insuficiência cardíaca congestiva descompensada ${ }^{101}$.

Um estudo constatou a incidência de arritmias em 65 pacientes por meio de alterações eletrocardiográficas antes e durante 77 procedimentos cirúrgicos odontológicos, sob anestesia local com lidocaína $2 \%$ associada à adrenalina 1:100.000, no qual o volume do anestésico variou entre 0,8 e $8,8 \mathrm{~mL}$, com média de 3,0 mL. Quarenta e seis cirurgias foram realizadas em 40 pacientes sem doença cardiovascular, que desenvolveram arritmias em $17 \%$ dos procedimentos (ESSV e EV monomórficas). Trinta e uma cirurgias odontológicas foram realizadas em 25 pacientes cardiopatas (sete hipertensos e 18 coronariopatas), e constatação de arritmias em 33\% dos procedimentos (EV polimórficas, fibrilação atrial, arritmia sinusal, marcapasso errante e escape 
nodal). Pacientes idosos com doença cardiovascular tiveram maior incidência de arritmias pré e transoperatórias, porém não houve relação consistente entre a quantidade de anestésico e o desenvolvimento de $\operatorname{arritmias}^{102}$.

Alguns autores referem que o uso de anestésico local associado à adrenalina pode ser realizado em pacientes em uso de $\beta$-bloqueador nãoseletivo, porém, a dose inicial deve ser mínima, como meio cartucho de adrenalina 1:100.000, injetado cuidadosamente para evitar administração intravascular. A monitorização do ritmo cardíaco e da pressão arterial a cada 5 minutos devem ser realizadas, e se não houver alterações, até dois cartuchos adicionais podem ser utilizados ${ }^{103,104}$. Neves e col. ${ }^{14}$, ao estudarem 62 portadores de doença arterial coronária com obstrução $\geq 70 \%$ e indicação de revascularização miocárdica, não observaram variações significativas de FC e PA, tanto na presença como na ausência de adrenalina 1:100.000 associada à lidocaína $2 \%$ para executar procedimentos restauradores, respeitando a dose máxima por sessão de $3,6 \mathrm{~mL}$. Na maioria desses pacientes $(54,8 \%)$ em uso de betabloqueadores adrenérgicos não-seletivos não houve diferença na PA quando comparados ao grupo controle.

Middlehurst e col. ${ }^{105}$ realizaram estudo com 75 pacientes cardiopatas (hipertensos, valvopatas, coronariopatas, portadores de insuficiência cardíaca, arritmia e cardiomiopatia) submetidos a procedimento cirúrgico odontológico, divididos em dois grupos. Cinquenta pacientes utilizaram lidocaína $2 \%$ com noradrenalina 1:50.000 e vasopressina 0.25 Ul/mL (média de 4,9 mL). O outro grupo, composto de 25 pacientes, recebeu o mesmo anestésico (média de 5,5 $\mathrm{mL}$ ) com associação de midazolam endovenoso. Apesar da anestesia local ter induzido a mudanças estatisticamente significantes na média de valores de FC 
e PA para ambos os grupos, a magnitude fisiológica e relevância clínica de tais mudanças foram mínimas. O uso de midazolam reduziu a PAS dos pacientes deste grupo. Os autores recomendaram que um protocolo para a prática clínica com anestesia local em pacientes cardiopatas seja seguido para a minimização dos riscos, como o uso racional de anestesia local, como a lidocaína $2 \%$ com adrenalina em concentração eficaz mínima, aspiração prévia e monitoramento, incluindo também a prescrição de um agente sedativo, como o midazolam, que atenua a resposta simpatoadrenal.

Ainda que alguns dos estudos aqui referidos tenham incluído portadores de arritmias cardíacas, as canalopatias não estavam presentes.

A abordagem do emprego de anestésicos locais em pacientes com canalopatias se limitam a relatos de $\operatorname{casos}^{79,80}$. Rochford e Seldin ${ }^{27}$ contraindicam o uso de anestésico local com adrenalina, relatando o caso de uma criança de oito anos com SQTL, em uso do betabloqueador nadolol, admitida em hospital para exodontia sob anestesia geral. Para o procedimento odontológico, foi realizada anestesia local com mepivacaína $3 \%$ sem vasoconstritor. Após duas horas, o paciente não apresentou alterações eletrocardiográficas e recebeu alta no mesmo dia.

Karp e Ganoza ${ }^{106}$ descreveram o atendimento odontológico de um menino de sete anos de idade com história médica de SQTL com CDI e síndrome de Pierre Robin que sofreu trauma dentário após episódio de síncope com desenvolvimento de $\mathrm{TdP}$ e, posteriormente, foi submetido à exodontia sob anestesia geral sem intercorrências.

É importante ressaltar a identificação precoce dos sinais de alerta como meio de prevenção de eventos cardíacos em pacientes com SQTL no 
consultório odontológico por meio da aquisição de história médica completa. Como recomendação geral, aqueles que apresentam história pessoal ou familiar de síncope devem ser encaminhados ao cardiologista para avaliação eletrocardiográfica antes de qualquer intervenção odontológica. Por outro lado, pacientes com diagnóstico de canalopatias, que apresentarem evento de síncope no consultório odontológico, devem ser encaminhados ao departamento de emergência do hospital ${ }^{107}$.

De acordo com Chapman e Penkeyman ${ }^{108}$, a parada cardíaca é um evento raro em pacientes submetidos a tratamento odontológico. No entanto, dentistas devem estar preparados caso esta venha a ocorrer. A parada cardíaca discutida neste relato ocorreu em um paciente idoso, portador de marcapasso, submetido a tratamento odontológico restaurador sob anestesia local com 2,2 mL de prilocaína associada à felipressina. Depois de diagnosticada, foi instituída a RCP imediatamente, bem sucedida com 0 desfibrilador externo semiautomático.

Manoharan e col. ${ }^{109}$ relataram o caso de um menino de 12 anos de idade que apresentou FV após anestesia odontológica associada à sedação com óxido nitroso. Por ter sido precocemente diagnosticada e tratada através de RCP imediata e efetiva, mostrou a importância da disponibilidade e acesso a um desfibrilador externo automático.

Nosso estudo teve o cuidado de empregar um protocolo de tratamento odontológico com triagem prévia de pacientes com canalopatias, feita por equipe médica com experiência em arritmias cardíacas de origem genética. Os critérios de exclusão foram planejados objetivando o maior perfil de segurança possível e com monitorização dos parâmetros clínicos e eletrocardiográficos, 
em ambiente hospitalar. Felizmente, no presente estudo, não houve casos de parada cardíaca ou necessidade de manobras de RCP.

Embora anormalidades na repolarização determinadas geneticamente possam ser importantes no início de arritmias fatais, o desequilíbrio simpáticovagal pode ser um fator de modulação nas canalopatias ${ }^{110}$.

A monitorização da FC nos permitiu avaliar, como descrito na literatura, o padrão dinâmico da atividade autonômica gerada pela ativação e/ou inibição simpática e parassimpática ${ }^{111}$. Também foram feitos os registros de percepção de ansiedade pelo paciente durante o procedimento odontológico, buscando relacionar a possível influência do estresse sobre os parâmetros vitais, como estudado por outros autores ${ }^{112,113}$. Já a análise das variações de PA teve como finalidade quantificar o risco causado pelo uso de vasoconstritor, somado ao estresse do procedimento odontológico ${ }^{114,115}$.

Dados mostraram que o impacto emocional relacionado à extração dentária sob anestesia local em 70 pacientes foi considerado pequeno, justificado pela natureza do procedimento ou pela ausência de complicações durante o período de seguimento. No entanto, os resultados enfatizam a importância de fatores psicológicos, já que a ansiedade pode ser influenciada por técnicas operacionais (tipo de anestesia, duração do ato operatório ou posição do dente extraído) ${ }^{116}$.

De acordo com nossos resultados, a má condição de saúde bucal, com alto índice de CPOD observado, reflete a importância e a necessidade de tratamento odontológico adequado para portadores de canalopatias cardíacas, impactando em sua qualidade de vida ${ }^{84}$. 
Em resumo, nosso protocolo de tratamento odontológico numa população de pacientes com doenças arrítmicas específicas, as canalopatias cardíacas, foi capaz de demonstrar um perfil de segurança, sem aumento de eventos ameaçadores à vida, independente do uso ou não de vasoconstritor associado à lidocaína, desde que seguidos os critérios de inclusão e exclusão do estudo. Estes resultados iniciais apontam para que os médicos que seguem estes pacientes com doenças arrítmicas raras, como as canalopatias, possam ter mais respaldo científico para alicerçarem suas tomadas de decisão na indicação destes pacientes para procedimentos odontológicos. 


\section{LIMITAÇÕES DO ESTUDO}

Devido à amostra reduzida, são necessários estudos com maior número amostral de pacientes, de preferência com registros multicêntricos, para reproduzir a segurança em relação aos eventos arrítmicos pelo uso da anestesia odontológica com ou sem vasoconstritor em pacientes com canalopatias cardíacas.

Os pacientes portadores de SQTL, por terem maior variabilidade do perfil genético, podem apresentar maior heterogeneidade na apresentação clinica e eletrocardiográfica, gerando mensurações diferentes do QTc. Entretanto, tivemos o cuidado de acrescentar variáveis categóricas destas alterações do QTc em relação ao período basal do ECG.

Todos os resultados favoráveis de segurança deste estudo se aplicam somente a esta população previamente selecionada, onde eram excluídos pacientes submetidos à terapia por CDI há menos de três meses, aqueles com síncopes recorrentes nos últimos três meses ou com documentação de arritmias sustentadas há menos de três meses, o que reflete também a preocupação ética, visando minimizar possíveis danos. 


\section{CONCLUSÕES}

O uso da anestesia local odontológica com lidocaína, independente do uso de vasoconstritor, não resultou em arritmias ameaçadoras à vida e demonstrou-se seguro neste protocolo de atendimento odontológico em portadores de canalopatias cardíacas.

O tratamento odontológico foi bem tolerado nestes pacientes, sem a presença de sintomas, alterações de pressão arterial ou de complicações que justificassem a interrupção do procedimento. 


\section{PERSPECTIVAS CLÍNICAS}

Uma de nossas contribuições reside no fato deste ser o primeiro estudo prospectivo e controlado em demonstrar que esses pacientes selecionados com canalopatias cardíacas podem ser submetidos de modo seguro a procedimentos odontológicos, desde que seguidos os critérios propostos no protocolo deste ensaio clínico.

Os pacientes com canalopatias cardíacas são, em sua grande maioria, jovens e, como todo indivíduo, poderão necessitar de tratamento odontológico em algum momento de suas vidas. Entretanto, como são doenças raras e com risco de morte súbita, são conhecidas como "doenças-órfãs" de estudos de grande impacto. Como não são descritos protocolos específicos de tratamento odontológico para esses pacientes, ressalta-se a importância do registro no sítio eletrônico ClinicalTrials.gov.

Vale frisar que estes dados foram aplicáveis nos pacientes com canalopatias cardíacas consideradas estáveis pelo protocolo de estudo, com respaldo do tratamento feito em ambiente hospitalar. Futuramente, os resultados favoráveis deste estudo poderão auxiliar na otimização e no planejamento do tratamento odontológico, em relação ao perfil de segurança nesta população de pacientes com canalopatias cardíacas. 


\section{ANEXOS}

\section{Anexo A - Tabela de randomização dos anestésicos}

\begin{tabular}{|c|c|c|c|c|c|c|c|c|c|c|c|}
\hline \multicolumn{12}{|c|}{$A=$ sem adrenalina } \\
\hline \multirow[t]{2}{*}{ Ordem } & \multirow[t]{2}{*}{$\mathrm{RGHC}$} & \multicolumn{2}{|c|}{$\begin{array}{l}1 \text { a intervenção } \\
\text { (randomização } \\
\text { do anestésico) }\end{array}$} & \multirow[t]{2}{*}{ Data } & \multirow{2}{*}{$\begin{array}{c}10 \\
\text { anestésico } \\
\text { (tipo e lote) }\end{array}$} & \multicolumn{2}{|c|}{$\begin{array}{l}2^{\mathrm{a}} \text { intervenção } \\
\text { (randomização } \\
\text { do anestésico) }\end{array}$} & \multirow[t]{2}{*}{ Data } & \multirow{2}{*}{$\begin{array}{c}2^{\circ} \\
\text { anestésico } \\
\text { (tipo e lote) }\end{array}$} & \multicolumn{2}{|c|}{$\begin{array}{c}\quad \mathrm{n} \text { - de } \\
\text { cartuchos } \\
\text { utilizados }\end{array}$} \\
\hline & & $A$ & $\mathrm{~B}$ & & & $A$ & B & & & $1^{\mathrm{a}}$ & $2^{\mathrm{a}}$ \\
\hline 1 & $55727339 \mathrm{~J}$ & $x$ & & $18 / 05 / 2016$ & 15042786 & & $x$ & * & * & 2 & * \\
\hline 2 & 55727626D & $x$ & & $22 / 06 / 2016$ & 15042786 & & $x$ & 20/07/2016 & 1602D1008 & 2 & 2 \\
\hline 3 & $55510833 G$ & & $x$ & $29 / 06 / 2016$ & 1602D1008 & $x$ & & $10 / 08 / 2016$ & 15042786 & 2 & 2 \\
\hline 4 & $55731342 \mathrm{E}$ & & $x$ & $27 / 07 / 2016$ & 1602D1008 & $x$ & & $24 / 08 / 2016$ & 15042786 & 2 & 2 \\
\hline 5 & $55751425 \mathrm{C}$ & & $x$ & 03/08/2016 & 1602D1008 & $x$ & & $17 / 08 / 2016$ & 15042786 & 2 & 2 \\
\hline 6 & $55718955 \mathrm{G}$ & $x$ & & $31 / 08 / 2016$ & 15042786 & & $x$ & $14 / 09 / 2016$ & 1602D1008 & 2 & 2 \\
\hline 7 & $55502040 \mathrm{~B}$ & & $x$ & $21 / 09 / 2016$ & 1602D1008 & $x$ & & 03/10/2016 & 15042786 & 2 & 2 \\
\hline 8 & $90411272 \mathrm{G}$ & $x$ & & $28 / 09 / 2016$ & 15042786 & & $x$ & $10 / 10 / 2016$ & 1602D1008 & 2 & 2 \\
\hline 9 & $55750760 \mathrm{~K}$ & $x$ & & 05/10/2016 & 15042786 & & $x$ & $17 / 10 / 2016$ & 1602D1008 & 2 & 2 \\
\hline 10 & 6153990B & & $x$ & $13 / 10 / 2016$ & 1602D1008 & $x$ & & $26 / 10 / 2016$ & 15042786 & 2 & 2 \\
\hline 11 & $3136583 F$ & & $x$ & $24 / 10 / 2016$ & 1602D1008 & $x$ & & 09/11/2016 & 15042786 & 2 & 2 \\
\hline 12 & $55477253 \mathrm{E}$ & $x$ & & $03 / 11 / 2016$ & 15042786 & & $x$ & 29/11/2016 & 1602D1008 & 2 & 2 \\
\hline 13 & $55444376 \mathrm{C}$ & & $x$ & $23 / 11 / 2016$ & 1602D1008 & $x$ & & $01 / 12 / 2016$ & 15042786 & 2 & 2 \\
\hline 14 & $55767215 \mathrm{~K}$ & $x$ & & $07 / 12 / 2016$ & 15042786 & & $x$ & $14 / 12 / 2016$ & 1602D1008 & 2 & 2 \\
\hline 15 & $55701593 \mathrm{~J}$ & $x$ & & $12 / 12 / 2016$ & 15042786 & & $x$ & 19/12/2016 & 1602D1008 & 2 & 2 \\
\hline 16 & $55763214 \mathrm{~J}$ & & $x$ & 05/01/2017 & 1602D1008 & $x$ & & $12 / 01 / 2017$ & 15042786 & 2 & 2 \\
\hline 17 & $55742072 \mathrm{H}$ & $x$ & & $15 / 02 / 2017$ & 15042786 & & $x$ & $22 / 02 / 2017$ & 1602D1008 & 2 & 2 \\
\hline 18 & $55715862 \mathrm{D}$ & & $x$ & $16 / 03 / 2017$ & 1602D1008 & $x$ & & 08/03/2017 & 15042786 & 2 & 2 \\
\hline 19 & 55727339J & $x$ & & $13 / 03 / 2017$ & 15042786 & & $x$ & $22 / 03 / 2017$ & 1602D1008 & 2 & 2 \\
\hline 20 & $55750127 \mathrm{G}$ & & $x$ & $19 / 06 / 2017$ & 1602D1008 & $x$ & & $26 / 06 / 2017$ & 15042786 & 2 & 2 \\
\hline 21 & $55426688 \mathrm{~J}$ & & $x$ & $27 / 07 / 2017$ & 1602D1008 & $x$ & & 07/08/2017 & 15042786 & 2 & 2 \\
\hline 22 & $55541190 \mathrm{H}$ & $x$ & & 09/07/2017 & 15042786 & & $x$ & $06 / 08 / 2018$ & 1705D1021 & 2 & 2 \\
\hline 23 & $55739328 \mid$ & & $x$ & $16 / 08 / 2017$ & 1602D1008 & $x$ & & 04/10/2017 & 17020900 & 2 & 2 \\
\hline 24 & 55720634E & $x$ & & $28 / 08 / 2017$ & 15042786 & & $x$ & $20 / 09 / 2017$ & 1602D1008 & 2 & 2 \\
\hline 25 & 770746031 & $x$ & & $27 / 09 / 2017$ & 15042786 & & $x$ & $18 / 10 / 2017$ & 1602D1008 & 2 & 2 \\
\hline 26 & $55438231 \mathrm{~J}$ & & $x$ & $21 / 11 / 2107$ & 1705D1021 & $x$ & & $11 / 12 / 2017$ & 17020900 & 2 & 2 \\
\hline 27 & $55315470 \mathrm{C}$ & & $x$ & $22 / 01 / 2018$ & 1705D1021 & $x$ & & $31 / 01 / 2018$ & 17020900 & 2 & 2 \\
\hline 28 & $5210743 G$ & $x$ & & 07/02/2018 & 17020900 & & $x$ & $21 / 03 / 2018$ & 1705D1021 & 2 & 2 \\
\hline 29 & 55726733E & & $x$ & $25 / 04 / 2018$ & 1705D1021 & $x$ & & 08/05/2018 & 17020900 & 2 & 2 \\
\hline 30 & $55708583 \mathrm{~K}$ & $x$ & & $29 / 05 / 2018$ & 17020900 & & $x$ & $12 / 06 / 2018$ & 1705D1021 & 2 & 2 \\
\hline 31 & $55750768 \mathrm{C}$ & & $x$ & 05/06/2018 & 1705D1021 & $x$ & & $14 / 06 / 2018$ & 17020900 & 2 & 2 \\
\hline 32 & $3253832 F$ & $x$ & & 03/07/2018 & 17020900 & & $x$ & $17 / 07 / 2018$ & 1705D1021 & 2 & 2 \\
\hline 33 & $2793163 F$ & $x$ & & $25 / 07 / 2018$ & 17020900 & & $x$ & 09/08/2018 & 1705D1021 & 2 & 2 \\
\hline
\end{tabular}

* Paciente não pôde comparecer na 2ª intervenção e posteriormente foi incluída como 19. 


\section{Anexo B}

Medicações em uso dos pacientes da amostra portadores de SQTL (dosagem em mg/dia)

\begin{tabular}{|c|c|c|c|c|c|c|c|c|c|c|c|c|c|c|c|}
\hline $\begin{array}{l}\text { Randomi } \\
\text { zação }\end{array}$ & Propranolol & Nadolol & Enalapril & Captopril & Clonidina & Losartana & Anlodipino & $\begin{array}{c}\text { Hidrala } \\
\text { zina }\end{array}$ & $\begin{array}{l}\text { Hidrocloro } \\
\text { tiazida }\end{array}$ & $\begin{array}{l}\text { Espiron } \\
\text { olactona }\end{array}$ & Atorvastatina & $\begin{array}{l}\text { Sinvas } \\
\text { tatina }\end{array}$ & Omeprazol & Sertralina & Outros \\
\hline 2 & 80 & & 40 & & & & 10 & & & & 20 & & & & \\
\hline 7 & 180 & & 4 & & & & & & & & & 20 & 20 & & \\
\hline 12 & 160 & & 40 & & & & & & & 5 & & & 20 & & $\begin{array}{c}\text { metformina - 1700, } \\
\text { insulina } 10 \mathrm{UI}\end{array}$ \\
\hline 17 & 100 & & & & & & & & & & & & & & \\
\hline 19 & 320 & & 10 & & & & & & & & 20 & & & 50 & $\begin{array}{c}\text { diazepan - 10, } \\
\text { quetiapina - } 200\end{array}$ \\
\hline 20 & 120 & & & & & & & & & & & & & & \\
\hline 21 & 480 & & & 50 & & & & & 25 & & & & & & \\
\hline 22 & & 120 & & & & & & & & & 20 & & & & $\begin{array}{c}\text { lamotrigina - } 25, \\
\text { escitalopram - } 20 \text {, } \\
\text { carbonato de } \\
\text { magnésio - } 1000 \text {, } \\
\text { colecalciferol } \\
25000 U / \text { semana } \\
\end{array}$ \\
\hline 23 & 160 & & & & & & & & & & & & & & \\
\hline 24 & 120 & & & & & & & & & & & & & & \\
\hline 25 & 140 & & & & & & & & & & 20 & & 20 & & $\begin{array}{c}\text { budesoinida, } \\
\text { salbutamol, } \\
\text { montelucaste, } \\
\text { buspirona }\end{array}$ \\
\hline 26 & 320 & & & & & & & & & & & & & & \\
\hline 27 & 360 & & & & & & & & & & & & & & varfarina - 5 \\
\hline 29 & 240 & & & & & & & & & & & & & & \\
\hline 30 & 120 & & & & 0,2 & 100 & 10 & 150 & & & 40 & & 20 & & \\
\hline 32 & 120 & & & & & & & & & & 40 & & & 100 & \\
\hline
\end{tabular}




\section{Anexo B}

Medicações em uso dos pacientes da amostra portadores de $\mathrm{SBr}$ (dosagem em mg/dia)

\begin{tabular}{|c|c|c|c|c|c|c|c|c|c|c|c|c|c|c|c|}
\hline $\begin{array}{l}\text { Randomi } \\
\text { zação }\end{array}$ & Atenolol & Enalapril & $\begin{array}{c}\text { Clonidi } \\
\text { na }\end{array}$ & $\begin{array}{c}\text { Losarta } \\
\text { na }\end{array}$ & Anlodipino & $\begin{array}{l}\text { Hidrocloroti } \\
\text { azida }\end{array}$ & $\begin{array}{c}\text { Furose } \\
\text { mida }\end{array}$ & $\begin{array}{c}\text { Indapa } \\
\text { mida }\end{array}$ & $\begin{array}{c}\text { Cilosta } \\
\text { zol }\end{array}$ & Quinidina & $\begin{array}{c}\text { Atorvas } \\
\text { tatina }\end{array}$ & Sinvastatina & Omeprazol & Sertralina & Outros \\
\hline 3 & & & & & & & & & & & & & & & levotiroxina \\
\hline 4 & & & & & & & & & & & & & & & seretide \\
\hline 5 & & & & & & & & & & & & 20 & & & \\
\hline 6 & 25 & & & & & 25 & & & & & & & 20 & & \\
\hline 8 & & & & & & & & & & & & & & & \\
\hline 9 & & 40 & 0,1 & & 10 & & & & & & & & & & ciprofibrato \\
\hline 10 & & & & & & & & & & & & & & & anticoncepcional \\
\hline 11 & 100 & & & & & & & & 100 & & & & & & \\
\hline 13 & & & & 100 & 10 & 50 & 40 & & & & 20 & & 80 & & fluoxetina - 20 \\
\hline 14 & & & & & & & & & 200 & 600 & & & & & \\
\hline 15 & & & & & & & & & & 400 & & & 20 & 50 & \\
\hline 31 & & & & 50 & 2,5 & & & 2,5 & & & & & & & \\
\hline
\end{tabular}

Medicações em uso dos pacientes da amostra portadores de TVPC (dosagem em mg/dia)

\begin{tabular}{|c|c|c|c|c|c|c|}
\hline Randomização & Propranolol & Metoprolol & Propafenona & Losartana & Hidroclorotiazida & Sinvastatina \\
\hline 16 & & 200 & 300 & & & \\
\hline 18 & 240 & 300 & & & & \\
\hline 33 & 120 & & 300 & 100 & 50 & 20 \\
\hline
\end{tabular}




\section{REFERÊNCIAS}

1 Hasan B, Asif T, Hasan M. Lidocaine-Induced Systemic Toxicity: A Case Report and Review of Literature. Cureus. 2017;9(5):1275.

2 Malamed SF. Manual de anestesia local. Rio de Janeiro: Guanabara Koogan; 2013.

3 Naftalin LW, Yagiela JA. Vasoconstrictors: indications and precautions. Dental Clinics of North America. 2002;46(4):733-46.

4 Finder RL, Moore PA. Adverse drug reactions to local anesthesia. Dental Clinics of North America. 2002;46(4):747-57.

5 Neal JM, Bernards CM, Butterworth JFt, Di Gregorio G, Drasner K, Hejtmanek MR, Mulroy MF, Rosenquist RW, Weinberg GL. ASRA practice advisory on local anesthetic systemic toxicity. Reg Anesth Pain Med. 2010;35(2):152-61.

6 Groban L, Deal DD, Vernon JC, James RL, Butterworth J. Ventricular arrhythmias with or without programmed electrical stimulation after incremental overdosage with lidocaine, bupivacaine, levobupivacaine, and ropivacaine. Anesth Analg. 2000;91(5):1103-11.

7 Tierney KJ, Murano T, Natal B. Lidocaine-Induced Cardiac Arrest in the Emergency Department: Effectiveness of Lipid Therapy. The Journal of Emergency Medicine. 2016;50(1):47-50.

8 Pallasch TJ. Vasoconstrictors and the heart. J Calif Dent Assoc. 1998;26(9):668-73, 76.

9 Yagiela JA NE, Down FJ, editor. Farmacologia e terapêutica para dentistas. 4 ed. Rio de Janeiro: Guanabara Koogan; 2000.

10 Andrade E, editor. Terapêutica medicamentosa em Odontologia. 3 ed. São Paulo: Artes Médicas; 2014. 
11 Riemersma WA, Schuttelaar ML, Coenraads PJ. Type IV hypersensitivity to sodium metabisulfite in local anaesthetic. Contact dermatitis. 2004;51(3):148.

12 Araújo LMT, Amaral JLG. Alergia à lidocaína: relato de caso. Revista Brasileira de Anestesiologia. 2004;54:672-6.

13 Santos-Paul MA, Neves IL, Neves RS, Ramires JA. Local anesthesia with epinephrine is safe and effective for oral surgery in patients with type 2 diabetes mellitus and coronary disease: a prospective randomized study. Clinics (Sao Paulo). 2015;70(3):185-9.

14 Neves RS, Neves IL, Giorgi DM, Grupi CJ, Cesar LA, Hueb W, Grinberg M. Effects of epinephrine in local dental anesthesia in patients with coronary artery disease. Arq Bras Cardiol. 2007;88(5):545-51.

15 Neves IL, Avila WS, Neves RS, Giorgi DM, Santos JF, Oliveira Filho RM, Grupi CJ, Grinberg M, Ramires JA. Maternal-fetal monitoring during dental procedure in patients with heart valve disease. Arq Bras Cardiol. 2009;93(5):463-742.

16 Laragnoit AB, Neves RS, Neves IL, Vieira JE. Locoregional anesthesia for dental treatment in cardiac patients: a comparative study of $2 \%$ plain lidocaine and $2 \%$ lidocaine with epinephrine $(1: 100,000)$. Clinics (Sao Paulo). 2009;64(3):177-82.

17 Manani G, Facco E, Casiglia E, Cancian M, Zanette G. Isolated atrial fibrillation (IAF) after local anaesthesia with epinephrine in an anxious dental patient. Br Dent J. 2008;205(10):539-41.

18 Niwa H, Sugimura M, Satoh Y, Tanimoto A. Cardiovascular response to epinephrine-containing local anesthesia in patients with cardiovascular disease. Oral Surg Oral Med Oral Pathol Oral Radiol Endod. 2001;92(6):610-6. 
19 Takahashi Y, Nakano M, Sano K, Kanri T. The effects of epinephrine in local anesthetics on plasma catecholamine and hemodynamic responses. Odontology. 2005;93(1):72-9.

20 Lipp M, Dick W, Daublander M, Fuder H, Stanton-Hicks M. Exogenous and endogenous plasma levels of epinephrine during dental treatment under local anesthesia. Regional anesthesia. 1993;18(1):6-12.

21 Campbell RL, Langston WG. A comparison of cardiac rate-pressure product and pressure-rate quotient in healthy and medically compromised patients. Oral Surg Oral Med Oral Pathol Oral Radiol Endod. 1995;80(2):145-52.

22 Abu-Mostafa N, Aldawssary A, Assari A, Alnujaidy S, Almutlaq A. A prospective randomized clinical trial compared the effect of various types of local anesthetics cartridges on hypertensive patients during dental extraction. J Clin Exp Dent. 2015;7(1):84-8.

23 Hasse AL, Heng MK, Garrett NR. Blood pressure and electrocardiographic response to dental treatment with use of local anesthesia. J Am Dent Assoc. 1986;113(4):639-42.

24 Alemany-Martinez A, Valmaseda-Castellon E, Berini-Aytes L, GayEscoda C. Hemodynamic changes during the surgical removal of lower third molars. J Oral Maxillofac Surg. 2008;66(3):453-61.

25 Liau FL, Kok SH, Lee JJ, Kuo RC, Hwang CR, Yang PJ, Lin CP, Kuo YS, Chang $\mathrm{HH}$. Cardiovascular influence of dental anxiety during local anesthesia for tooth extraction. Oral Surg Oral Med Oral Pathol Oral Radiol Endod. 2008;105(1):16-26.

26 Ahmed MF, Elseed Al. The medical management and dental implications of long QT syndrome. Dent Update. 2005;32(8):472-4.

27 Rochford C, Seldin RD. Review and management of the dental patient with Long QT syndrome (LQTS). Anesth Prog. 2009;56(2):42-8. 
28 Jowett NI, Cabot LB. Patients with cardiac disease: considerations for the dental practitioner. Br Dent J. 2000;189(6):297-302.

29 Cerrone M, Priori SG. Genetics of sudden death: focus on inherited channelopathies. Eur Heart J. 2011;32(17):2109-18.

30 Mizusawa Y. Recent advances in genetic testing and counseling for inherited arrhythmias. J Arrhythm. 2016;32(5):389-97.

31 Bai R, Napolitano C, Bloise R, Monteforte N, Priori SG. Yield of genetic screening in inherited cardiac channelopathies: how to prioritize access to genetic testing. Circ Arrhythm Electrophysiol. 2009;2(1):6-15.

32 Kauferstein S, Kiehne N, Neumann T, Pitschner HF, Bratzke H. Cardiac gene defects can cause sudden cardiac death in young people. Dtsch Arztebl Int. 2009;106(4):41-7.

33 Semsarian C, Ingles J. Molecular autopsy in victims of inherited arrhythmias. J Arrhythm. 2016;32(5):359-65.

34 Priori SG, Blomstrom-Lundqvist C, Mazzanti A, Blom N, Borggrefe M, Camm J, Elliott PM, Fitzsimons D, Hatala R, Hindricks G, Kirchhof $P$, Kjeldsen K, Kuck KH, Hernandez-Madrid A, Nikolaou N, Norekval TM, Spaulding C, Van Veldhuisen DJ. [2015 ESC Guidelines for the management of patients with ventricular arrhythmias and the prevention of sudden cardiac Death. The Task Force for the Management of Patients with Ventricular Arrhythmias and the Prevention of Sudden Cardiac Death of the European Society of Cardiology]. G Ital Cardiol (Rome). 2016;17(2):108-70.

35 Schwartz PJ, Stramba-Badiale M, Crotti L, Pedrazzini M, Besana A, Bosi G, Gabbarini F, Goulene K, Insolia R, Mannarino S, Mosca F, Nespoli L, Rimini A, Rosati E, Salice P, Spazzolini C. Prevalence of the congenital long-QT syndrome. Circulation. 2009;120(18):1761-7.

36 Jackson H, Huisman LA, Sanatani S, Arbour LT. Long QT syndrome. CMAJ. 2011;183(11):1272-5. 
37 Antzelevitch C. Role of spatial dispersion of repolarization in inherited and acquired sudden cardiac death syndromes. Am J Physiol Heart Circ Physiol. 2007;293(4):H2024-38.

38 Napolitano C, Bloise R, Monteforte N, Priori SG. Sudden cardiac death and genetic ion channelopathies: long QT, Brugada, short QT, catecholaminergic polymorphic ventricular tachycardia, and idiopathic ventricular fibrillation. Circulation. 2012;125(16):2027-34.

39 Ruan Y, Liu N, Napolitano C, Priori SG. Therapeutic strategies for longQT syndrome: does the molecular substrate matter? Circ Arrhythm Electrophysiol. 2008;1(4):290-7.

40 Brink PA, Schwartz PJ. Of founder populations, long QT syndrome, and destiny. Heart rhythm. 2009;6(11 Suppl):25-33 .

41 Meyer JS, Mehdirad A, Salem BI, Kulikowska A, Kulikowski P. Sudden arrhythmia death syndrome: importance of the long QT syndrome. Am Fam Physician. 2003;68(3):483-8.

42 Schwartz PJ, Moss AJ, Vincent GM, Crampton RS. Diagnostic criteria for the long QT syndrome. An update. Circulation. 1993;88(2):782-4.

43 Ackerman MJ, Khositseth A, Tester DJ, Hejlik JB, Shen WK, Porter CB. Epinephrine-induced QT interval prolongation: a gene-specific paradoxical response in congenital long QT syndrome. Mayo Clin Proc. 2002;77(5):413-21.

44 Brugada P, Brugada J. Right bundle branch block, persistent ST segment elevation and sudden cardiac death: a distinct clinical and electrocardiographic syndrome. A multicenter report. J Am Coll Cardiol. 1992;20(6):1391-6.

45 Satish OS, Yeh KH, Wen MS. Brugada syndrome - an update. Chang Gung Med J. 2005;28(2):69-76.

46 Benito B, Brugada J, Brugada R, Brugada P. Brugada syndrome. Rev Esp Cardiol. 2009;62(11):1297-315. 
47 Matsuo K, Akahoshi M, Seto S, Yano K. Disappearance of the Brugadatype electrocardiogram after surgical castration: a role for testosterone and an explanation for the male preponderance. Pacing Clin Electrophysiol. 2003;26(7 Pt 1):1551-3.

48 Paparella G, Sarkozy A, Brugada P. Brugada syndrome: the prognostic dilemma and value of sincope. Minerva Med. 2009;100(4):307-19.

49 Chen Q, Kirsch GE, Zhang D, Brugada R, Brugada J, Brugada P, Potenza D, Moya A, Borggrefe M, Breithardt G, Ortiz-Lopez R, Wang Z, Antzelevitch C, O'Brien RE, Schulze-Bahr E, Keating MT, Towbin JA, Wang Q. Genetic basis and molecular mechanism for idiopathic ventricular fibrillation. Nature. 1998;392(6673):293-6.

50 Hedley PL, Jorgensen P, Schlamowitz S, Moolman-Smook J, Kanters JK, Corfield VA, Christiansen M. The genetic basis of Brugada syndrome: a mutation update. Hum Mutat. 2009;30(9):1256-66.

51 Ackerman MJ, Priori SG, Willems S, Berul C, Brugada R, Calkins H, Camm AJ, Ellinor PT, Gollob M, Hamilton R, Hershberger RE, Judge DP, Le Marec H, McKenna WJ, Schulze-Bahr E, Semsarian C, Towbin JA, Watkins H, Wilde A, Wolpert C, Zipes DP. HRS/EHRA expert consensus statement on the state of genetic testing for the channelopathies and cardiomyopathies: this document was developed as a partnership between the Heart Rhythm Society (HRS) and the European Heart Rhythm Association (EHRA). Europace. 2011;13(8):1077-109.

52 Matsuo K, Kurita T, Inagaki M, Kakishita M, Aihara N, Shimizu W, Taguchi A, Suyama K, Kamakura S, Shimomura K. The circadian pattern of the development of ventricular fibrillation in patients with Brugada syndrome. Eur Heart J. 1999;20(6):465-70.

53 Patane S, Marte F, La Rosa FC, Albanese A, La Rocca R, Villari SA. Revelation of Brugada electrocardiographic pattern during a febrile state. Int J Cardiol. 2010;140(1):e19-21. 
54 Siniorakis E, Arvanitakis S, Psatheris G, Marinakis N, Papadopoulos I, Exadactylos N. Recurrence of fever-related Brugada pattern and right ventricular functional correlates. Int J Cardiol. 2010.

55 Kurisu S, Inoue I, Kawagoe T, Ishihara M, Shimatani Y, Nakama Y, Maruhashi T, Kagawa E, Dai K, Aokage T, Matsushita J, Ikenaga H. Therapeutic hypothermia after out-of-hospital cardiac arrest due to Brugada syndrome. Resuscitation. 2008;79(2):332-5.

56 Wakita R, Watanabe I, Okumura Y, Yamada T, Takagi Y, Kofune T, Okubo K, Masaki R, Sugimura H, Oshikawa N, Saito S, Ozawa Y, Kanmatsuse K. Brugada-like electrocardiographic pattern unmasked by fever. Jpn Heart J. 2004;45(1):163-7.

57 Brugada P. Brugada syndrome: More than 20 years of scientific excitement. J Cardiol. 2016;67(3):215-20.

58 Vohra J, Rajagopalan S. Update on the Diagnosis and Management of Brugada Syndrome. Heart Lung Circ. 2015;24(12):1141-8.

59 Sahinkaya HH, Yasar E, Tekgul ZT, Horsanali BO, Ozeroglu E. Anaesthetic Management of a Patient with Brugada Syndrome. Turk J Anaesthesiol Reanim. 2016;44(2):96-8.

60 Priori SG, Wilde AA, Horie M, Cho Y, Behr ER, Berul C, Blom N, Brugada J, Chiang CE, Huikuri H, Kannankeril P, Krahn A, Leenhardt A, Moss A, Schwartz PJ, Shimizu W, Tomaselli G, Tracy C, Ackerman M, Belhassen B, Estes NA, 3rd, Fatkin D, Kalman J, Kaufman E, Kirchhof P, Schulze-Bahr E, Wolpert C, Vohra J, Refaat M, Etheridge SP, Campbell RM, Martin ET, Quek SC. Executive summary: HRS/EHRA/APHRS expert consensus statement on the diagnosis and management of patients with inherited primary arrhythmia syndromes. Europace. 2013;15(10):1389-406.

61 Reid DS, Tynan M, Braidwood L, Fitzgerald GR. Bidirectional tachycardia in a child. A study using His bundle electrography. $\mathrm{Br}$ Heart J. 1975;37(3):339-44. 
62 Leenhardt A, Denjoy I, Guicheney P. Catecholaminergic polymorphic ventricular tachycardia. Circ Arrhythm Electrophysiol. 2012;5(5):1044-52.

63 Lee SY, Kim JB, Im E, Yang WI, Joung B, Lee MH, Kim SS. A case of catecholaminergic polymorphic ventricular tachycardia. Yonsei Med J. 2009;50(3):448-51.

64 Napolitano C, Priori SG, Bloise R. Catecholaminergic Polymorphic Ventricular Tachycardia. In: Pagon RA, Adam MP, Ardinger HH, Wallace SE, Amemiya A, Bean LJH, Bird TD, Ledbetter N, Mefford HC, Smith RJH, Stephens K, editors. GeneReviews(R). Seattle (WA)1993.

65 Leenhardt A, Lucet V, Denjoy I, Grau F, Ngoc DD, Coumel P. Catecholaminergic polymorphic ventricular tachycardia in children. A 7year follow-up of 21 patients. Circulation. 1995;91(5):1512-9.

66 Priori SG, Napolitano C, Tiso N, Memmi M, Vignati G, Bloise R, Sorrentino V, Danieli GA. Mutations in the cardiac ryanodine receptor gene (hRyR2) underlie catecholaminergic polymorphic ventricular tachycardia. Circulation. 2001;103(2):196-200.

67 Sumitomo N. Current topics in catecholaminergic polymorphic ventricular tachycardia. J Arrhythm. 2016;32(5):344-51.

68 Imberti JF, Underwood K, Mazzanti A, Priori SG. Clinical Challenges in Catecholaminergic Polymorphic Ventricular Tachycardia. Heart Lung Circ. 2016;25(8):777-83.

69 Hoefman E, Bindels PJ, van Weert HC. Efficacy of diagnostic tools for detecting cardiac arrhythmias: systematic literature search. Neth Heart J. 2010;18(11):543-51.

70 Steinberg JS, Varma N, Cygankiewicz I, Aziz P, Balsam P, Baranchuk A, Cantillon DJ, Dilaveris P, Dubner SJ, El-Sherif N, Krol J, Kurpesa M, La Rovere MT, Lobodzinski SS, Locati ET, Mittal S, Olshansky B, Piotrowicz E, Saxon L, Stone PH, Tereshchenko L, Turitto G, Wimmer NJ, Verrier RL, Zareba W, Piotrowicz R. 2017 ISHNE-HRS expert consensus 
statement on ambulatory ECG and external cardiac monitoring/telemetry. Heart rhythm. 2017;14(7):e55-e96.

71 Monteforte N, Napolitano C, Priori SG. Genetics and arrhythmias: diagnostic and prognostic applications. Rev Esp Cardiol (Engl Ed). 2012;65(3):278-86.

72 Ernesto C, Cruz FE, Lima FS, Coutinho JL, Silva R, Urmenyi TP, Carvalho AC, Rondinelli E. Investigation of ion channel gene variants in patients with long QT syndrome. Arq Bras Cardiol. 2011;96(3):172-8.

73 Campuzano O, Sarquella-Brugada G, Brugada R, Brugada J. Genetics of channelopathies associated with sudden cardiac death. Glob Cardiol Sci Pract. 2015;2015(3):39.

74 Antzelevitch C, Patocskai B. Brugada Syndrome: Clinical, Genetic, Molecular, Cellular, and lonic Aspects. Curr Probl Cardiol. 2016;41(1):757.

75 Hofman N, Tan HL, Alders M, Kolder I, de Haij S, Mannens MM, Lombardi MP, Dit Deprez RH, van Langen I, Wilde AA. Yield of molecular and clinical testing for arrhythmia syndromes: report of 15 years' experience. Circulation. 2013;128(14):1513-21.

76 Lieve KV, Wilde AA. Inherited ion channel diseases: a brief review. Europace. 2015;17 Suppl 2:ii1-6.

77 Tomaselli GF, Barth AS. Ion Channel Diseases: an Update for 2016. Curr Treat Options Cardiovasc Med. 2016;18(3):21.

78 Wynn RL. Articaine 4\% with 1:200,000 epinephrine: an acceptable option for patients with long QT syndrome. Gen Dent. 2007;55(3):176-8.

79 Theodotou N, Cillo JE, Jr. Brugada syndrome (sudden unexpected death syndrome): perioperative and anesthetic management in oral and maxillofacial surgery. J Oral Maxillofac Surg. 2009;67(9):2021-5. 
80 Olufunke Adewumi A, Grace Tucker L. Dental management of a patient with catecholaminergic polymorphic ventricular tachycardia: a case report. J Dent Child (Chic). 2013;80(2):101-4.

81 Liu C, Zhao L, Tang H, Li Q, Wei S, Li J. Life-threatening false alarm rejection in ICU: using the rule-based and multi-channel information fusion method. Physiol Meas. 2016;37(8):1298-312.

82 Council on Clinical Affairs AAPD. Guideline on Use of Local Anesthesia for Pediatric Dental Patients. Pediatric dentistry. 2015;37(5):71-7.

83 Mount GJ, Hume WR. A new cavity classification. Australian dental journal. 1998;43(3):153-9.

84 Costa SM, Vasconcelos M, Abreu MH. [Impact of dental caries on quality of life among adults resident in greater Belo Horizonte, State of Minas Gerais, Brazil]. Ciencia \& saude coletiva. 2013;18(7):1971-80.

85 Malamed S, editor. Manual de anestesia local. 4 ed. Rio de Janeiro: Guanabara Koogan; 2001.

86 Caceres MT, Ludovice AC, Brito FS, Darrieux FC, Neves RS, Scanavacca MI, Sosa EA, Hachul DT. Effect of local anesthetics with and without vasoconstrictor agent in patients with ventricular arrhythmias. Arq Bras Cardiol. 2008;91(3):142-7.

87 Postema PG, Wilde AA. The measurement of the QT interval. Curr Cardiol Rev. 2014;10(3):287-94.

88 Al-Khatib SM, LaPointe NM, Kramer JM, Califf RM. What clinicians should know about the QT interval. Jama. 2003;289(16):2120-7.

89 Palatini P, Dorigatti F, Bonso E, Ragazzo F. Validation of Microlife BP W100 wrist device assessed according to the European Society of Hypertension and the British Hypertension Society protocols. Blood pressure monitoring. 2009;14(1):41-4. 
90 Buchanan $\mathrm{H}$, Niven N. Validation of a Facial Image Scale to assess child dental anxiety. Int J Paediatr Dent. 2002;12(1):47-52.

91 Kirkwood BR, Sterne JAC. Essential medical statistics. $2^{\underline{a}}$ ed. Massachusetts, USA. 2006.

92 Figallo MAS, Cayon RTV, Lagares DT, Flores JRC, Portillo GM. Use of anesthetics associated to vasoconstrictors for dentistry in patients with cardiopathies. Review of the literature published in the last decade. $\mathrm{J}$ Clin Exp Dent. 2012;4(2):107-11.

93 Blinder D, Manor Y, Shemesh J, Taicher S. Electrocardiographic changes in cardiac patients having dental extractions under a local anesthetic containing a vasopressor. J Oral Maxillofac Surg. 1998;56(12):1399-402.

94 Blinder D, Shemesh J, Taicher S. Electrocardiographic changes in cardiac patients undergoing dental extractions under local anesthesia. J Oral Maxillofac Surg. 1996;54(2):162-5.

95 Owczuk R, Wujtewicz MA, Sawicka W, Piankowski A, Polak-Krzeminska A, Morzuch E, Wujtewicz M. The effect of intravenous lidocaine on QT changes during tracheal intubation. Anaesthesia. 2008;63(9):924-31.

96 Matsumura K, Miura K, Takata Y, Kurokawa H, Kajiyama M, Abe I, Fujishima M. Changes in blood pressure and heart rate variability during dental surgery. Am J Hypertens. 1998;11(11 Pt 1):1376-80.

97 Bouloux GF, Punnia-Moorthy A. Bupivacaine versus lidocaine for third molar surgery: a double-blind, randomized, crossover study. J Oral Maxillofac Surg. 1999;57(5):510-4; discussion 5.

98 Lagares DT, Figallo MAS, Portillo GM, Flores JRC, Portillo CM, Oyague RC, Perez JLG. Cardiovascular effect of dental anesthesia with articaine (40 $\mathrm{mg}$ with epinefrine $0,5 \mathrm{mg} \%$ and $40 \mathrm{mg}$ with epinefrine $1 \mathrm{mg} \%$ ) versus mepivacaine (30 $\mathrm{mg}$ and $20 \mathrm{mg}$ with epinefrine $1 \mathrm{mg} \%$ ) in medically compromised cardiac patients: a cross-over, randomized, 
single blinded study. Medicina oral, patologia oral y cirugia bucal. 2012;17(4):655-60.

99 Caceres MT, Ludovice AC, Brito FS, Darrieux FC, Neves RS, Scanavacca MI, Sosa EA, Hachul DT. Effect of local anesthetics with and without vasoconstrictor agent in patients with ventricular arrhythmias. Arq Bras Cardiol. 2008;91(3):128-33, 42-7.

100 Conrado VC, de Andrade J, de Angelis GA, de Andrade AC, Timerman L, Andrade MM, Moreira DR, Sousa AG, Sousa JE, Piegas LS. Cardiovascular effects of local anesthesia with vasoconstrictor during dental extraction in coronary patients. Arq Bras Cardiol. 2007;88(5):50713.

101 Perusse R, Goulet JP, Turcotte JY. Contraindications to vasoconstrictors in dentistry: Part I. Cardiovascular diseases. Oral Surg Oral Med Oral Pathol. 1992;74(5):679-86.

102 Hughes CL, Leach JK, Allen RE, Lambson GO. Cardiac arrhythmias during oral surgery with local anesthesia. J Am Dent Assoc. 1966;73(5):1095-102.

103 Yagiela JA. Adverse drug interactions in dental practice: interactions associated with vasoconstrictors. Part $V$ of a series. J Am Dent Assoc. 1999;130(5):701-9.

104 Hersh EV, Giannakopoulos H. Beta-adrenergic blocking agents and dental vasoconstrictors. Dental clinics of North America. 2010;54(4):68796.

105 Middlehurst RJ, Gibbs A, Walton G. Cardiovascular risk: the safety of local anesthesia, vasoconstrictors, and sedation in heart disease. Anesth Prog. 1999;46(4):118-23.

106 Karp JM, Ganoza GG. Dental trauma after cardiac syncope in a patient with long QT syndrome. Pediatric dentistry. 2006;28(6):547-52. 
107 Karp JM, Moss AJ. Dental treatment of patients with long QT syndrome. J Am Dent Assoc. 2006;137(5):630-7.

108 Chapman PJ, Penkeyman HW. Successful defibrillation of a dental patient in cardiac arrest. Australian Dental Journal. 2002;47(2):176-7.

109 Manoharan G, Moohan V, Adgey J. Ventricular fibrillation in a 12-yearold boy recovering from dental anaesthesia. Int J Cardiol. 2001;81(23):271-3.

110 Fujiki A, Nishida K, Mizumaki K, Nagasawa H, Shimono M, Inoue H. Spontaneous onset of torsade de pointes in long-QT syndrome and the role of sympathovagal imbalance. Jpn Circ J. 2001;65(12):1087-90.

111 ASJr. M, Moreira HG, Daher MT. Analysis of heart rate variability in hypertensive patients before and after treatment with angiotensin IIconverting enzyme inhibitors. Arq Bras Cardiol. 2004;83(2):169-72; 5-8.

112 Rood JP. Adverse reaction to dental local anaesthetic injection--'allergy' is not the cause. Br Dent J. 2000;189(7):380-4.

113 Brand HS, Bekker W, Baart JA. Complications of local anaesthesia. An observational study. Int J Dent Hyg. 2009;7(4):270-2.

114 Tsuchihashi T, Takata Y, Kurokawa H, Miura K, Maruoka Y, Kajiyama M, Fujishima M. Blood pressure response during dental surgery. Hypertens Res. 1996;19(3):189-94.

115 Nakamura Y, Matsumura K, Miura K, Kurokawa H, Abe I, Takata Y. Cardiovascular and sympathetic responses to dental surgery with local anesthesia. Hypertens Res. 2001;24(3):209-14.

116 Lopez-Jornet P, Camacho-Alonso F, Sanchez-Siles M. Assessment of general pre and postoperative anxiety in patients undergoing tooth extraction: a prospective study. The British journal of oral \& maxillofacial surgery. 2014;52(1):18-23. 


\section{Hospital das Clínicas da FMUSP}

Comissão de Ética para Análise de Projetos de Pesquisa - CAPPesq

Considerações Finais a critério do CEP:: Em conformidade com a Resolução CNS no 466/12 - cabe ao pesquisador: a) desenvolver o projeto conforme delineado; b) elaborar e apresentar relatórios parciais e final; c)apresentar dados solicitados pelo CEP, a qualquer momento; d) manter em arquivo sob sua guarda, por 5 anos da pesquisa, contendo fichas individuais e todos os demais documentos recomendados pelo CEP; e) encaminhar os resultados para publicação, com os devidos créditos aos pesquisadores associados e ao pessoal técnico participante do projeto; f) justificar perante ao CEP interrupção do projeto ou a não publicação dos resultados

São Paulo, 23 de Fevereiro de 2015

$$
\text { Aupduaumu }
$$

Coordenador

Comissão de Ética para Análise de

Projetos de Pesquisa - CAPPesq 


\section{Processo}

\section{Identificação do Processo}

\begin{tabular}{|ll|}
\hline Número do Processo & $2013 / 24283-1$ - Projeto de Pesquisa - Regular \\
Situação & Em Execução \\
Grupo de Financiamento & Auxílio à Pesquisa \\
Linha de Fomento & Programas Regulares / Auxílios a Pesquisa / Projeto de Pesquisa / Projeto \\
Beneficiário & de Pesquisa - Regular - Fluxo Contínuo. \\
Responsável & Francisco Carlos da Costa Darrieux \\
Data Início & Francisco Carlos da Costa Darrieux \\
Duração & $01 / 06 / 2015$ \\
\hline
\end{tabular}

Instituição de Pesquisa/Empresa Instituto do Coração do Hospital das Clínicas de São Paulo/INCOR/SSSP Departamento Unidade Clínica de Arritmia e Marcapasso

Data de Abertura

$25 / 11 / 2013$

Processos Relacionados

Nenhum processo relacionado cadastrado

Projeto - Identificação

\section{Título em Português}

Efeitos da anestesia local odontológica com adrenalina em portadores de canalopatias cardíacas

Título em Inglês

Effects of dental local anesthesia with epinephrine in patients with cardiac channelopathies

\section{Classificação}

Grande Área Ciências da Saúde

Área Odontologia

Sub-área Clinica Odontológica

Especialidade Pacientes com Necessidades Especiais - Odontologia Hospitalar

\begin{tabular}{ll}
\hline Palavras-chave & $\begin{array}{l}\text { Anestesia local, Arritmias cardíacas, canalopatias, monitorização Holter, Odontologia, } \\
\text { Testes Genéticos }\end{array}$
\end{tabular}

\section{Projeto - Instituições}

Instituição de Pesquisa/Empresa Principal

Nome

Instituto do Coração do Hospital das Clínicas de São Paulo/INCOR/SSSP

\section{Projeto - Pessoas Envolvidas}

Equipe

\begin{tabular}{|c|c|c|c|c|}
\hline Nome & Função & $\begin{array}{c}\text { Horas } \\
\text { Semanais } \\
\text { Dedicadas } \\
\text { ao Projeto }\end{array}$ & Vigência & Vínculo Principal \\
\hline $\begin{array}{l}\text { Francisco Carlos da Costa } \\
\text { Darrieux }\end{array}$ & $\begin{array}{l}\text { Pesquisador } \\
\text { Responsável * }\end{array}$ & 20 & $\begin{array}{c}01 / 06 / 2015 a \\
31 / 05 / 2017\end{array}$ & $\begin{array}{l}\text { Instituto do Coração do } \\
\text { Hospital das Clínicas de } \\
\text { São Paulo/INCOR/SSSP }\end{array}$ \\
\hline $\begin{array}{l}\text { Ana Carolina Guimarães } \\
\text { Oliveira }\end{array}$ & $\begin{array}{l}\text { Pesquisador } \\
\text { Associado }\end{array}$ & 40 & $\begin{array}{c}01 / 06 / 2015 a \\
31 / 05 / 2017\end{array}$ & \\
\hline Itamara Lucia Itagiba Neves & $\begin{array}{l}\text { Pesquisador } \\
\text { Associado }\end{array}$ & 8 & $\begin{array}{c}01 / 06 / 2015 a \\
31 / 05 / 2017\end{array}$ & $\begin{array}{l}\text { Instituto do Coração do } \\
\text { Hospital das Clínicas de }\end{array}$ \\
\hline
\end{tabular}

http://internet.caph.fapesp.br/SAGe_WEB/printProcess.do?method=printProcess\&popup=true\&abstractProcessld=149743\&org.apache.struts.taglib.htm।.T ... 1/17 


\section{APÊNDICE, Termo de Consentimento Livre e Esclarecido}

TERMO DE CONSENTIMENTO LIVRE E ESCLARECIDO

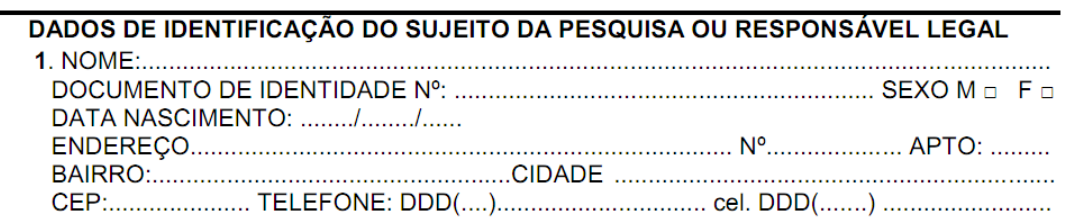

2.RESPONSÁVEL LEGAL

NATUREZA (grau de parentesco, tutor, curador etc.)

DOCUMENTO DE IDENTIDADE

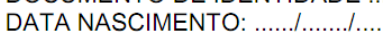

ENDEREÇO

BAIRRO

TELEFONE: DDD (

SEXO: $M \square F \square$

CEP:.

$N^{\circ}$

APTO :

.

\section{DADOS SOBRE A PESQUISA}

TÍTULO DO PROTOCOLO DE PESQUISA: Aspectos de segurança da anestesia local odontológica em portadores de canalopatias cardíacas

DADOS DO PESQUISADOR EXECUTANTE:

PESQUISADOR: Ana Carolina Guimarães Oliveira

CARGO/FUNÇÃO: Pesquisadora Colaboradora INSCRIÇÃO CONSELHO REGIONAL N CROSP 95859 UNIDADE DO HCFMUSP: Unidade de Odontologia do Instituto do Coração

\section{DADOS DO PESQUISADOR RESPONSÁVEL:}

PESQUISADOR: Francisco Carlos da Costa Darrieux

CARGO/FUNÇÃO: Médico Assistente INSCRIÇÃO CONSELHO REGIONAL: CRMSP 60587

UNIDADE DO HCFMUSP: Unidade Clínica de Arritmia e Marcapasso do Instituto do Coração

AVALIAÇÃO DO RISCO DA PESQUISA:

RISCO MÍNIMO $\boldsymbol{\otimes} \quad$ RISCO MÉDIO $\quad \square \quad$ RISCO BAIXO $\square \quad$ RISCOMAIOR

DURAÇÃO DA PESQUISA: 24 meses

\section{1 - Desenho do estudo e objetivo}

Você está sendo convidado (a) a participar deste estudo por apresentar um tipo específico de arritmia no coração e necessitar de restauração em algum dente. Antes de decidir se fará parte 
deste estudo, leia atentamente este Termo de Consentimento. O objetivo desta pesquisa é observar o que ocorre com seu batimento cardiaco depois de tomar anestesia dentária para a restauração do dente. Se você concordar em participar, faremos avaliação clínica e radiográfica de sua boca, daremos orientação de como higienizá-la adequadamente para prevenir as cáries dentárias e as doenças da gengiva e realizaremos tratamento odontológico restaurador registrando seu batimento cardiaco.

2 - Descrição dos procedimentos que serão realizados, com seus propósitos e identificação dos que forem experimentais e não rotineiros

Se você concordar em participar, a restauração do seu dente será realizada com anestesia para remoção da cárie ou da restauração antiga e preenchimento do dente com material apropriado, com a diferença de que o procedimento será realizado sob monitorização do ritmo do seu coração. Para tanto, instalaremos um aparelho que registrará seu eletrocardiograma por 28 horas (Holter), instalado no dia do procedimento e retirado no dia seguinte. E verificaremos sua pressão arterial e faremos eletrocardiograma comum em três momentos diferentes durante o procedimento odontológico.

\section{3 - Relação dos procedimentos rotineiros e como são realizados}

Inicialmente vamos examinar sua boca, daremos orientação de higiene bucal correta e solicitaremos uma radiografia dos seus dentes que será feita no Instituto de Radiologia. Em uma próxima sessão, instalaremos um aparelho chamado Holter que registrará o seu eletrocardiograma durante 28 horas. Após instalado o equipamento, você deverá permanecer sentado na sala de espera por uma hora. Em seguida, já no consultório odontológico, aplicaremos uma anestesia local, usada normalmente pelo dentista, para realizarmos uma restauração dentária. No seu próximo retorno, faremos tudo da mesma forma como acabamos de descrever, porém, aplicaremos outro tipo de anestesia local que também é normalmente usada pelos dentistas. Os procedimentos serão realizados no consultório odontológico da Unidade de Odontologia do InCor e não terão nenhum custo para você.

\section{4 - Descrição dos desconfortos e riscos esperados nos procedimentos dos itens 2 e 3}

O desconforto do procedimento será mínimo, pois a anestesia impede que você sinta dor durante a execução da restauração dentária. $O$ anestésico e a quantidade que utilizaremos apresentam risco mínimo para pacientes portadores de doenças cardiacas. A instalação e permanência do aparelho de Holter poderá causar algum desconforto. Caso você venha a sentir algum mal-estar, a equipe estará atenta para interromper o procedimento.

\section{5 - Benefícios para o participante}

Você terá como beneficios a realização do tratamento odontológico, orientação de higiene bucal e esclarecimentos de dúvidas quanto à saúde bucal de forma segura e planejada. Serão realizados procedimentos oferecidos pela Unidade de Odontologia: exodontia, restauração, endodontia e periodontia. Ao término do tratamento, daremos alta da Odontologia do InCor a 
você, sendo que as consultas posteriores deverão ser feitas em serviço externo de sua preferência.

6 - Relação de procedimentos alternativos que possam ser vantajosos, pelos quais o paciente pode optar.

Não existem opções alternativas para tratamento da cárie dentária que não seja restauração.

\section{7 - Garantia de acesso}

Em qualquer etapa do estudo, você terá acesso aos profissionais responsáveis pela pesquisa para esclarecimento de eventuais dúvidas. O principal investigador é Dr. Francisco Carlos da Costa Darrieux, que pode ser encontrado na Unidade Clínica de Arritmia e Marcapasso do Instituto do Coração do HCFMUSP; Telefone: (11) 2661-5341. Se houver alguma consideração ou dúvida sobre a ética da pesquisa, entre em contato com o Comitê de Ética em Pesquisa (CEP) - Rua Ovídio Pires de Campos, 225 - $5^{\circ}$ andar, tel 2661-6442 ramais 16, 17, 18 ou 20, FAX: 2661-6442 ramal 26 - E-mail: cappesq@hcnet.usp.br.

\section{8 - Retirando o Consentimento}

É garantida a liberdade da retirada de consentimento a qualquer momento e deixar de participar do estudo, sem qualquer prejuizo à continuidade de seu tratamento na Instituição.

\section{9 - Direito de confidencialidade}

As informações obtidas serão analisadas em conjunto com outros pacientes, não sendo divulgada a identificação de nenhum paciente. Você tem direito de ser mantido atualizado sobre os resultados parciais da pesquisa, quando em estudos abertos, ou de resultados que sejam do conhecimento dos pesquisadores.

\section{0 - Despesas e compensações}

Não há despesas pessoais para o participante em qualquer fase do estudo, incluindo exames e consultas. Também não há compensação financeira relacionada à sua participação. Em caso de dano pessoal diretamente causado pelos procedimentos ou tratamentos propostos neste estudo (nexo causal comprovado), o participante tem direito a tratamento médico na Instituição, bem como às indenizações legalmente estabelecidas.

11 - Compromisso do pesquisador de utilizar os dados e material coletado somente para pesquisa

Os dados referentes à pesquisa descrita serão utilizados somente para fins acadêmicos, descritos nesse termo e com o seu consentimento, de forma ética e moral sem outros interesses. Se utilizados no futuro para fins de outra pesquisa, da mesma forma terá a identidade preservada. 
Acredito ter sido suficientemente informado a respeito das informações que li ou que foram lidas para mim, descrevendo o estudo: Aspectos de segurança da anestesia local odontológica em portadores de canalopatias cardíacas.

Discuti com Dr. Francisco Carlos da Costa Darrieux e Ana Carolina Guimarães Oliveira sobre minha decisão em participar nesse estudo. Ficaram claros para mim: os propósitos do estudo, os procedimentos a serem realizados, seus desconfortos e riscos, as garantias de confidencialidade e de esclarecimentos permanentes. Ficou claro também que minha participação é isenta de despesas e que tenho garantia do acesso ao tratamento hospitalar quando necessário. Concordo voluntariamente em participar deste estudo e poderei retirar meu consentimento a qualquer momento, antes ou durante o mesmo, sem penalidades, prejuizo ou perda de qualquer benefício que eu possa ter adquirido no meu atendimento neste serviço.

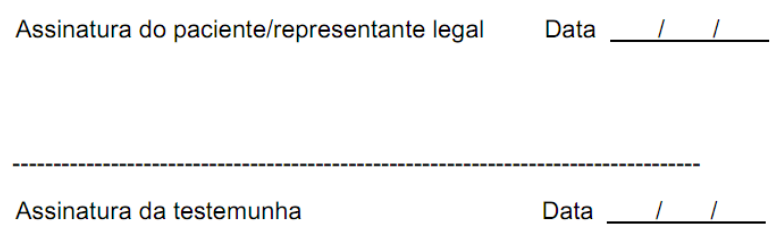

Para casos de pacientes menores de 18 anos, analfabetos, semi-analfabetos ou portadores de deficiência auditiva ou visual.

Declaro que obtive de forma apropriada e voluntária o Consentimento Livre e Esclarecido deste paciente ou representante legal para a participação neste estudo. 
APÊNDICE, Ficha clínica

FICHA CLÍNICA N

Data:

\section{I- ANAMNESE}

Nome:

Endereço:

Telefones:

Sexo:

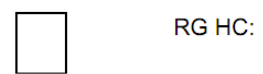

Data do nascimento:

1 1 Idade:

Naturalidade:

UF:

Tipo de canalopatia:

$\square$ sв

$\square$ SQTL

$\square$ TVPC

CDI（ )

Medicamentos em uso:

Comorbidades:

Alergias a medicamentos

$\square$ s

$\square$ N

Se sim, quais:

Peso:

$\mathrm{Kg}$

Altura:

m

IMC:

\section{II - AVALIAÇÃO RADIOGRÁFICA}

Radiografia: $\square$ Panorâmica $\square$ Periapical

\section{III - EXAME CLÍNICO}

Rápido perfil periodontal:

\begin{tabular}{|c|c|c|c|c|c|c|c|c|}
\hline \multicolumn{2}{|c|}{ Gengivite } & \multicolumn{2}{c|}{ Cálculo periodontal } & \multicolumn{2}{c|}{ Doença periodontal } & \multicolumn{3}{c|}{ Higiene bucal } \\
\hline $\operatorname{sim}$ & não & $\operatorname{sim}$ & não & $\operatorname{sim}$ & não & ruim & razoável & boa \\
\hline & & & & & & & & \\
\hline
\end{tabular}


ÍNDICE CPO-D=

No de dentes: $\square$ cariados $\square$ perdidos $\square$ obturados

\begin{tabular}{|c|c|c|c|c|c|c|c|c|c|c|c|c|c|c|c|c|c|}
\hline & 18 & 17 & 16 & 15 & 14 & 13 & 12 & 11 & 21 & 22 & 23 & 24 & 25 & 26 & 27 & 28 & SOMA \\
\hline C & & & & & & & & & & & & & & & & & \\
\hline$P$ & & & & & & & & & & & & & & & & & \\
\hline 0 & & & & & & & & & & & & & & & & & \\
\hline & & & & & & & & & & & & & & & & & \\
\hline A & & & & & & & & & & & & & & & & & \\
\hline $\mathrm{H}$ & & & & & & & & & & & & & & & & & \\
\hline
\end{tabular}

\begin{tabular}{|l|l|l|l|l|l|l|l|l|l|l|l|l|l|l|l|l|l|}
\hline & 48 & 47 & 46 & 45 & 44 & 43 & 42 & 41 & 31 & 32 & 33 & 34 & 35 & 36 & 37 & 38 & SOMA \\
\hline $\mathrm{C}$ & & & & & & & & & & & & & & & & & \\
\hline $\mathrm{P}$ & & & & & & & & & & & & & & & & & \\
\hline O & & & & & & & & & & & & & & & & & \\
\hline & & & & & & & & & & & & & & & & & \\
\hline A & & & & & & & & & & & & & & & & & \\
\hline $\mathrm{H}$ & & & & & & & & & & & & & & & & & \\
\hline
\end{tabular}

\section{IV - ANOTAÇÕES DE HORÁRIOS, PASSOS E SINTOMAS}

Condição 1

\begin{tabular}{|c|c|c|c|c|c|c|c|c|}
\hline \multirow{2}{*}{$\begin{array}{c}\text { Data do } \\
\text { proced. }\end{array}$} & \multicolumn{2}{|c|}{ Horário dos períodos de estudo } \\
\cline { 2 - 8 } & Pnício & término & início & término & início & término & início & término \\
\hline & & & & & & & & \\
\hline
\end{tabular}

\begin{tabular}{|c|c|c|c|c|c|c|c|c|c|c|}
\hline \multicolumn{5}{|c|}{ Pressão Arterial } & \multicolumn{3}{|c|}{ Grau de Ansiedade } & \multirow{2}{*}{ Dente } & \multirow{2}{*}{ Anestésico } \\
\cline { 1 - 4 } \multicolumn{2}{|c|}{ PB1 } & \multicolumn{2}{|c|}{ TA1 } & \multicolumn{2}{|c|}{ FP1 } & \multirow{2}{*}{ IA1 } & FP1 & & \\
\hline PAS & PAD & PAS & PAD & PAS & PAD & & & & & \\
\hline & & & & & & & & & & \\
\hline
\end{tabular}

Restauração:

Classe I $\square$
Amálgama $\square$

Classe II

$\square$

Classe V

Provisória $\square$ 
Condição 2

\begin{tabular}{|c|c|c|c|c|c|c|c|c|}
\hline \multirow{2}{*}{$\begin{array}{l}\text { Data do } \\
\text { proced. }\end{array}$} & \multicolumn{2}{|c|}{ Horário dos períodos de estudo } \\
\cline { 2 - 8 } & Pnício (Basal) & término & PA2 (Anestesia) & PP2 (Procedimento) & \multicolumn{2}{c|}{ PPP2 (Pós-proced) } \\
\hline & & & & & & & & \\
\hline & & & & & & & & \\
\hline
\end{tabular}

\begin{tabular}{|c|c|c|c|c|c|c|c|c|c|c|}
\hline \multicolumn{5}{|c|}{ Pressão Arterial } & \multicolumn{2}{|c|}{ Grau de Ansiedade } & \multirow{2}{*}{ Dente } & \multirow{2}{*}{ Anestésico } \\
\cline { 1 - 5 } \multicolumn{2}{|c|}{ PB2 } & \multicolumn{2}{|c|}{ TA2 } & \multicolumn{2}{|c|}{ FP2 } & \multirow{2}{*}{ PB2 } & IA2 & FP2 & & \\
\hline PAS & PAD & PAS & PAD & PAS & PAD & & & & & \\
\hline
\end{tabular}

Restauração: Classe I Amálgama

$\square$

Classe II

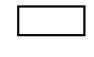

Classe V

Resina fotop.

Provisória $\square$

\begin{tabular}{|c|c|c|}
\hline Horário & Períodos & Descrição de sinais e sintomas (se houver) \\
\hline & & \\
\hline & & \\
\hline & & \\
\hline
\end{tabular}

V-ECG

\begin{tabular}{|l|l|l|l|}
\hline Condições & ECG 1 & ECG 2 & ECG 3 \\
\hline Condição 1 & & & \\
\hline Condição 2 & & & \\
\hline
\end{tabular}

\section{VI - GENOTIPAGEM}

VII - OBSERVAÇÕES: 